Portland State University

PDXScholar

$11-7-1989$

\title{
Cultural Value Differences in Arguments Between Presidents Ronald Reagan and Oscar Arias
}

Juan Carlos Flores

Portland State University

Follow this and additional works at: https://pdxscholar.library.pdx.edu/open_access_etds

Part of the International and Intercultural Communication Commons, and the Political Science Commons

Let us know how access to this document benefits you.

\section{Recommended Citation}

Flores, Juan Carlos, "Cultural Value Differences in Arguments Between Presidents Ronald Reagan and Oscar Arias" (1989). Dissertations and Theses. Paper 3877.

https://doi.org/10.15760/etd.5761

This Thesis is brought to you for free and open access. It has been accepted for inclusion in Dissertations and Theses by an authorized administrator of PDXScholar. Please contact us if we can make this document more accessible: pdxscholar@pdx.edu. 
AN ABSTRACT OF THE DISSERTATION OF Juan Carlos Flores for the Master of Arts in Speech Communication presented November 7, 1989.

Title: Cultural Value Differences in Arguments between Presidents Ronald Reagan and Oscar Arias.

APPROVED BY THE MEMBERS OF THE THESIS COMMITEE:

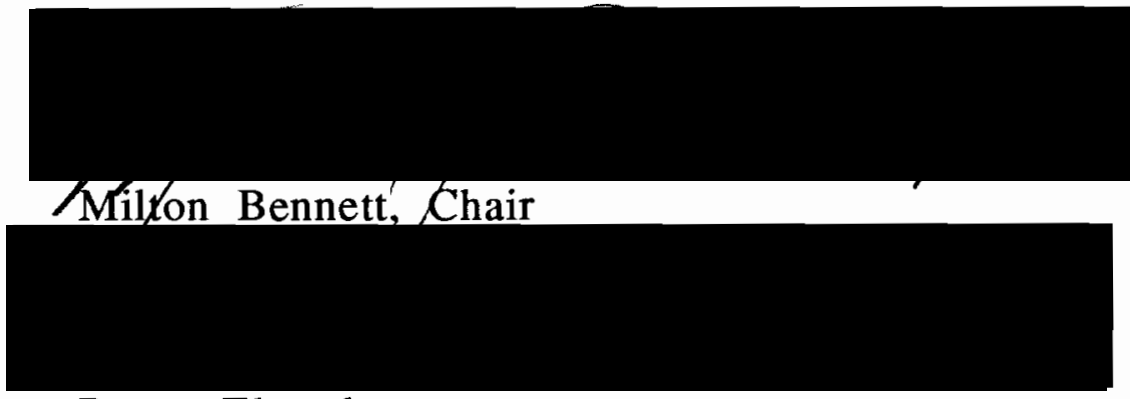

$$
\text { Peter Ehrenhaus }
$$

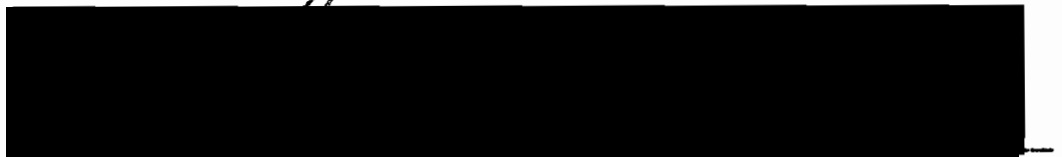

Mel Gurtov

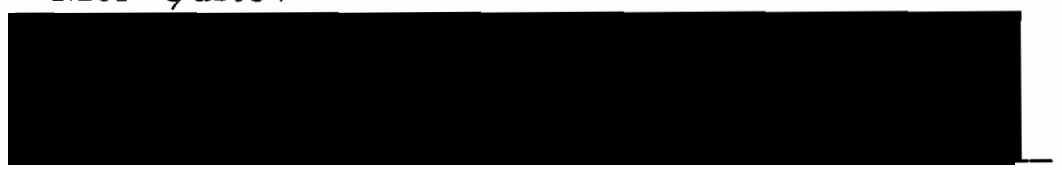

Earl Rees

Costa Rica embodies many of the characteristics which the United States would like to foster in Central America and elsewhere. In recent years, however, misunderstandings have often been 
present in the development of relations between both nations, and leaders. These differences have been particularly visible between Presidents Reagan and Arias when carrying out their foreign policies towards Central America.

Recent developments in warfare, social and political unrest and economic crises in the region added to the emergence of a Central American political leadership--independent of U.S. decision making-have increased international misunderstandings between both political speakers. These misunderstandings are shown by Reagan and Arias' through their public discourses which have revealed deterioration in communication and cooperation between them.

Since Reagan and Arias come from different cultures, their values are different, making it difficult for the two men to communicate effectively. Towards discovering the differences in cultural values underlying arguments between them, this study uses the Toulmin model to provide a critical and interpretative analysis of the exchange of political arguments from both leaders concerning Central America. Data were collected from public discourses by Reagan and Arias. An intercultural communication perspective is then used to assess the effects of the arguments on international understanding.

This research was successful in isolating a number of political arguments concerning Reagan and Arias' respective policies toward Central America, it revealed consistently different underlying cultural values. These differences in cultural values may affect the mutual understanding between the two political leaders, since their 
discourses did not acknowledge each other's cultural values or patterns of thinking.

At the core of Reagan and Arias' disagreements is the ethnocentric assumption that each is similar to the other. This assumption is not a recommended strategy for intercultural interaction.

Because of the novelty of this type of interdisciplinary interpretative research, the results can not be compared adequately with previous research on values in public discourse.

Further investigation in this area should support the worth of studying political argumentation from the combines approaches of rhetorical analysis and intercultural communication. 


\title{
CULTURAL VALUE DIFFERENCES IN ARGUMENTS BETWEEN
} PRESIDENTS RONALD REAGAN AND OSCAR ARIAS

by

JUAN CARLOS FLORES

A thesis submitted in partial fulfillment of the requirements for the degree of

\author{
MASTER OF ARTS \\ in \\ SPEECH COMMUNICATION
}

Portland State University

1989 
TO THE OFFICE OF GRADUATE STUDIES:

The members of the Committee approve the thesis of Juan

Carlos Flores presented November 7, 1989.
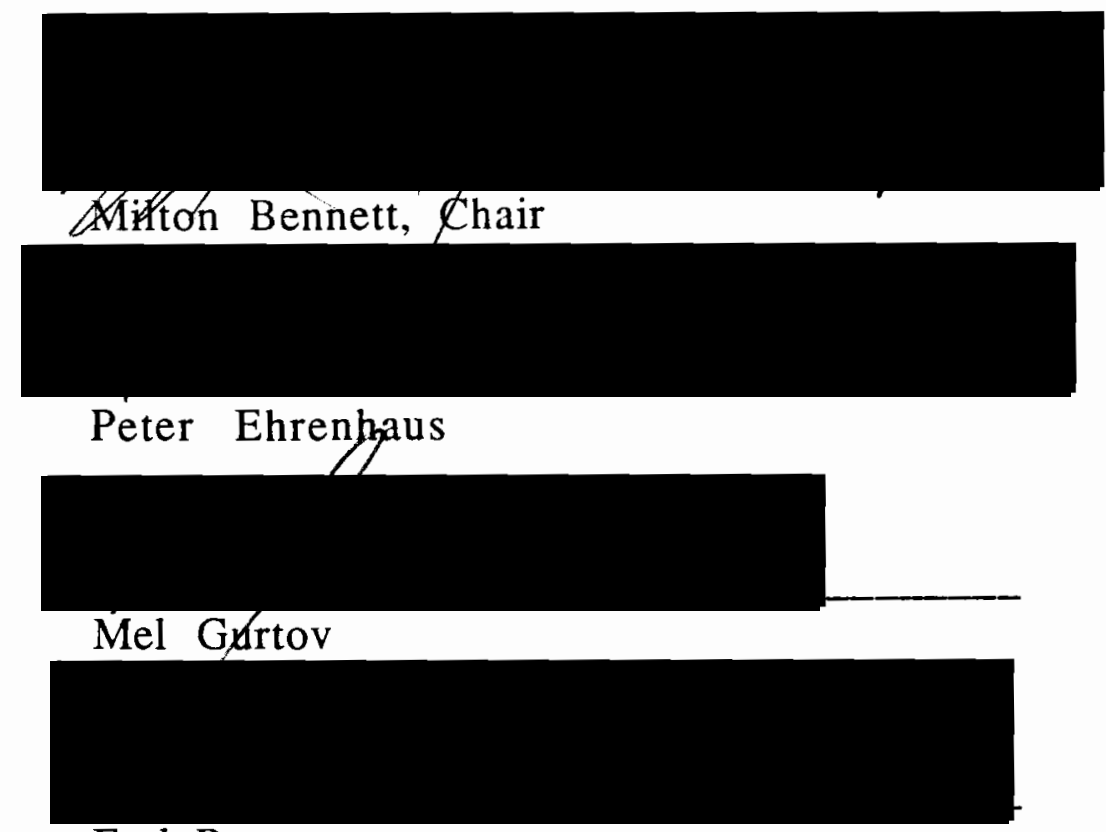

Earl Rees

\section{APPROVED:}

Theodore G. Grove, Chair, Department of Speech Communication

C. William Savery, Interim Vice Prokost for Graduate Studies and Research 


\section{ACKNOWLEDGEMENTS}

I wish to express my sincere appreciation to all those whose generous assistance and unconditional support have contributed to the success of this thesis. Listed below are those to whom I am indebted.

Milton Bennett and Peter Ehrenhaus. It has been my honor to have Dr Bennett as thesis advisor and Dr. Ehrenhaus as member of my thesis committee. Bennett's and Ehrenhaus outstanding, although different, approaches to communication in their respective "Advance Intercultural Communication" and "Persuasion" gave me insight into a potential combination of disciplines; intercultural communication and rhetoric which consciously overlapped into my thesis project. Once I embarked on my research, both willingly shared with me insights born of their nearly fifteen years of careful and creative investigations of their respective communication perspectives. During the eleven months it took to write this thesis, we spent many stimulating hours together exploring, conferring and sometimes discussing. For me, these exchanges were vital to clarify my thesis purposes as well as to guide me through the research process. Without their experience and support this thesis could not have been accomplished.

Mel Gurtov, and Earl Rees deserve special thanks for serving as members of my final oral examination committee. Each of them 
contributed with valuable time and care to the reading of my manuscript. Through detailed suggestions regarding style and substance, I benefited from the excellent scholarship of each member.

Lil Mena, whose sacrifices on behalf of this project were many, helped me more than any other with her love, understanding, patience, perspective, and companionship.

In addition, my gratitude extends to the treasured members of my physical and spiritual families and friends whose large and small contributions made the work seem less difficult and the goal, more worthwhile. The following is a partial list.

Javier and Margarita Flores

Juan and Rosita Mena

Oscar Arias Sanchez

Guillermo Constenla

Luis Alberto Monge

Francisco J. Flores

Tony and Lilian Bell

Victor Julio Peralta

Arturo Ceballos

Stephen and Amy Lock

Maureen Orr

Steve Kosokoff

Stephen Toulmin

and of course,

Aristotle 
TABLE OF CONTENTS

PAGE

ACKNOWLEDGEMENTS. . . . . . . . . . . . . . iii

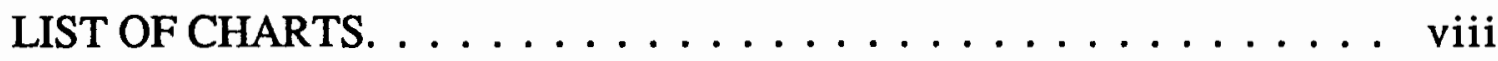

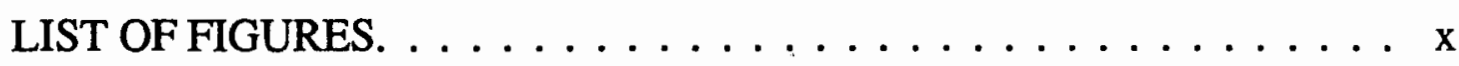

\section{CHAPTER}

I INTRODUCTION. . . . . . . . . . . . 1

Statement of the Problem.........5

Rationale and Literature Review. . . . . . . 6

Research Questions

Definitions

Design of the study............ 10

The Data

The Methodology

Potential Significance. . . . . . . . . . . 16

I I REAGANS USE OF NARRATIVE FORMS AND

ARGUMENT ON CENTRAL AMERICAN ISSUES. . . . . . 17

Description of arguments.......... 19

Analysis. . . . . . . . . . 38

Narrative forms

Warrants 
Correlation of warrants and claims...... 38

Summary. ................. 44

II I ARIAS' USE OF ARGUMENTS ON CENTRAL

AMERICAN ISSUES. . . . . . . . . . . . . . . 46

Description of arguments.........5 50

Analysis.................. 59

Arguments

Warrants

Correlation of warrants and claims......667

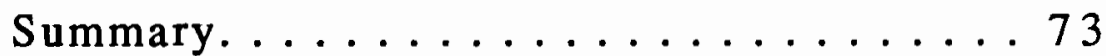

IV CULTURAL VALUES AFFECTING POLITICAL

ARGUMENTS EXCHANGED BETWEEN PRESIDENTS

REAGAN AND ARIAS. . . . . . . . . . . . 74

Cultural Values underlying arguments.....76

Reagan's warrants

Arias' warrants

Patterns of thinking underlying arguments... 95

Intercultural Conflict in Values and Styles. . . 96

Intercultural conflicts

Cultural Values: implications

Patterns of thinking: implications

The Golden Rule . . . . . . . . . . 110

A far-reaching intercultural implication 
V CONCLUSIONS AND RECOMMENDATIONS. . . . . . . . 114

Summary of Major findings. . . . . . . . 114

Limitations of the present study. ......116

Recommendations............. 117

REFERENCES. . . . . . . . . . . . . . . . . . 120

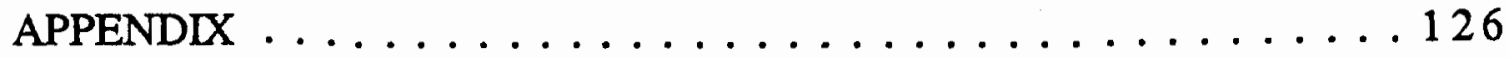




\section{LIST OF CHARTS}

I Four examples of Reagan's arguments on

Central America's strategic value as the first common theme...........23

II Three examples of Reagan's arguments on the second common theme, communists cannot

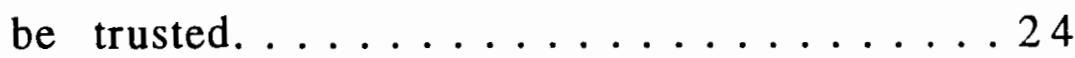

II T Two examples of Reagan's arguments on the third common theme, democratic success in Central America............ 25

IV Three examples of Reagan's arguments on the fourth common theme, defense of the "Freedom Fighters" in Nicaragua....... 25

V Two examples of Reagan's arguments on the fifth common theme, U.S. moral commitment toward freedom and democracy.......26 
VI Five examples of Reagan's arguments on the sixth common theme, U.S. good intentions antagonized by Nicaragua's actions......27

VII Three examples of Reagan's arguments on the seventh common theme, U.S. stake in preserving stability in allied countries.... 28

VIII Comprehensive list of warrants and types of reasoning supporting Reagan's arguments. . . 40

IX Three examples of Arias' arguments on the first common theme, democracy can overcome totalitarian threats $\ldots \ldots \ldots . \ldots 54$

$\mathrm{X}$ Three examples of Arias' arguments on the second common theme, fair treatment in international trade and finance.......55

XI Four examples of Arias' arguments on the third common theme, viability of peaceful solutions in Central America. ........56

XII Three examples of Arias' arguments on the fourth common theme, correlation between peace-making and opposition to warfare... 57 
XIII Two examples of Arias' arguments on the fifth common theme, acknowledgement of majority concerns in Central America by local governments. ............ 57

XIV Three examples of Arias' arguments on the sixth common theme, reconciliation as pre-requisite

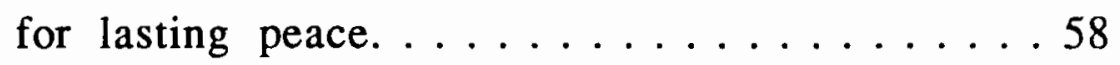

$\mathrm{XV}$ Comprehensive list of warrants and types of reasoning supporting Arias' arguments. . . . 68

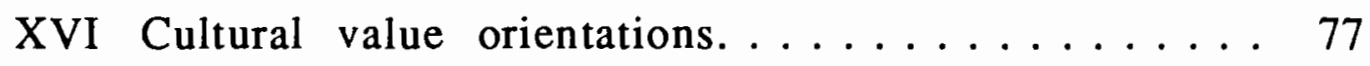
XVII Findings on value orientations from Reagan' and Arias arguments. . . . . . . . . . . 94 


\section{LIST OF FIGURES}

FIGURE

PAGE

1. Diagram illustrating three main components of most arguments according to Stephen Toulmin's model. . . . . . . . . . . . 12

2. An Example of a Simple Argument Diagrammed with the Toulmin model. ...........12

3. Graph correlation between general warrants and claims in Reagan's arguments............442

4. Graph correlation between general warrants and claims in Arias' arguments. ......... 70 


\section{CHAPTER I}

\section{INTRODUCTION}

The purpose of this thesis is to discover the different cultural values that may underlie public arguments between President Reagan of the United States and President Arias of Costa Rica, and to explore the effect of those possible differences on intercultural understanding. The arguments upon which this thesis focuses took place in a political and historical context that is briefly summarized below.

Costa Rica and the United States are democracies and traditional allies in the American hemisphere. Although the former is considered underdeveloped, both countries share similar social, political and economic standards according to the World Bank annual report (1986). In addition, politicians from both countries have said that Costa Rica is the only country in Latin America without "antiYankee" political sentiments.

In a broadcasted interview (Flores, 1984) former Costa Rica President Luis A. Monge explained that this positive attitude toward the United States and its government is based on two main factors: First, Costa Rica, unlike most Central American countries, has never been successfully invaded by U.S. military forces; second, Costa Rica's democratic system affords to all its citizens obligations and rights similar to those granted to citizens of United States. In fact, in their book Confronting revolution: Security through diplomacy in Central America (1986), Morris J. Blachman, William M. Leogrande and Kenneth Sharpe wrote that "Costa Rica embodies all the virtues the United States would like to promote elsewhere in the [Central American] region" (p. 17). 
As with any country, Costa Rica has its differences with the United States. But, until recently, these differences rarely led to open arguments in political exchanges or in economic relations. Historians list five main events that have shaped relations between the United States and Costa Rica. The historian Carlos Monge Alfaro (1982) wrote about two of these events, and Morris J. Blachman and Ronald G. Hellman (1986) about the other three. These include: (1) the military invasion of Costa Rica by U.S. mercenaries in 1856; (2) the U.S. political intervention in the selection of the president of Costa Rica in 1919; (3) the military invasions of Costa Rica in 1949 and 1955 carried out by Nicaragua which, at the time, was U.S.'s closest Central American ally; (4) the Costa Rican political, medical and economic support to the Sandinistas during the civil war against Somoza's dictatorship; and, (5) despite U.S. pressures, the unilateral neutrality declared by the Costa Rican government in 1983.

Tension between the two countries began in 1856 when, after the U.S. takeover of the Nicaraguan government, an American adventurer named William Walker invaded Costa Rica. Both U.S. politicians and members of the private sector supported Walker financially and politically. He was defeated by Costa Rican civilian resistance (Monge, pp. 208-14).

In 1919, after the fall of the autocratic regime of the Tinoco family, the U.S. government intervened in the selection of the president of Costa Rica. Monge claimed that the intervention had been carried out "in a way which damaged Costa Rican sovereignty" (pp. 286-7).

Tension rose in 1949 and again in 1955 when socialist policies adopted by the Costa Rican government of Jose Figueres --supported by the U.S. on the onset of the revolution of 1948-- provoked a Nicaraguan military intervention backing the former president of Costa Rica, Rafael Angel Calderón Guardia.

During the sixties, the reelected president Figueres supported the Sandinistas guerrillas against the heirs of Somoza, and again a decade ago Costa Rica supported the Sandinista guerrillas and helped 
them to organize a democratic government for Nicaragua. As a result, relations between the U.S. and Costa Rica were strained as were relations between Costa Rica and the U.S.-backed dictatorship in Nicaragua (Blachman \& Hellman, p. 172).

The fifth historic event key to Costa Rican -United States relations is the decision made by the administration of Costa Rican President Luis A. Monge to declare the unilateral neutrality of Costa Rica on November 17,1983. This announcement reflected a posture of nonparticipation in any U.S. policy based on military attempts to overthrow the Nicaraguan regime. As Blachman and Hellman conclude, "U.S. policy thus ends up exacerbating the kinds of pressures that are antithetical to the very kind of democracy Washington praises and the Costa Rican cherish" (p. 181). U.S. interference in Costa Rica has been estimated as a problem by the general Costa Rican population. In 1984 a public opinion survey polled respondents who were asked to name a country that interferes too much in Costa Rica's internal affairs. "Some $43 \%$ of those with a high school education named the United States" (Dillon, 1984, June 17). In what has often been called the "most pro-North American country in Latin America," there has been an "uncharacteristic irritation about U.S. meddling in their financial and political affairs" (Blachman, et al., p. 170).

In 1987, the new president of Costa Rica, Oscar Arias, started a peace initiative for Central America. He invoked peaceful rather than the traditional military solutions to the region's problems and opposed the U.S. backed "Freedom Fighters" in Nicaragua (Contras). Arias' initiative clearly differed from President Reagan's policies toward Central America. In a 1988 interview with reporters of CBS's "60 minutes," Arias discussed the different plans and what they meant.

After almost ten years of peace negotiations by different groups and increasing pressures from the Reagan Administration, Arias' plan initiated a Central American president's summit in Guatemala. From this summit the first peace accord for the region emerged (Central America presidents' summit, 1987). On August 5, 
1987, the day before the agreement was reached in Guatemala, President Reagan announced his own proposal for peace in Central America. A month later, Time magazine described Reagan's attitude toward the Arias' peace plan as one of disdain. Reagan, the magazine said, charged that the plan "[fell] short of the safeguards" contained in an earlier proposal put forward by himself and the Democratic Congressional leader, Jim Wright. In response to Reagan's contempt, Arias said: "Reagan believes that our plan has loopholes, and I accept that it might. No human work is perfect. But now the ball is in the court of the Central Americans" (Smolowe, 1987, p.34).

As the Arias peace plan gained international support, the Reagan administration adapted its position. When Reagan addressed the Organization of American States (OAS) on October 7, 1987, Reagan said that he did not plan to make any demands on any Central American president who signed the Guatemala accord. However, later in his address Reagan pointed out that "without the freedom fighters [Contras], the Sandinistas never would have signed the Guatemala accord, and there would be no pressure on the Sandinistas to reform" (Reagan., 1987, p. 3). Within the U.S. Congress, military support for the Contras decreased. As a result, the Reagan administration kept a close eye on the second summit of Central American presidents, which took place in Costa Rica in January, 1988. Two weeks before the summit, Lt. Gen. Colin Powell, Reagan's National Security Adviser, irritated Nicaragua's neighbors by suggesting they might suffer U.S. aid cutbacks if they abandoned the Contras. Powell also urged them to condemn the Sandinista's intransigence as a major obstacle to peace (Greenwald, 1988, p. 39). President Arias replied by saying "War is easy. Peace requires goodwill from many people" (Greenwald, 1988, p. 39).

During the 1988 summit the Nicaraguan regime conceded more openness in dealing with its domestic civil and military political opposition. In the following weeks, the Reagan administration shifted its traditionally friendly position towards Costa Rica. The U.S State Department managed to expel Guido Férnandez, Costa Rican 
ambassador to the U.S., for intervening successfully against the aid for the Contras and fostering the Arias' peace plan. As a result, Férnandez quit his post. In Costa Rica several months later, Férnandez stated his impressions to a reporter of CBS's "60 Minutes"(1988). Citing U.S. government sources, Férnandez said that "Oscar Arias has been the spoiler of the U.S. administration policy toward Central America." In the same program, Sen. Christopher Dodd, D-Conn., chairman of the Committee in Hemisphere Affairs, confirmed a drastic change in U.S policy towards Costa Rica. He mentioned three examples of this attitude change. First, in September, 1986, even though Congress had approved $\$ 80$ million in urgently needed economic support to Costa Rica, the United States waited almost one year to release the funds. Second, although Costa Rica is of vital strategic value for the United States, the U.S. administration delayed almost a year before sending a new ambassador to Costa Rica. Third, before the International Monetary Fund (IMF) the U.S. position had been flexible in helping Costa Rica negotiate its payments of its external debt. However, during the last two years; it had been extremely difficult for the Arias administration to get the U.S. to vote in favor of critical payment arrangements of Costa Rica's debt. These changes led President Arias in June, 1988, to tell an American journalist that since Reagan strongly supported the Contras--who represent the military solution rejected by Arias peace initiative--"Costa Rica and the peace plan will get much more support either from Mr. Dukakis or Mr. Bush" (CBS, 60 Minutes, 1988).

\section{STATEMENT OF THE PROBLEM}

To fully understand the disagreements between Reagan and Arias, it is necessary to look beyond the political and historical context to possible differences in basic cultural values. This thesis identifies what cultural values support each of the respective claims 
made by Reagan and Arias in speeches and public addresses concerning Central American problems. Since Reagan and Arias come from different cultures, their values may be different -- making it difficult for the two men to communicate effectively. Their mutual misinterpretations can be understood better by following a two-step process: (1) analysis of arguments; and (2) interpretation of this analysis in terms of an intercultural communication perspective.

\section{RATIONALE AND LITERATURE REVIEW}

Few of the writings on values in public discourse and argument are concerned with the intercultural approach to the study of cultural values. According to Henry Scheele (1984), few scholars have endeavored to examine closely the values of the speaker either in general or interculturally.

Among the few scholarly works found are the value analysis by Henry McGuckin's about Nixon's 1972 Checkers' speech, Wayne Thompson's study of values in Barbara Jordan's keynote address delivered at the 1976 Democratic Convention, and Scheele's value study of Ronald Reagan's 1980 presidential acceptance address. Each author focused chiefly on the use of value appeals as rhetorical strategies that persuade audiences to respond favorably to the purpose of winning an issue or goal within an intracultural context. All of them (Scheele, 1984; Thompson, 1979; McGuckin, 1968) rely on the identification of a set of values which emerges from the speech itself. Several additional considerations need to be made to support the identification of values within arguments from the intercultural perspective.

First, according to Stanley Paulson (1962), students of communication recognize that cultural values are often present in public discourse. In order to identify values within arguments between two different speakers from two different cultures, this research will move from the study of arguments in public discourse 
within the frame of U.S. culture, which is considered here "intracultural rhetoric," to the study of arguments in public discourse between speakers from different cultures, which is considered in this thesis "intercultural rhetoric."

Second, Paschal Viglionese (1982) suggests that certain areas of study which are traditionally kept separate, overlap somehow. The separation is mainly in response to a need felt among academicians to define as neatly as possible the concerns and parameters of their disciplines. Viglionese explained that although interdisciplinary collaboration may widen a perspective, for some scholars it often seems to cloud neat definitions of research. Condon and Yousef (1975) respond to this assertion by stating that the universe of communication studies is expanding, and that new metaphorical models for the description of communicative acts are continually being developed. They conclude that this kind of study, which Condon and Yousef specifically call intercultural communication, demands a more interdisciplinary approach.

Third, Lorand B. Szalay (1974), has pointed out that the thrust of communication studies is not toward fixed, repeatable messages of the literary type, but rather toward categories of situation, processes and value systems. Szalay goes on to state that by doing the same type of communication research abroad as we have done at home, as in many cross-cultural values studies, the necessary information for more effective international relations and communications cannot be obtained. The rationale for using the same techniques in domestic and in intercultural situations is supported by such factors as professional interests, institutional inertia, and cultural egocentrism. It is bound to reinforce cultural myopia, concludes Szalay. Other social sciences are displaying an increased interest in the impact of values upon argument in international political exchanges. An example of this trend is the emerging Global Humanism School. Mel Gurtov, a representative of the school, explains in his book, Global Politics in the Human Interest (1988), that the line which once so neatly divided domestic from foreign affairs and foreign from global 
affairs is now much harder to find. Conflicts which involve countries like the United States, such as the intervention in Central America, affect people and nations well beyond the participants. He suggests a need for additional tools to analyze them. Gurtov states that "international affairs are still politics, but political science is no longer sufficient for the study of international affairs" (p.6). Fourth, if communication researchers try to apply a single set of values to both Reagan and Arias' arguments, they will bias the analysis. As Condon and Yousef pointed out, when values are stated only from the perspective of one society, it is difficult to make comparisons which are needed for international understanding. Therefore, the culturally different contexts of the arguments demand an intercultural approach.

According to Condon and Yousef, any intercultural study of values seeks underlying principles as categories both for distinguishing cultures and for finding commonplaces among cultures. But since each culture is a system with its own assumptions and consistent within itself, different cultures will express different types of reasoning. Condon and Yousef make an important warning regarding analyzing arguments from the intercultural perspective. They said that what appears to be non sequitur in another society may actually be quite logical [consistent] given the assumptions of that culture.

A unique reason for studying Costa Rica and United States presidential discourse in terms of cultural values is provided by Barbara Stanford (1987). She says in the United States there is an overemphasis on the problems and failures of other countries. This tends to give people a very distorted picture of the world, a sense of despair, and a feeling that there is not much reason to become acquainted with other countries. Stanford also points out that, worldwide, there are few studies about Costa Rica and less curriculum materials about Costa Rica than about any other Central America country. This lack of information is due to a research bias which allows more attention to cultures whose international 
situations can be considered bad news. She suggests more research on Costa Rica, particularly about its value system not only to fight the scholarly bias, but to enhance U.S. understanding of other countries' cultures. Consequently, this thesis poses the following research questions in order to explore interculturally political arguments from public discourses concerning Central American issues between Presidents Ronald Reagan and Oscar Arias.

\section{Research Questions}

1. What arguments are present in Reagan's and Arias' public discourses concerning their respective policies toward Central America political, economic and military problems?

2. How do Reagan's and Arias' particular arguments reveal their respective underlying cultural values?

3. How might the difference in underlying cultural values affect the mutual understanding evident in their discourse?

Before pursuing these research questions, it is essential that the reader have a clear understanding of the key concepts used throughout this thesis.

\section{Definitions}

Argument: Toulmin (1958) and Condon and Yousef (1975) define argument as the process of determining and providing "proofs" going from evidence (data) to conclusions (claims), making inferences and deductions, and in one way or another going from what is known or assumed to an appropriate conclusion.

Persuasion: Brembeck and Howell (1976) define persuasion as communication intended to influence choice. The word communication denotes that this phenomenon is symbolic and attempt has a predetermined goal, the word influence suggests that behavioral change of some sort is sought and the 
word choice reflects the view that the receiver has options available to him.

Propaganda: Brembeck and Howell consider propaganda a form of persuasive campaign designed to influence large numbers of people, usually in non-face-to-face situations. Its purpose may be concealed or revealed.

Cultural Value: Anthropologists Clyde and Florence Kluckhohn (1951), have written extensively on value theory. They say the only defining point of values generally agreed upon by scholars deal with normative as opposed to existential propositions. Values deal with what is judged to be good, bad, right or wrong. Statements based on values describe the ideal or the standards by which behavior is evaluated. They do not necessarily describe actual behavior.

Intercultural communication: Richard E. Porter and Larry A. Samovar (1975) say that intercultural communication occurs whenever a message producer is a member of one culture and a message receiver is a member of another. In this circumstance, we are faced with problems inherent in a situation where a message encoded in one culture must be decoded in another. The process of coding allows us to move from the traditional analysis of values based on listing values in accordance with intracultural research.

\section{DESIGN OF THE STUDY}

This study will employ a critical and interpretative case study methodology.

\section{The Data}

The data for this study are public addresses given by Ronald Reagan and Oscar Arias. The documents examined deal with the U.S. foreign policy towards Costa Rica and Central America, and involve the concepts of peace, war, freedom, communism and democracy. 
This thesis selected as data persuasive discourses identified as argumentation rather than propaganda. Winston L. Brembeck and William S. Howell (1976) point out that "argumentation is a form of persuasion that employs essentially reasoned discourse while using non-logical appeals as supplementary means of influence"(p. 19). Propaganda is a type of persuasive campaign designed to influence large numbers of people, usually in non-face-to-face situations. Its purpose is either revealed or concealed, and employs such vehicles as organization, mass media, the stage, books, and billboards to carry its messages. Despite the fact that both argumentation and propaganda may be based on persuasive messages, they differ in their means and ends. The former as derived from these definitions offers a reasoned choice among options, the latter not. The former yields evidence to support its conclusions, the latter not.

\section{The Methodology}

Most critical and interpretative research identifies value expressions and notes their frequency to determine their importance within discourse. The interest in this thesis, however, is to identify the actual cultural values which may support the arguments in Reagan and Arias' discourses. Another concern is to learn how the sets of underlying cultural values may affect mutual understanding interculturally. To do this, this research looks at Reagan and Arias' discourse in relation to their cultures. In both cases this study travels from the particular to the general and from the speech to the culture.

To identify accurately the structure of each discourse, this thesis relies on the Toulmin (1958) model for the study of argumentation. According to Toulmin, an individual who makes an assertion puts forth a claim - "a claim on our [the listener's] attention and to our beliefs" (Toulmin, p. 11). He explains that the claim implicit in an assertion is like a claim to a right or a title. Its merits depend on the merits of the argument which can be produced in its 
support. Whatever the particular nature of the assertion may be eg., President Reagan praising the "Contras" or Oscar Arias blaming the "Contras" - the assertion can be challenged and attention can be drawn to the grounds (backing, data, facts, evidence, considerations, features) on which the merits of the assertion are dependent (p. 11). Hence, the scheme for this thesis' methodological purposes uses three key terms: (1.) The data (D), which yield evidence, lead to (2.) the conclusion, which is a claim (C), by way of (3.) the warrant $(\mathbf{W})$. Terms of evidence leading to conclusions by way of warrants can usually be phrased in this form: given evidence, therefore conclusions, because of warrant(s). Sometimes all three are explicitly stated in an argument, but more often the data and the warrant (and occasionally the claim) are omitted. The relationship between data and the claim can be symbolized as a continuum that is intersected by a warrant which lends authority for taking the step from one to the other.

The model to analyze arguments looks like Figure 1:

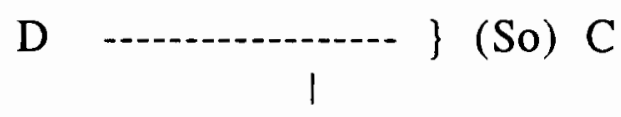

(Since) W

Figure 1. Diagram illustrating three main components of most arguments according to Stephen Toulmin's model.

Or, to give an example see Figure 2:

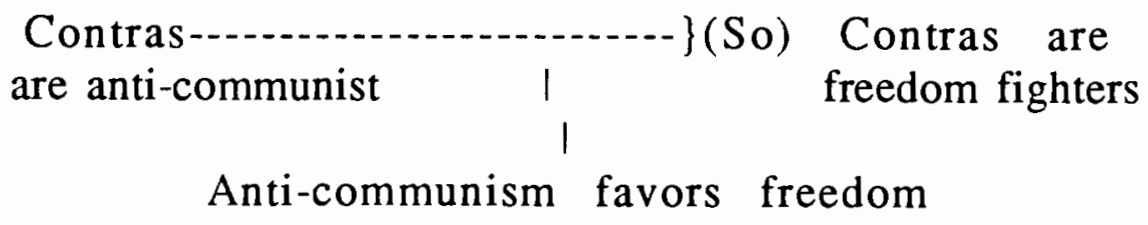

Figure 2. An Example of a Simple Argument Diagrammed with the Toulmin Model. 
Toulmin makes it clear that the explicit appeal in the argument goes directly from the claim to the data, which is relied on as a foundation. The warrant is, in a sense, incidental and explanatory, its task being simply to explicitly register the legitimacy of the step involved and to refer it back to the larger class of steps whose legitimacy is being presupposed. Data and warrants differ in their appeal: data appeal to the explicit grounds of a claim and warrants to the implicit principles which the claim conveys. In addition, one may remark that warrants generally, certify the soundness of all arguments of the appropriate type, and accordingly must be established in quite a different way from the facts we produce as data which is argument specific. (See Toulmin, 1958, pp. 99-100.) The three elements of an argument take different forms. Evidence or data (D) may be observed as sense data, they may be hypothetical, or they may be an assertion of something assumed to be true or known to be valid. Conclusions also take many forms: judgments of better or worse, explanations of causes or predictions of future events, and directive statements for policies or actions. Even though the model of arguments presented implies a certainty of conclusions arising from evidence of one or another, several scholars (Rieke \& Sillars, 1975; Condon \& Yousef, 1975; Toulmin, 1958) say that conclusions are not certain. Thus it is the function of argument to state what is most likely. Aristotle pointed out that people do not argue about what is certain nor what cannot be known - so rhetoric and argumentation fills the vast middle ground of more or less, better or worse, and so on.

In a second part of Chapter IV, a second model of intercultural analysis of arguments developed by Condon and Yousef (1975) will be used in combination with a summary of cultural assumptions and values designed by Edward C. Stewart, Jack Danielian and Robert J. Foster (1969). Both tools have in common that they focus on the range of possible solutions to common human problems which shape the value systems of most societies, whether Western or non Western. It is not too much to say that a complete argument is bound by assumptions based on experience and values. The choice 
of "evidence" is as likely to be derived from expected conclusions as the reverse, and the warrants that link them are not significantly different from value orientations (Stewart, et al.). The three main elements of an argument are the same across cultures, according to Condon and Yousef. But they do say that how one classifies something, and what one chooses to notice or ignore, depends a great deal on the language and values of the culture. For this reason, it is helpful to attempt to distinguish data from evidence whenever possible. At the point of evidence we have already symbolically transformed the data through the language and value system of the society in which it arises. With conclusions and warrants structurally tied together, the relationship between language and culture is even closer. What must be stressed is that the relationship of the evidence, warrant and conclusion in conventional argumentative analyses is one of consistency. Thus, in different cultures, the"same evidence" can lead to quite different conclusions which are each logically consistent. This is possible because of different warrants directed toward different goals and based on different values and assumptions of different cultures.

Condon and Yousef provide a chart of the value orientations and Stewart, Danielian and Foster provide a summary of contrasting cultural assumptions and values which this thesis uses in Chapter IV in identifying the cultural values implicit in the warrants of Reagan and Arias' arguments. (See Chart XVI.) For instance, in the hypothetical argument used in this chapter, the warrant (Anticommunism favors freedom) would be analyzed using the Condon and Yousef chart of value orientations and the Stewart, Danielian and Foster's summary of cultural assumptions and values to draw the cultural value(s) that may underlies the argument. Assumptions about human nature, the natural world, and the supernatural appear most frequently in arguments. To these Condon and Yousef added related categories. These are the concept of a moral order in society, the influence of 'outsiders' in their thoughts as well as actions, and assumptions about natural laws or basic truths (p. 219). These 
categories are especially relevant to evidence because they involve culturally related predispositions toward witnesses and physical evidence.

Chapters I and II of this thesis describe the arguments found, using Toulmin's model, from each speaker's discourses. Next, Chapter IV cross-examines the data collected, by looking at the warrants of each speaker's arguments, interpreting similarities and differences which, in terms of cultural values, affect intercultural understanding through arguments. Any interpretation of the data relied upon the lists value orientations used by Condon and Yousef in linking argumentation and cultural values and the summary of cultural assumptions and values used by Stewart, Danielian and Foster in contrasting American cultural patterns and those of other nations. The last chapter is concerned with the conclusions and their potential significance for future research. Basically, Chapters II, III and IV must be described as parts of a three-phase process which takes into account the warning Rieke \& Sillars (1984) have included in their analysis of arguments. They stated the following:

A process of analysis which permits you to examine all relevant evidence before you search for a claim would seem ideal. Unfortunately, argumentation and the decision making associated with it spring up in the midst of a problem area, there is no beginning place for it. In general argumentation we do not have the luxury of an ideal method (p. 52).

Both authors cite Morris Cohen's view concerning with this methodological issue. Cohen states:

Starting with the problem which initiates inquiry, coupled with skepticism with respect to traditional beliefs, ones pursues hypotheses, testing them by the method of trial and error (p. 52).

As we can observe from both remarks, the study of argumentation is difficult. However, Rieke and Sillars point out that 
although the potential for chaos in creating or analyzing argument is great, it need not to occur because

every problem has a storehouse of knowledge and standards by which selection takes place. There is a simple control on the mechanism; the human mind is unable to tolerate chaos, moving inevitably to decrease the number of options and focus on something about which it can be reasonable (p. 52).

\section{POTENTIAL SIGNIFICANCE}

This study attempts to continue the interdisciplinary direction called for by several authors cited earlier in this chapter. Combining the humanities (Rhetoric) and social science (Communication) approaches of Speech Communication, this study takes a wider approach to the topic of argument and culture, generating at least the following benefits:

A. The results of this study may indicate that the method is generally useful, and intercultural researchers will then have a tool with which to analyze other international arguments from the intercultural perspective.

B. This work will be heuristically valuable. By analyzing a contemporary political event, we can explain the causes of misunderstanding by looking at public arguments interculturally. We can also reconcile two different approaches to the study of values; the cross-cultural approach and the intercultural approach.

C. Studying discourse from the intercultural viewpoint will increase the accuracy of assessment needed to overcome misunderstanding between cultures. By considering potential cultural assumptions implicit in a public discourse, we can increase understanding between different cultures by clarifying differences. 


\section{CHAPTER II}

\section{REAGAN'S USE OF NARRATIVE FORMS \\ AND ARGUMENT ON CENTRAL AMERICAN ISSUES}

Between 1980 and 1988, the United States government engaged in what President Ronald Reagan called "our moral responsibility" (Reagan, 1983, p. 454) towards democracy, freedom and free enterprise in Central America. Reagan's rhetoric and actions during those eight years focused on Nicaragua, and what he considered the "region's threatened nations" (p. 453) the democratic countries of Guatemala, Honduras, El Salvador, and Costa Rica. During this period, Reagan defined through public discourse a policy towards Central America to three main audiences, the U.S. Congress, the U.S. general public, and the Latin American governments.

Reactions from the diplomatic arena to Reagan's Central American policy differed from the less successful response of American audiences. The emergence of Latin American and European efforts to bring peace to Central America without isolating Nicaragua, such as the Contadora group, the Cartagena Group, Arias' peace initiative and economic aid from the European Economic Community, illustrated the reaction in the diplomatic arena. The approval of humanitarian and military aid to the so called "freedom fighters" until the emergence of regional peace initiatives -. independent of U.S. decision-making-- and the explicit demand from U.S. citizens (43.7\% of a 1987 public opinion poll) for less involvement in Central American affairs (Janda \& Schrodt, 1987, p.85) illustrated the reaction within the United States.

Other factors should be taken into account to fully explain the failure of U.S. policy in Central America. This chapter focuses on the 
role Reagan's rhetoric played in persuading the aforementioned audiences to support his policy. Reagan was referred to as "the Western world's most gifted communicator" (Lewis, 1987, p. 106). As pointed out by Lewis (p. 106) he manipulated his language, his strategy, or his style to make himself and his policies appear to be attractive. The form which prevails in most of his speeches has been identified by Lewis as recurring to narrative forms which embody American values. Says Lewis,

story telling is fundamental to the relationship between Reagan and his audience. Stories are not just a rhetorical device that Reagan uses to embellish his ideas; Reagan's message is a story. Reagan uses story-telling to direct his policies, ground his explanations, and inspire his audiences, and the dominance of narrative forms helps to account for the variety of reactions to his rhetoric (p. 107).

Using Lewis' ideas on narrative form, I plan to identify two kinds of stories used by Reagan in his discourses concerning Central American issues: anecdotes and myths. The former defines the character of an issue, and is illustrated and reinforced in quick stories, jokes or incidents that are "the verbal counterpart of the visual image." The latter structures Reagan's message. Myths are the pedagogic images of the nature and destiny of man (p. 108). Lewis also suggests that Reagan's narratives are based on three elements: story, moral and common sense. The story is the primary basis for defining the situation, morality is the primary basis for justifying public policy, and common sense is the primary basis for analyzing political issues.

Reagan, as pointed out by Lewis, uses the narrative form to carry a clear message to those whose experience leads them to accept the story as either true or as true-to-life and whose values lead them to accept the moral. By identifying the audience members (as Americans), the narrative "makes those who accept this identity accountable to a system of values" (p. 109). The success of Reagan's 
public discourse depends on the audience's value identification with Reagan, the speaker.

A complementary approach is provided by Stephen E.

Toulmin's The uses of argument (1958). As Reagan expresses his viewpoints about a situation using narrative forms, he makes assertions and puts forth claims.

As pointed out in the first chapter, the scheme used here consists of three key terms: 1) The data (D), which yield evidence, lead to 2) the conclusion, which is a claim (C), by way of 3 ) the warrant (W). The warrant becomes vital for the purposes of this study because within warrants are the underlying values which sustain the claims. The warrant must be examine in order to find the moral or values in Reagan's narrative arguments.

In order to describe and analyze Reagan's discourses, in the light of Lewis' narrative forms and Toulmin's approaches, twentyseven arguments from seven discourses have been selected. The following criteria has been used to select and analyzed both Reagan's discourses: explicitness of the claims made, disregard of redundant arguments, and focus on Central American issues. Similar criteria are used in the next chapter with Arias' discourses. All twenty-seven arguments were studied, and twenty-three were chosen for this chapter to represent sufficiently the different common themes or lines of argument used by Reagan. Each of the chosen discourses are described; their arguments are made explicit; the themes which they support are introduced; and the type of reasoning as well as the warrants supporting the claims are described and analyzed.

\section{DESCRIPTION OF ARGUMENTS}

This chapter is based on data from seven discourses made public by Ronald Reagan between 1982 and 1988, concerning specific U.S. foreign policy toward Central America in general and Nicaragua in particular. These discourses were chosen as representative of the policies articulated by the Reagan administration during its eight 
years in power. Three of them were presented before the U.S. Congress, two during the "State of the Union" address (1987 and 1988), and one as requested by the President (1983). Two other discourses were delivered to the American people via television and radio in 1984, 1986, and the last two before specifically Latin American audiences in 1982 and 1987. The main topic of these discourses are described below.

"The problems in Central America" (1983), a speech delivered to a joint session of Congress, had three main objectives: (1) to explain the strategic value of Central America to the U.S. and the threat of a Nicaragua Soviet-Cuban backed government; to U.S. security, (2) to describe the road to democracy, freedom, and peace that most Central American countries, except Nicaragua, have followed; and (3) to advise that the U.S should act now instead of regretting inaction later.

The 1987 and 1988 "State of the Union" addresses, delivered to Congress, had two common objectives: (1) to address the cause of freedom as well as the willingness of the U.S to support its allies in Central America, and (2) to remind Congress that the U.S. does not need to intervene directly in Central America if the Nicaragua freedom fighters are helped by the Congress.

"Central American Policy: No communist colonies in America" (1984) and "Nicaragua: Aiding the Contras" (1986) were speeches delivered to the American people. They shared three basic concerns: (1) Soviet and Cuban dominance in Central America through Nicaragua; (2) new requests for aid to the Nicaragua freedom fighters to finish-off a"terrorist" state, and (3) threats to flourishing democracies in Central America and U.S interests, represented by Nicaraguan expansionist intent.

"Aid to the Caribbean Basin: Freedom is our common destiny" and "Central America at a critical juncture" were addresses delivered before the Organization of American States on February 24, 1982 and on October 7, 1987, respectively. Both seem to have had four main purposes: (1) to stress the consubstantiality of US interests and those of Latin American and Caribbean countries by looking at the 
similarity between US values and Latin American and Caribbean values; (2) to encourage counteraction of the peace rhetoric from the Sandinistas by exploiting some aspects of the new peace initiatives led by democratic nations in the region and downplaying others; (3) to describe the expansionist and threatening role of Nicaragua as a terrorist state backed by Cuba and Soviet Union; and (4) to stress moral commitment of the U.S. to allies in the region and to the freedom fighters against Nicaragua.

Seven recurrent themes can be found in these seven discourses:

(1) Central America is of great strategic value for the U.S. both because of the past history of the region and because of a "common destiny" for both US and the Caribbean basin countries.

(2) Nicaragua is a threat because of the military build-up and communist ideology encouraged by Soviet and Cuban presence. Therefore, the Sandinistas can't be trusted.

(3) Democracy, economic freedom, human rights are flourishing in Central America despite Nicaragua danger.

(4) Freedom fighters must be funded because they are fighting communism thus protecting America's doorstep.

(5) The U.S. has a moral commitment to defend freedom, democracy and economic freedom everywhere, but particularly it must do so in its zones of influence.

(6) The U.S favors diplomatic efforts, dialogue, and peace, but the Sandinistas are only interested in aggression and terrorism.

(7) Unwillingness from the U.S to aid its allies in Central America and restrain Soviet expansion may weaken the trust of other allies who depend on the U.S. to protect them. The U.S. has a stake in preserving stability.

These seven themes are illustrated in Reagan's rhetoric by a selection of arguments which are representative of the whole set of arguments by each speaker's discourse. (See appendix of arguments.) Each argument, is part of the twenty-seven studied, and each is assigned a Roman numeral in the arguments chart on the next pages. There is a continuous reference to these numerals in describing and 
analyzing each speech's narrative structure after the following descriptive section of this chapter.

Arguments offered by Reagan in supporting of the first common theme, Central America' strategic value, are shown in Chart I.

Regarding the second common theme, that the Sandinistas in Nicaragua cannot be trusted because they are communist, backed by the Soviets and the Cubans, Reagan offers several arguments as shown in Chart II.

In considering his third theme, that Central America is a region of flourishing democracies where economic freedom and human rights are improving, Reagan puts forth the arguments shown in Chart III.

The fourth common theme repeated in Reagan's discourse is that Nicaraguan Freedom Fighters are striving for freedom and democracy against the Sandinistas communists, and thus the Freedom Fighters defend American interests and principles. These claims are supported by the arguments in Chart IV.

The fifth common theme is represented by claims made by Reagan concerning a moral commitment toward freedom and democracy in Central America and support for those who fight for freedom and independence as shown in Chart V.

The sixth common theme claims U.S. commitment to the use of negotiation and diplomatic efforts to bring peace to Central America as opposed to the violent tactics of the Nicaraguan Sandinistas. Reagan's supportive arguments are in Chart VI.

The last topic is grounded in the Reagan Administration's concern that weaken the U.S. alliance with Central American nations remain strong. As Reagan put it, if Central America fell into communist hands, the security of the U.S. and its allies would be compromised. This is shown in Chart VII. 


\section{CHART I}

\section{FOUR EXAMPLES OF REAGANS ARGUMENTS ON THE FIRST COMMON THEME, CENTRAL AMERICA' STRATEGIC VALUE}

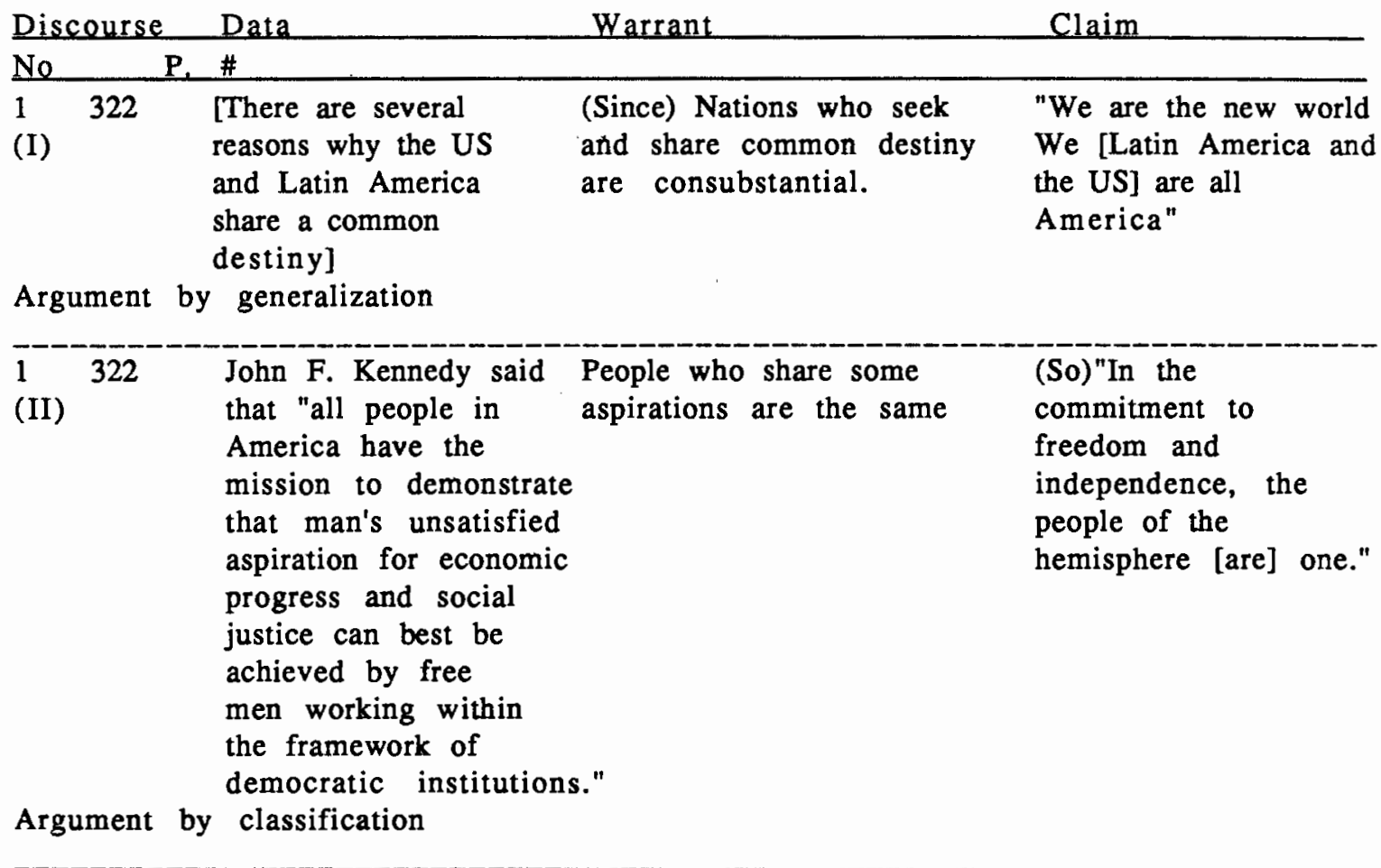

(VII)
$\begin{array}{lll}\text { directly affect the } \\ \text { the security and } \\ \text { well-being of [US] } \\ \text { people." }\end{array}$
$\begin{aligned} & \text { and security and well-being is the U.S.lifeline to } \\ & \text { argument by the U.S.proper. }\end{aligned}$
parallel case

\begin{tabular}{|c|c|}
\hline $\begin{array}{l}4 \quad 386 \\
(X V I)\end{array}$ & $\begin{array}{l}\text { Nicaragua is a Soviet- The Soviet Union and Cuba } \\
\text { Cuban backed } \\
\begin{array}{ll}\text { communist regime. a regimes because of } \\
\text { a desire to dominate. }\end{array}\end{array}$ \\
\hline
\end{tabular}

(So) "[The] Soviets and [the] Cubans can become the dominant power in the regional Argument by sign corridor." 


\section{CHART II}

\section{THREE EXAMPLES OF REAGAN'S ARGUMENTS ON THE SECOND COMMON THEME, COMMUNISTS CANNOT BE TRUSTED}

\begin{tabular}{|c|c|c|c|}
\hline Discours & Data & Warrant & Claim \\
\hline No & $P . \#$ & & \\
\hline $\begin{array}{lr}7 & 261 \\
(\mathrm{XXVI})\end{array}$ & $\begin{array}{l}\text { The Sandinistas broke } \\
\text { their promises for } \\
\text { democratic reforms } \\
\text { by failing to comply } \\
\text { with international } \\
\text { accords. }\end{array}$ & $\begin{array}{l}\text { (Since) Past violations } \\
\text { of trust can only be } \\
\text { overcome by large } \\
\text { acts of good faith. }\end{array}$ & $\begin{array}{l}\text { (So) "[Sandinistas'] } \\
\text { challenge is to take } \\
\text { irreversible steps } \\
\text { towards democracy." }\end{array}$ \\
\hline
\end{tabular}

Argument by sign

\begin{tabular}{|c|c|c|c|}
\hline $\begin{array}{lr}6 & 2 \\
(\mathrm{XXIII})\end{array}$ & $\begin{array}{l}\text { "Nicaragua does } \\
\text { not grant freedom } \\
\text { to all its citizens." }\end{array}$ & $\begin{array}{l}\text { (Since) Democracy } \\
\text { guarantees freedom } \\
\text { for all. }\end{array}$ & $\begin{array}{l}\text { (So) "The Sandinistas } \\
\text { in Nicaragua are not } \\
\text { democratic." }\end{array}$ \\
\hline
\end{tabular}

Argument by classification

$\begin{array}{llll}5 & \text { Backed by U.S. } & \text { The only thing that can } & \text { (So)"[U.S ] diplomatic } \\ \text { (XXI) } & \begin{array}{l}\text { diplomatic effort in } \\ \text { stop democratization is } \\ \text { the region, }\end{array} & \begin{array}{l}\text { efforts for democracy } \\ \text { democracy in Central America }\end{array} \\ & \begin{array}{l}\text { is moving forward } \\ \text { despite aggression }\end{array} & & \text { will fail if communism } \\ \text { from Nicaragua." } & & \begin{array}{l}\text { prevails and expands } \\ \text { from Nicaragua. }\end{array}\end{array}$

Argument by classification 


\section{CHART III}

\section{TWO EXAMPLES OF REAGAN'S ARGUMENTS ON \\ THE THIRD COMMON THEME, DEMOCRATIC SUCCESS IN CENTRAL AMERICA}

\begin{tabular}{|c|c|c|c|}
\hline \multicolumn{2}{|c|}{ Discourse Data } & Warrant & \multirow[t]{2}{*}{ Claim } \\
\hline$\underline{N}$ & $P$. \# & & \\
\hline $\begin{array}{lr}7 & 261 \\
(\mathrm{XXVII})\end{array}$ & $\begin{array}{l}\text { There are signs of } \\
\text { democratization in } \\
\text { Central America. }\end{array}$ & $\begin{array}{l}\text { (Since) Moves toward } \\
\text { democracy reflect } \\
\text { a general trend. }\end{array}$ & $\begin{array}{l}\text { (So) "Political freedom } \\
\text { is winning a battle ] } \\
\text { against totalitarism. } \\
\text { [...] Freedom is finding } \\
\text { its way in Central } \\
\text { America." }\end{array}$ \\
\hline Argument & by sign & & \\
\hline $\begin{array}{l}3 \quad 485 \\
(\mathrm{XIV})\end{array}$ & $\begin{array}{l}\text { "People in CA want } \\
\text { hope and better } \\
\text { lives." }\end{array}$ & $\begin{array}{l}\text { (Since) Only democracy } \\
\text { and freedom guarantees } \\
\text { people's hope for a better } \\
\text { future. }\end{array}$ & $\begin{array}{l}\text { (So) "Central American } \\
\text { people want freedom } \\
\text { and democracy." }\end{array}$ \\
\hline
\end{tabular}

Argument by generalization

\section{CHART IV}

\section{THREE EXAMPLES OF REAGAN'S ARGUMENTS ON THE FOURTH COMMON THEME, DEFENSE OF THE "FREEDOM FIGHTERS" IN NICARAGUA}

\begin{tabular}{|c|c|c|c|}
\hline Discours & Data & Warrant & Claim \\
\hline No & P. \# & & \\
\hline $\begin{array}{l}4 \quad 388 \\
(X V I I I)\end{array}$ & $\begin{array}{l}\text { Freedom Fighters are } \\
\text { fighting communism in } \\
\text { hopes of democracy. }\end{array}$ & $\begin{array}{l}\text { (Since) Those who support } \\
\text { and fight for democracy } \\
\text { help the U.S. }\end{array}$ & $\begin{array}{l}\text { (So) "The resistance } \\
\text { has contributed } \\
\text { directly to the } \\
\text { security of the U.S." }\end{array}$ \\
\hline
\end{tabular}

Argument by cause

5259 The Freedom Fighters (Since) Noble struggles (XXII) are struggling against prevail. the Soviets and communism.

Argument by cause

63 "Nicaraguans are against (Since) Those who fight (XXIV) tyranny and they fight communism in Nicaragua for this ideal.

Argument by parallel case today and those who fought for independence in 1776 are alike.
(So)"Freedom fighters won't allow the Soviets to have a beachhead [in Central America]."
(So) "They [Freedom fighters] are fighting for independence Nicaragua." 


\section{CHART V}

\section{TWO EXAMPLES OF REAGAN'S ARGUMENTS ON THE FIFTH COMMON THEME, U.S. MORAL COMMITMENT TOWARD FREEDOM AND DEMOCRACY}

\begin{tabular}{|c|c|c|c|}
\hline Discourse & Data & Warrant & Claim \\
\hline No $\quad F$ & \# & & \\
\hline $\begin{array}{l}6 \\
(X X V)^{4}\end{array}$ & $\begin{array}{l}\text { The U.S. is committed to } \\
\text { preserve freedom and } \\
\text { democracy anywhere, } \\
\text { particularly, on its } \\
\text { doorstep. } \\
\text { by cause }\end{array}$ & $\begin{array}{l}\text { (Since) The commander-in- } \\
\text { chief (President) is the } \\
\text { protector of that moral } \\
\text { commitment. }\end{array}$ & $\begin{array}{l}\text { (So) Reagan "won't } \\
\text { walk from the fight for } \\
\text { freedom in Central } \\
\text { America." }\end{array}$ \\
\hline (XII) & $\begin{array}{l}\text { President Truman said } \\
\text { in } 1947 \text { that the "US } \\
\text { must support free } \\
\text { peoples who are } \\
\text { resisting attempted } \\
\text { subjugation by armed } \\
\text { minorities or by } \\
\text { outside pressures." }\end{array}$ & $\begin{array}{l}\text { (Since) Today the situation } \\
\text { is the same as then. "The } \\
\text { political and strategic } \\
\text { stakes are the same } \\
\text { [ in C.A.]" }\end{array}$ & $\begin{array}{l}\text { (So) "President } \\
\text { Truman's words are as } \\
\text { apt today as they were } \\
\text { in 1947." }\end{array}$ \\
\hline
\end{tabular}

Argument by parallel case 


\section{CHART VI}

\section{FIVE EXAMPLES OF REAGAN'S ARGUMENTS ON THE SIXTH COMMON THEME, U.S. GOOD INTENTIONS ANTAGONIZED BY NICARAGUA'S ACTIONS}

\begin{tabular}{|c|c|c|c|}
\hline Discourse & Data & Warrant & Claim \\
\hline No & $\#$ & & \\
\hline
\end{tabular}

\section{Nicaraguan intentions:}

4387 The "Sandinistas are (XVII) transforming their nation into a safe house, a command post for the international terrorism."
(Since) Nations that harbor and support terrorists are outlaws.
(So) "Nicaragua is an outlaw regime."

Argument by sign

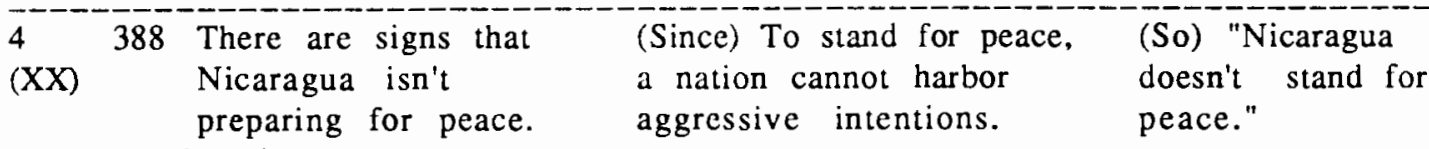

Argument by sign

\section{U.S. intentions:}

3 482-83 The "U.S. doesn't start (Since) U.S. defense policy (XIII) wars."

Argument by sign to preserve peace and freedom. stresses military strength
(So) The "U.S. will be never be the aggressor."
2451 The U.S. works in good Since) The US acts in good

(VIII) faith towards Nicaragua and other regional countries.

\section{faith to those who also} act in good faith.

Argument by sign

\begin{tabular}{|c|c|c|c|}
\hline $\begin{array}{l}2 \\
(X)\end{array}$ & $\begin{array}{l}\text { The "U.S. has } \\
\text { attempted to have a } \\
\text { dialogue w/Nicaragua. } \\
\text { But, [Nicaragua] persists } \\
\text { in spreading violence." }\end{array}$ & $\begin{array}{l}\text { What is true of these } \\
\text { cases is true of all. } \\
\text { These are signs of war. }\end{array}$ & $\begin{array}{l}\text { (So)"Nicaragua refuses } \\
\text { make peace[...] They } \\
\text { are against peace." }\end{array}$ \\
\hline
\end{tabular}

Argument by Sign

(So) "Our actions were hardly the actions of a nation implacably hostile to Nicaragua." 


\section{THREE EXAMPLES OF REAGANS ARGUMENTS ON THE SEVENTH COMMON THEME, U.S. STAKE IN PRESERVING STABILITY IN ALLIED COUNTRIES}

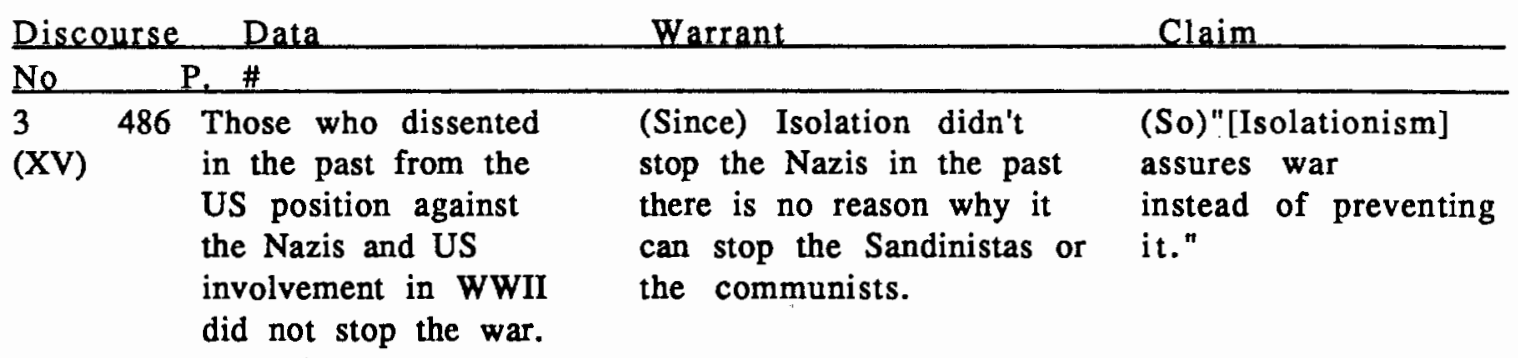

Argument by analogy

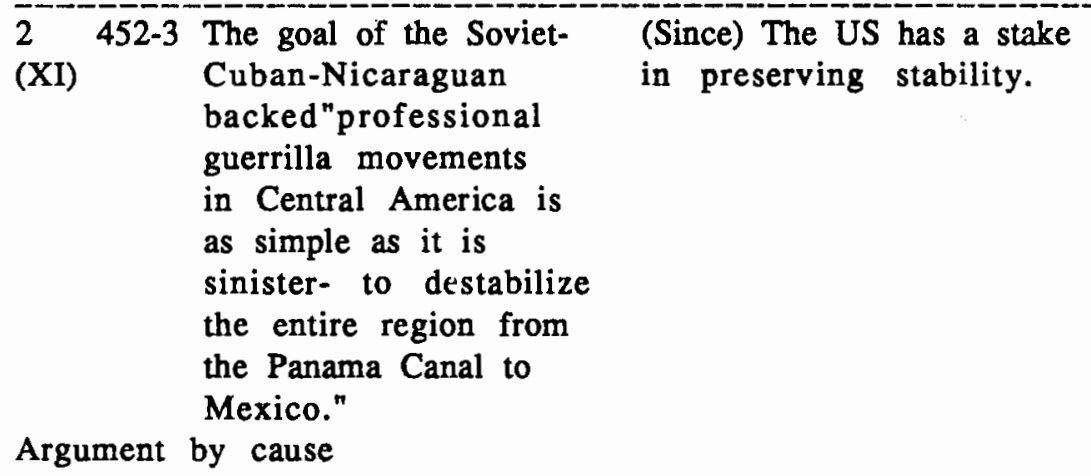

\begin{tabular}{|c|c|c|c|}
\hline $\begin{array}{l}1 \\
\text { (V) }\end{array}$ & 325 & $\begin{array}{l}\text { "Freedom's foes would } \\
\text { stamp out human } \\
\text { rights, pluralism, and } \\
\text { free institutions." }\end{array}$ & $\begin{array}{l}\text { (Since) The US supports } \\
\text { freedom (police role) } \\
\text { from the US }\end{array}$ \\
\hline
\end{tabular}

Argument by sign
(So) The "US will support the security of the region's threatened nations."
(So) "Freedom and peace requires help to those nations confronted with communist aggression." 


\section{ANALYSIS}

\section{Narrative forms}

According to Lewis, Reagan's narrative discourse combines three key elements: the story which is told, the moral which provides a direction to the story or situation narrated, and the common sense which makes the story intelligible and any disagreement with the story irrelevant. The sample arguments given above are the basis to locate and analyze narrative forms in Reagan's rhetoric on Central American issues. Each argument is part of the twenty-seven mentioned, and each is assigned a Roman numeral in the arguments chart on the previous pages. There is a continuous reference to these numerals in describing and analyzing each speech's narrative structure.

The data given by Reagan to justify his claims are often stories or anecdotes. In this section the story-situation, moral and common sense elements are introduced according to the lines of arguments common to the seven discourses previously described. This section follows, in order, the seven lines of argumentation, focusing on one story at a time. The arguments presented are illustrations, and not exhaustive of all those available.

Reagan's 1983 address on "The Problems in Central America," stressed the Caribbean basin's strategic value, which was the first line of argument, through reminiscences of events which occurred during World War II. "In early 1942 a handful of Hitler's submarines sank more tonnage there than in all of the Atlantic Ocean. And they did this without a single naval base anywhere in the area" (p. 450). This reminiscence was compared with a description of the modern Soviet submarine brigade which operates in Cuba, the Soviet-Cuban military presence now in Nicaragua, and a Libyan airlift camouflaged supply of weapons to Nicaragua which was discovered by the Brazilian government. Because the Libyan air cargo could not use the Grenada airfield due to U.S. military 
intervention of the island, this last element, is brought by Reagan as a favorable argument to foster an active role of his country in the region's affairs. These three stories were told one after another by Reagan, to show again how the evil-enemies of the U.S - Nazis, communists, and terrorists- used the Caribbean Basin to dominate and threaten U.S. security and well being (Argument VII).

The question Reagan posits at the end appeals to the common sense of his audience. "If the Nazis during War World II and the Soviets today could recognize the Caribbean and Central America as vital to our interests," he asks " shouldn't we also?" The moral behind this story is explained to the audience by using common sense. That moral is the appropriateness of American goals, the moral right the U.S. has to protect its own well being. By recognizing the strategic value of Central America and the Caribbean Basin, the right of the U.S. to get involved is validated in the name of defense of its own interests. Reagan does not stop there. In fact, to assure the validity of U.S. concerns on Central America, he equates Central Americans to U.S. citizens. By listing several similarities between US colonization and Latin American colonization, Reagan asserts that "We are the new world[...] We [U.S. and L.A.] are all America." (Argument I) He also uses the credibility of President John F. Kennedy to support the notion that in the"commitment to freedom and independence, the people of the hemisphere are one." (Argument II) If we are all consubstantial, then we may logically conclude that happenings in Central America are the United States' business.

In Reagan's 1987 address to the Organization of American States, "Central America at a Critical Juncture" (Discourse 6), several events are presented in support of the second line of argument. The harassment by the Sandinistas of an authorized peaceful demonstration in Managua is recounted, as well as other events which would prove that the Sandinistas in Nicaragua are undemocratic and thus untrustworthy (Discourse 6, Argument XXIII). In the aforementioned address, Reagan presents freedom as a concept which doesn't exclude anybody. "Democracy," he says, "doesn't mean selectively granting temporary freedoms in order to 
placate world opinion but permanent, across-the-board human rights, guaranteed by a constitution and protected by the checks and balances of democratic government" (Discourse 6, p. 2).

Reagan's 1988 "State of the Union" address included a story which relates to the third line of argument, that democracy is flourishing in Central America. Democracy is an inevitable outcome in that region, Reagan argued, because it is based on "the love of freedom that God places in each of us and whose defense He has entrusted in a special way to this nation" (p. 258). In this discourse, he claimed that movement toward "economic freedom is indivisible of political freedom - and against totalitarian rule" (p. 261). Reagan uses "tide" as a metaphor for this movement towards democracy in Central America, and as a force which the Sandinistas cannot deny unless their cause is not freedom (Argument XXVII). While Reagan praises the tide of freedom, he subordinates this drive to two factors: Freedom Fighters emerging worldwide (Afghanistan, Cambodia, Angola, Nicaragua), and the American tradition of fostering freedom abroad which is illustrated by Lafayette, Pulanski and Von Steuben during the American Revolution of 1776. Reagan's story begins inductively. He tells of the emergence of democracies everywhere, the role of freedom fighters in creating conditions for democratization in Nicaragua, and the importance of international democratic support to freedom fighters anywhere shown by the American Revolution. The story makes sense because of the common places Reagan touched upon, such as the role of international freedom fighters in the U.S.' war for independence and the knowledge that communist regimes backed by the Soviets are embattled by Freedom Fighters.

The moral, that the U.S. goal of helping democratic forces makes democracy flourish is correct, is shown by idealizing those who die fighting for freedom anywhere as fighting for the same cause as revolutionary Americans did. Reagan says "[They are] fighting and dying for the same democratic liberties we hold sacred. Their cause is our cause. Freedom." He allows no difference between the Freedom Fighter and the American people; "they are like us," he 
says. This approach, which is further analyzed in Chapter IV as relating to ethnocentrism, permits his audience to consider that democracies in Central America should be structured like the U.S., because the values of the people are the same.

In Reagan's 1986 address on "Nicaragua," the Nicaraguan government is referred to as " a second Cuba, [and] a second Libya" (p. 386), while the Contras are said to be "freedom fighters" who are "like the French Resistance that fought the Nazis" (p. 388). The discourse is rooted in the fourth line of line argument which advocates that Freedom Fighters are Americans because they protect America's doorstep by fighting communism (Argument XVIII). The moral direction is given by accepting that there is a "right way" which Americans use to solve problems, particularly in dealing with its traditional foes: atheism, communism, and Naziism.

As Lewis has pointed out in referring to the same discourse:

By using the daily dilemmas of diets and allowances and the widely accepted evils of the Nazis and Cuba as parallels to current American policy-making, Reagan suggests that what might have been seen as complex and distant problems are amenable to simple and familiar (if not always pleasant) solutions (p. 293).

Finally, people make sense of this complex situation by only following the didactic metaphor employed by Reagan: Sandinistas = Nazis, while Freedom Fighters $=$ French resistance. This example also reflects the type of reasoning known as analogy which is, among other reasoning types, later explored when the way how Reagan asserts his arguments is explained by the warrants found.

The fifth line of argument is conveyed strongly in Reagan's 1987 speech "Central America in a critical juncture" (Discourse 6) to the Organization of American States. Reagan shares his own interpretation of the Guatemala accords to negotiate peace in Central America. He argues that the Central American peace initiative began with the 1979 OAS- negotiated settlement, to bring democracy and peace in Central America and says the Sandinistas won't comply with 
the democratic expectations of its neighbors. The reason, he says, is that they are a regime backed by the U.S.S.R. and Cuba, and therefore, should not be trusted (Discourse 6, Argument XXV). In the same address before the OAS, Reagan said that "the Soviet-bloc Cuban forces must leave" Central America (Discourse 6, p. 2). The reason they must depart, however, is not rooted in Latin American concerns, but those of the U.S. "We will not tolerate communist colonialism on the American mainland. Freedom in Nicaragua, liberation from all tyrants, domestic and foreign- that is the commitment of the United States, a bipartisan consensus on the conditions that will satisfy U.S. security interests" (Discourse 6, p. 2). The moral is presented here as a goal-setting that is, communism cannot be negotiated in American's mainland which includes, consubstantially, Central America and the Caribbean. This policy is called a bipartisan consensus by Reagan himself. The consensus is inclusive, says Reagan, of "every democratic nation in the hemisphere." So, again, those Central American nations are presented as like the U.S.; they are American. And Reagan attributes to the Nicaraguan Freedom Fighters the same purposes, origin and situation of the Freedom Fighters of the United States' independence of 1776 (Argument XXIV). To make sense of their situation, Reagan demands the audience think only in American terms.

In Reagan's 1986 address "Nicaragua: Aiding the Contras" (Discourse 3, Argument XIV), his 1984 presentation"Central American Policy: No communist colonies in America" (Discourse 4, Argument XVI) and his 1983 talk "The problems in Central America" (Discourse 2, Argument VIII) there are explicit references to the sixth common theme, that the U.S. has good-will and peaceful intentions versus Sandinista ill-will and terrorist-warfare intentions. Reagan tells the story of how much money and military presence the Soviets have invested in Nicaragua, and contrasts this with the mostly altruistic, economic, and technical aid the U.S. gives all the nations of Central America and the Caribbean (Discourse 2, p. 451). $\mathrm{He}$ points out that a second difference between U.S. and Sandinista 
policy toward the region is that the U.S. insists on diplomatic efforts rather than military intervention, which the Sandinistas promote (Discourse 4, pp. 482-83). The third part of the story relates the fact that Nicaragua offers refuge and training to international terrorist groups such as PLO, the Red Brigades, and guerrilla movements from elsewhere in Central America, whereas the U.S. shows continuous support for international cooperation and rule of law (Discourse 4, p. 387). The moral of each element in the story - good will vs. ill will, diplomacy vs. violence, international law vs terror are explained in common sense terms. This three-fold story is neatly explicit in the following remarks: In Reagan's 1984 speech "Central American Policy" (Discourse 3) he said " the defense policy of the United States is based on a simple premise: We do not start wars" (p. 483). In his 1983 address "The Problems of Central America" (Discourse 2) Reagan asks, "Can anyone doubt the generosity and good faith of the American people?" (p. 451). Finally, in his 1986 speech, "Nicaragua," (Discourse 4) he asks, "will we permit the Soviet Union to put a second Cuba, a second Libya, right on the doorsteps of the United States?" (p. 386).

The last common theme to Reagan's discourses concerns testing the willingness of the U.S. to protect its allies and interests in Central America. In Reagan's 1984 presentation "Central American Policy" (Discourse 3, Argument XV) a new story was unfolded to justify U.S. involvement in Central America, showing the U.S.'s willingness to defend its allies and interests. Reagan compares those who dissent from his policies towards the region with those who fostered isolationism during the thirties, a policy which allowed fascists to take power in Europe and part of Africa.

Like these new isolationists, those of the past" knew what was happening...but chose not to face the terrible challenge history had given them," says Reagan. Here Reagan's purpose is to label those who dissent from modern U.S. policy toward Central America as isolationists who become accomplices of terrorism and international transgression, and enemies of freedom and democracy. Instead of 
preventing WW II, Reagan remarks, the isolationist of the 30's "assured it" (p. 486).

This half-century flashback narrows the complexity of democratic opposition to Reagan policies within the United States. The moral direction given was that of doing, engaging in action "to stop the aggressors" rather than retreating to the passive posture of "wishful thinking" of the isolationist.

\section{Warrants}

The seven common themes or lines of argument found in our sample of seven discourses concern U.S. policy towards Central America and have proven useful to locate and analyze narrative forms. Even though myth structures the fabric of stories in Reagan's discourses, it is not the intention of this thesis to study the myths in Reagan's discourse. There are two reasons for this: first, the study of the myths is appropriate only in a specific narrative study, thus it goes beyond the scope of this thesis; second, other elements of Reagan's narrative forms such as stories and anecdotes pervade the warrants by showing principles or moral direction of his arguments which relate more directly to the thesis' goals. Therefore this chapter focuses on the warrants underlying Reagan's claims given certain data.

Lewis' narrative approach has proven useful by illuminating how story, moral and common sense existed in Reagan's choice of narrative forms, as well as how it conjured up alternative conceptions. All the stories analyzed were chiefly supported by warrants. As has been explained in the methodology section of the first chapter, the warrants rarely are explicit in the rhetoric. In fact, the implicitness of them is what allows the speaker to establish a link with his audience. The warrant provides justification for the act of inference require to move from data to claim (Sweeney, 1981, p. 42). 
Chart VIII (p. 40) shows a sample of warrants related to each specific line of argument, numbered from one to seven, according to the type of reasoning used by Reagan to assert his arguments case by case. Even if not exhaustive, the chart shows a noticeable dominance of argument by sign in his discourses. Out of the twenty-seven arguments studied for this research, twenty-two of which are shown in Chart VIII, argumentation by sign counts for $48 \%$. Arguments by generalization, cause and classification together account for another $44 \%$.

Argument by sign is a type of reasoning known legally as argument from circumstantial evidence. A sign type is based on a warrant that everything, condition, or idea has characteristics which will tell you whether or not it is present. (See Rieke \& Sillars, pp. 756.) This type of reasoning seems to fit Reagan's concerns for specific details or facts to support an argument. In fact, argument by sign is frequently used by Reagan in connection with all lines of arguments, but particularly those concerning the idea of "threat" to the United States well-being coming from Soviet and Cuban presence in Nicaragua, and the spreading of leftist guerillas in Central America.

Reasoning by sign is stressed chiefly when dealing with aspects of the Central American crisis which are unclear, or unknown, and which are presented to the audience as unfamiliar (Arguments VIII, X, XIII,XVI, XVII, XX, XXIII, XXVI, XXVII).

Arguments by generalization, which follows inductive reasoning (see Rieke \& Sillars, p. 73) are preferred by Reagan in arguing the consubstantiality of U.S goals and those of Central American countries covered under the umbrella of a "common destiny" which validates U.S involvement in Central American affairs (Arguments I, XIV).

Reagan applies reasoning by classification to specific cases or elements which have been identified as a member of one class. In order to exploit what he conceived as existing similarities between U.S. and Central American countries a remark, which was made by John F. Kennedy, was recalled to put all nations into the common destiny category (Argument II). Similarly, to back U.S. diplomatic 
efforts in the region Reagan puts forth a categorization according to which the future of democracy is not possible in the presence of expanding communism (Argument XXI).

Reasoning by cause is considered Western. Western cultures, like that of the United States, tend to see people, things, and ideas as causing events. In this type of argument, the data function as a cause for the claim, and the warrant is a statement justifying the cause-effect relationship (p. 74). Reagan turns his attention to this type when clarity and simplicity are more important. This type is not useful to make a case about "Soviet-Cuban threat" which requires facts to be credible. This type is useful when linear understanding is required, when there is no other way to explain a stance. As Reagan points out "The resistance has contributed directly to the security of the U.S." Why? Because those who support and fight for democracy help the U.S. ( Argument XVIII). Reagan also said "I won't walk away from the fight for freedom in Central America." Why? Because he is the commander-in-chief of the United States, thus he is the protector of the moral commitment of preserving freedom and democracy anywhere (Argument XXV). Other types of reasoning, such as parallel case, analogy, and authority, are downplayed in Reagan's arguments. It seems their importance is sacrified for the sake of the dominant role of reasoning by sign. The narrative style which has been described to be characteristic of Reagan's rhetoric has the sign type as a better means to achieve soundness and consistency because of the Reagan liking for specific details. Also, the issues addressed by Reagan often have origins - dubious, unknown, incomplete information- and they are hard to prove by using any type of reasoning but sign. Reagan's arguments studied are supported by the warrants and types of reasoning displayed in Chart VIII. 


\section{CORRELATION OF WARRANTS AND CLAIMS}

To make clear the correlation between Reagan's warrants and claims an additional task has been undertook. Figure 3 (below) shows the degree of connectedness between warrants and the claim they support. In the figure, the warrants summarized on chart VIII are grouped according to their degree of connectedness between Reagan's warrants and between Reagan's warrants with respect to claims. The following synthesis takes into account all twenty-seven of Reagan's arguments (See Figure 3) to draw the main warrants and its respective claims.

The first general warrant (W1) is concerned with consubstantiality. For example, [Nations who seek and share common destiny are consubstantial] (Argument I) synthesizes the warrants which underlie the following claims:

(1) "We are the new world [...] We [ U.S. and Latin America] are all America" (Argument I, p. 322).

(2) In the "commitment to freedom and independence, the people of the hemisphere are one" (Argument II, p. 322).

(3) "[U.S.] must help Central America and the Caribbean people to protect those values and principles that shape the proud heritage of this hemisphere" (Argument VI, p. 325).

(4) "Central America is the U.S. lifeline to the outside world" Argument VII, p. 450).

The second general warrant (W2) is concerned with political dualism, for most nations there are only two political alternatives, communism or democracy (capitalism). This is shown by the warrant [Communism and democracy are the two world ideologies at struggle] (Argument III) which synthesizes into one the warrants related to the following claims:

(1) "There are only two possible futures for Central America: [Democracy or dictatorship]" (Argument III, p. 324). 
The third general warrant (W3) concerns the U.S.' role as international policeman of stability and freedom. The warrant [U.S. supports freedom - U.S. as a policeman] (Argument V) synthesizes the warrants which underlie the following claims:

(1) "Freedom and peace requires U.S. help for those nations confronted with communist aggression" (Argument V, p. 325).

(2) "U.S. will support the security of the region's threatened nations" (Argument XI, p. 452-3).

(3) Reagan "won't walk away from the fight for freedom in Central America" (Argument XXV, p. 4).

The fourth general warrant (W4) describes the U.S. as a responsible and fair power. The warrant [the U.S. acts in good faith to those who also act in good faith] (Argument VIII) is at the core of the warrants which support the following claims:

(1) "Our actions were hardly the actions of a nation implacably hostile to Nicaragua" (Argument VIII, p. 451). 


\section{CHART VIII}

\section{COMPREHENSIVE LIST OF WARRANTS LINKED TO TYPES OF REASONING SUPPORTING REAGAN'S ARGUMENTS}

\begin{tabular}{|c|c|c|c|}
\hline Argument & Common Theme & Warrant & Reasoning type \\
\hline I & 1 & $\begin{array}{l}\text { Nations who seek and } \\
\text { share common destiny are } \\
\text { consubstantial. }\end{array}$ & Generalization \\
\hline$\overline{\mathrm{II}}$ & 1 & $\begin{array}{l}\text { Pcople who share the same } \\
\text { aspirations are the same. }\end{array}$ & Classification \\
\hline VII & 1 & $\begin{array}{l}\text { Regions which affect the } \\
\text { security and well-being of } \\
\text { the U.S. are as important as } \\
\text { the U.S. proper. }\end{array}$ & Parallel case \\
\hline $\mathrm{XVI}$ & 1 & $\begin{array}{l}\text { The Sovict Union and Cuba } \\
\text { back regimes because of a } \\
\text { desire to dominate. }\end{array}$ & Sign \\
\hline$\overline{X X V I}$ & 2 & $\begin{array}{l}\text { Past violations of trust can } \\
\text { only be overcome by large } \\
\text { acts of good faith. }\end{array}$ & Sign \\
\hline XXIII & 2 & $\begin{array}{l}\text { Democracy guarantees } \\
\text { freedom for all. }\end{array}$ & Classification \\
\hline $\mathrm{XXI}$ & 2 & $\begin{array}{l}\text { The only thing that can stop } \\
\text { democratization is violent } \\
\text { communist expansion. }\end{array}$ & Classification \\
\hline XXVII & 3 & $\begin{array}{l}\text { Moves to democracy reflect } \\
\text { a general trend. }\end{array}$ & Sign \\
\hline XIV & 3 & $\begin{array}{l}\text { Only democracy and } \\
\text { freedom guarantees people's } \\
\text { hope for a better future. }\end{array}$ & Generalization \\
\hline XVIII & 4 & $\begin{array}{l}\text { Those who support and } \\
\text { fight for democracy help } \\
\text { the US. }\end{array}$ & Cause \\
\hline XXIV & 4 & $\begin{array}{l}\text { Those who fight communism } \\
\text { in Nicaragua today and those } \\
\text { who fought for US independence } \\
\text { in } 1776 \text { are alike. }\end{array}$ & Parallel case \\
\hline
\end{tabular}




\section{CHART VIII}

\section{COMPREHENSIVE LIST OF WARRANTS LINKED TO TYPES OF REASONING SUPPORTING REAGAN'S ARGUMENTS (continued)}

\begin{tabular}{|c|c|c|c|}
\hline Argument & Common Theme & Warrant & Reasoning type \\
\hline XXII & 4 & Noble struggles prevail. & Cause \\
\hline$X X V$ & 5 & $\begin{array}{l}\text { The commander-in-chief } \\
\text { (President) is the protector } \\
\text { of that moral commitment. }\end{array}$ & Cause \\
\hline XII & 5 & $\begin{array}{l}\text { Today the situation is the } \\
\text { same as then (1947). } \\
\text { (Since)"The political and } \\
\text { strategic stakes are the same } \\
\text { [in Central America]." }\end{array}$ & Parallel case \\
\hline XVII & 6 & $\begin{array}{l}\text { Nations that harbor and } \\
\text { support terrorists are outlaws. }\end{array}$ & Sign \\
\hline$x \mathrm{X}$ & 6 & $\begin{array}{l}\text { To stand for peace, a nation } \\
\text { cannot harbor aggressive } \\
\text { intentions. }\end{array}$ & Sign \\
\hline XIII & 6 & $\begin{array}{l}\text { U.S. defense policy stresses } \\
\text { military strength to preserve } \\
\text { peace and freedom. }\end{array}$ & Sign \\
\hline VIII & 6 & $\begin{array}{l}\text { The U.S. acts in good faith to } \\
\text { those who also act in good faith }\end{array}$ & Sign \\
\hline $\mathrm{X}$ & 6 & $\begin{array}{l}\text { What is true of these cases is } \\
\text { true of all. These are signs of } \\
\text { war. }\end{array}$ & Sign \\
\hline $\mathrm{XV}$ & 7 & $\begin{array}{l}\text { Isolation didn't stop the } \\
\text { Nazis in the past, there is no } \\
\text { reason why it can stop the } \\
\text { Sandinistas or the communists. }\end{array}$ & Analogy \\
\hline $\mathrm{XI}$ & 7 & $\begin{array}{l}\text { The US has a stake in preserving } \\
\text { stability. }\end{array}$ & Cause \\
\hline $\mathrm{V}$ & 7 & $\begin{array}{l}\text { The U.S. supports freedom } \\
\text { (police role). }\end{array}$ & Sign \\
\hline
\end{tabular}



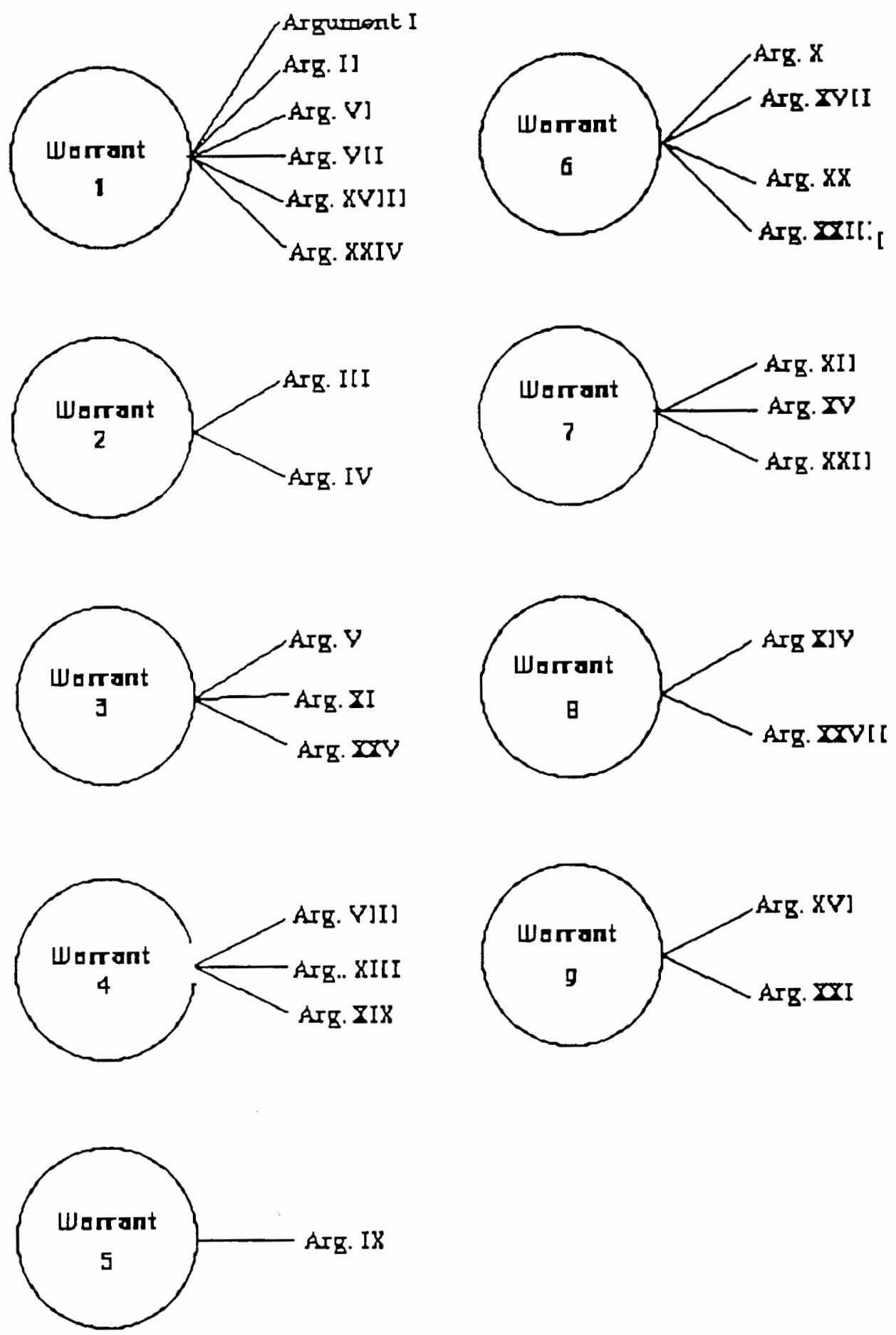

Figure 3. Graph correlation between general warrants and claims in Reagan's arguments. 
(3) "the U.S. has sought and still seeks - a negotiated peace and a democratic future in a free Nicaragua" (Argument XIX, p. 388).

(2) "the U.S. will never be the aggressor" (Argument XIII, p. 482).

The fifth general warrant (W5) concerns depriving the insurgency in Central America from political legitimacy. The warrant [Those who turn against their own are only out for themselves] (Argument IX) illustrates the claim below.

(1) "Salvadoran guerillas are a small minority who want power for themselves and their backers" (Argument IX, p. 451).

The sixth general warrant (W6) concerns those few signs of war or ill-will from which a general negative evaluation can be made. An example of this is the warrant [ To stand for peace, a nation cannot harbor aggressive intentions] (Argument XX). This is the core principle of the warrant which supports the following claims:

(1) "Nicaragua refuses to make peace [...] They are against peace" (Argument X, p. 452).

(2) "Nicaragua is an outlaw regime" (Argument XVII, p. 387).

(3) "Nicaragua doesn't stand for peace" (Argument XX, p. 388).

(4) "The Sandinistas in Nicaragua are not democratic" (Argument XXIII, p. 2).

The seventh is a general warrant (W7) and applies opinions from the 1930's and 1940's to contemporary problems. The example offered is the warrant [Today the situation is the same as then] (Argument XII) which supports the following claims:

(1) "President Truman's words are as apt today as they were in 1947" (Argument XII, p. 452).

(2) "[Isolationism] assures war instead of preventing it [in Central America]" (Argument XV, p. 486).

(3) "Freedom fighters won't allow the Soviets to have a beachhead [on the U.S. doorstep]" (Argument XXII, p. 259).

The eighth general warrant (W8) is concerned with democracy guaranteeing freedom and development. The example selected is that of [ Only democracy and freedom guarantees people's hope for a better future] (Argument XIV) which is at the core of warrants to the 
following claims:

(1) "Central American people want freedom and democracy" (Argument XIV, p. 485).

(2) "Political freedom is winning a battle against totalitarism. Freedom is findings its way in Central America" (Argument XXVII, p. 261).

The ninth general warrant (W9) concerns the threat posited by totalitarism on democratic systems and actions. This principle is illustrated by [Soviet Union and Cuba back regimes because of a desire to dominate] (Argument XVI). This warrant is at the core of those principles supporting the following claims:

(1) "The Soviet Union and Cuba can become the dominant powers in the regional corridor" (Argument XVI, p. 386).

(2) "[U.S.] diplomatic efforts will fail in Central America if communism prevails and expands from Nicaragua" (Argument XXI, p. 259).

\section{SUMMARY}

In this chapter a select number of Reagan's public discourses on Central America were described and analyzed. Using Lewis' ideas on narrative forms, Reagan's free-flowing speech was broken down to three elements: story, moral and common sense. Analysis demonstrated how Reagan used his chosen form of narrative to guide his audiences along the path he constructed from data to claim. Reagan's success depended on the degree to which a particular audience identified with the values underlying his words.

Toulmin's approach to analyzing argument provided a complementary angle to this chapter's research. Using the data and claims put forth on Reagan's speeches the chosen research methodology extracted the corresponding warrants, which provide authority to move from data to claim and determined the types of arguments employed. Reagan used argument by sign in nearly half the discourses studied here. Warrants found to be repetitive through 
the block of Reagan's discourse chosen for this study provide a base for determining cultural values which are inherent to his speeches and necessary to identify and understand in order to truly comprehend his words. 


\section{CHAPTER III}

\section{ARIAS' USE OF ARGUMENT ON CENTRAL AMERICAN ISSUES}

From the onset of his administration, President Oscar Arias defined the course of action of the Costa Rica government towards Central American problems as "in keeping with our highest ethical values. These values," he said, "should govern domestic policies as well as international relations with other governments" (Inaugural address, May 8, 1986, p. 9).

During the preceding political campaign the preservation of Costa Rica's peace and neutrality, despite the on-going politicalmilitary struggle in Central America had been one of the most important issues. For instance, in his inaugural address, Arias called for an international "Alliance for Freedom and Democracy" in Central America after promising (1) to keep Costa Rica neutral, (2) to foster economic and social changes lawfully, and (3) to defend the country from freedom foes using only international law. (The army had been abolished in Costa Rica in 1948, by the former president Jose Figueres.) (Monge, p. 14)

Between 1986 and 1989, Oscar Arias designed and executed domestic and international policies based on his three promises. The Alliance for Freedom and Democracy of early 1986 was replaced by the Arias' Peace Plan for Central America in mid 1987. The Peace Plan called for a cease-fire, peace negotiations among all the belligerent forces in Central America nations, an end to outside aid to rebel groups, and the adoption of democratic reforms. (Guatemala's summit, 1987) According to Thomas E. Skidmore and Peter H. Smith in their handbook Modern Latin America (1989) all five Central American republics endorsed the plan, as did the U.S. (albeit 
reluctantly). The Nobel Prize committee gave Arias the 1987 Peace Prize, but by early 1988 it was clear that his ambitious peace efforts faced great odds, given the bitter ideological and geopolitical interests underlying the region's warfare (p. 322).

During his administration, Arias defined a policy towards Central America through public discourse to four main audiences: the general public of Costa Rica, the governments and citizens of the U.S., Latin America and Europe. Reactions to his policy both in the diplomatic arena and by international audiences show its lasting success, no matter how much opposition or how many obstacles the plan has encountered. The emergence of Latin American, U.S. (nongovernmental), and European political, moral and economic support for the Costa Rican peace initiative, which was designed to bring all the conflicting parties to the negotiating table rather than isolating any of them, illustrates the reaction in the diplomatic arena.

Additional success followed the 1st and 2nd summits at Esquipulas, at which all participating Central American nations committed themselves to reach regional peace. The disapproval of U.S. policy towards Central America, in general, and the reduction of humanitarian and military aid to the so called "Freedom Fighters," well-known in Central America as "Contras," in particular, were due to four main factors: (1) the emergence of the regional peace initiative independent of U.S. desires; (2) the explicit demand from the U.S. public (43.7\% in a 1987 poll) for less involvement in Central American affairs (Janda \& Schrodt, 1987, p. 85); (3) the effort by the leaders in Central America to find their own solutions to their areas' conflict through the Arias' peace initiative rather than following the leadership of the out-of-region Contadora group members (Mexico, Panama, Venezuela, and Colombia); and (4) the winning of the Nobel Peace Prize by Arias. The last factor illustrates the positive reaction to Arias' peace plan before international audiences.

As was mentioned in Chapter II, other factors should be taken into account to fully explain the success of the Costa Rican president's policy in Central America. This chapter focuses on the role of Arias' rhetoric in persuading the aforementioned audiences to support his 
plan. Unlike Reagan, Arias has not been called a gifted communicator. In fact, during his race for the presidency of Costa Rica, between 1984-86, he was criticized for his ineffective attempts to communicate with large audiences. According to an official text, Arias was more effective in his interpersonal relations with rank-and file members of the social-democratic party, "Liberación Nacional" (National Liberation), where he held the highest positions including the office of general secretary (1979-1984) (Oscar Arias: El líder de la nueva generación, 1985).

Victor Ramírez, who was the media and publicity advisor for Arias during the 1984-86 presidential campaign, has said that Arias was sent to New York to be coached to improve his speech delivery and non-verbal communication. This account was confirmed by Guido Férnandez in his book, The first Sunday of February (1986). Férnandez said that Joe Napolitan, who is a veteran campaign advisor well known for his role in the triumph of John F. Kennedy during the sixties, suggested the idea. According to this account, Napolitan has said that

Oscar Arias doesn't need to worry because he lacks the appearance of John F. Kennedy, or because he doesn't inspire trust as Winston Churchill, or because he lacks the skills to communicate like Ronald Reagan [...] but he is who he is, so he needs to feel good about being himself, not trying to project a different image because of what he thinks people wants from him (p. 272).

The campaigner suggested that Arias go to New York for cosmetic changes, rather than radical surgery. According to Férnandez, the coaching session took place in September, 1985. According to Ramírez, the main reasons such action was taken were that Arias was so ineffective in several political stumps because of physical problems related to his voice, pitch, and articulation, and because his political message was often better understood by voters through the media and political advertising, which defused the 
awkwardness of Arias' communication "skills" (V. Ramírez, personal communication, December 10, 1985). Nevertheless, Arias' speaking ability was considered a disadvantage during the political campaign (Férnandez, 1986, p. 26).

Compared to Reagan, President Arias has a hard time trying to manipulate his language, his strategy, or his style to make himself and his policies appear to be attractive. It is also noticeable that the form which has prevailed in most of his pre- and post-presidential speeches has not been identified as narrative forms. In fact, it has not been categorized as any formal structure. He sometimes used poems or philosophical remarks, and occasionally even short anecdotes. Although these elements are an accessory to the structure, they lack the attachment or congruency with the whole of the discourse that is prevalent in Reagan's speeches. With Arias, these types of inclusions seem intended to embellish the discourse rather than to increase persuasion. Most of Arias' discourses are concerned with some sort of intellectual transcendentalism. $\mathrm{He}$ appeals to abstract ethical or spiritual categories which, contrary to Reagan, are never fully explained, detailed or defined. In fact, Arias' advisers have said that "Oscar [Arias] developed a style on the political stump which evolved from the academic chair to an emotional rhetoric" (Férnandez, 1986, n.p.). It is noteworthy to point out that even though all of Arias' speeches have been compiled, published, and translated from Spanish into English, French, and German, there has been little research based on his rhetoric, even among Costa Rican scholars. Both the nature of Arias' discourse and the reasons for the lack of information concerning it are beyond the scope of this research, although those topics may have relevance to future studies.

The discussion here will consider Arias' discourses using Stephen E. Toulmin's approach to argument (1958). As demonstrated in the preceding chapter, this approach is useful in describing and analyzing political arguments . The same methodological assumptions concerning the Toulmin model described in Chapter I 
were taken into account in studying the public discourses of Oscar Arias.

In order to describe and analyze Arias' discourses, twentythree arguments were selected. The same criteria used to pick Reagan's arguments were followed in choosing Arias' arguments. The latter have been chosen to represent the different themes used by him and discussed in this chapter. Each of the chosen discourses is described, its arguments extracted, the themes which it supports introduced, and the types of reasoning as well warrants supporting its claims described and analyzed.

\section{DESCRIPTION OF ARGUMENTS}

This chapter is based on data from seven discourses presented publicly by Oscar Arias between 1986 and 1988, concerning the specifics of Costa Rican foreign policy towards Central America in general, and Nicaragua in particular. These discourses were chosen as representative of the policies articulated by the Arias administration during its first three years in power. Three of them were presented before U.S. audiences between 1986 and 1988, one to President Reagan (1986), one to the media (1986), and one before U.S. students (1988). Two other discourses were presented to Latin American audiences, in 1986 and 1987. Another discourse was delivered to the Costa Rican people in 1988. The last discourse discussed was given to a European audience in 1987. The main topics of those discourses are described next.

"The roads to freedom" (1986) speech delivered to President Reagan and the press, is concerned with two main objectives, to explain (1) that threats to peace and democracy can only be overcome if all tyrannies are destroyed, and (2) that Central American democracies can only avoid war and oppression if given fair treatment in international trade and finance.

"Democracy in the Americas" (1986) an address delivered to the U.S. media, has two main claims: (1) despite the fact that in this 
era Latin America is returning to democracy, this return will remain unstable if severe economic pressures on these new democracies continue, and (2) democracies should not intervene militarily in Nicaragua's affairs, but politically encourage democratic reform.

The speech "Architects of the century of peace" (1988) was delivered before the 1988 graduates at Georgetown University in Washington D.C. It had a three-fold purpose and demonstrated: (1) that the Arias Peace plan is being crucified by the enemies of peace, (2) that there is no reason to support a military solution for Central American problems, and (3) that Central Americans are committed to peace.

"Peace- supreme hope of the world" (1988), an address delivered to Costa Rican academics and laymen at the Peace University in Costa Rica, was concerned with one claim, that in Central America there is no peace because there is no reconciliation between opposite parties in the on-going struggle. Both speeches "Opportunities for democracy in Latin America" (1986), presented to Latin American delegates to an International Democratic Exchange Conference in Costa Rica, and "The Peace is first" (1987), delivered to the president of Mexico and his cabinet, had four main purposes: to establish that there won't be peace and justice without democracy, (2) to state that if deeds don't encompass words of peace in Central America, the subsequent accords will be useless, (3) to increase the awareness that if concerns of the majority are not incorporated into political agendas, democracies will fail with a resulting spreading of violence, and (4) to remark that is too early to talk about the consolidation of democratic process in Latin America.

The address "Peace doesn't recognize borders" (1987), was delivered before European diplomats, academicians and politicians in Oslo, Norway, after Arias received the Nobel Peace Prize. It was a summary of the Arias political agenda. Five goals were achieved in this speech: (1) to explain that the peace process may never be finished because its development and preservation is part of democratic life, (2) to encourage democracy everywhere by giving no political or economic support to tyrannies, (3) to frame the peace 
initiative as basically anti-dogmatic and for freedom, (4) to reiterate that majority concerns must be included in political agendas to help democracy defeat tyranny, and (5) to remind the listeners that as long as the aforementioned objectives are achieved, democracy cannot be overpowered by totalitarism.

Six common themes can be drawn from these seven discourses:

(1) Threats to peace and democracy can be overcome if all tyrannies fall, and democracy is successful.

(2) Only fair treatment in international trade and finance can assure the political and economic stability of countries which are returning to democracy.

(3) Peaceful dialogue, rather than military intervention, is viable to solve Central American conflict. Democracies should encourage political reforms, but should not intervene militarily in other countries' affairs.

(4) The Arias Peace Plan is opposed only by those who favor war in Central America.

(5) Violence spreads when majority concerns are not included in Central American political agendas.

(6) There will be no permanent peace in Central America without reconciliation. Arias points out that in order to achieve peace and democracy requires deeds, not just words, and cooperation even if political agendas differ. These six common themes, found in the set of discourses studied, have been illustrated in Arias' rhetoric by the arguments shown in six corresponding charts.

In considering the first common theme, regarding overcoming threats to democracy, the arguments offered by Arias look like the Chart IX.

Following the second common theme, which questions how new, unstable Latin American democracies can possibly form without fair treatment in international trade and finance, Arias establishes his position through the Chart $\mathrm{X}$.

The third common theme is concerned with the viability of peaceful solutions to the Central American conflict. It tacitly rejects military intervention in Central America, particularly in Nicaragua, 
by defining democracies as nations which encourage political reform without physically intervening in other countries' affairs. The selection of arguments in Chart XI are used by Arias to support this point.

Following the fourth line of argument, the examples in Chart XII show Arias' intention to correlate his initiative to peace-seeking people, and opposition of it with those who favor war and are against Central America's wishes for peace.

The fifth line of argument, which addresses the need of Central American countries to include concerns of the majority, especially peace, on their political agendas is supported by the arguments included in Chart XIII.

The sixth line of argument reveals Arias' concern that the peace accord, be carried out by the five Central American Presidents in 1987. Arias assumes that reconciliation, expressed by working together to reach national and regional goals which were agreed upon by consensus, is a pre-requisite to permanent peace and democracy. The Chart XIV demonstrates this. 


\section{CHART IX}

\section{THREE EXAMPLES OF ARIAS' ARGUMENTS ON THE FIRST COMMON THEME, DEMOCRACY CAN OVERCOME TOTALITARIAN THREATS}

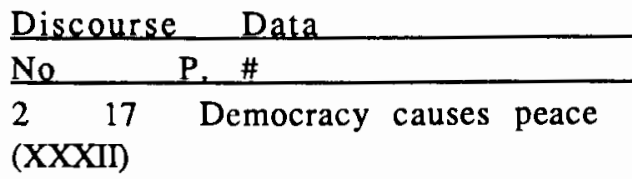

Warrant

(Since) Only democracy can guarantee reconciliation, endeavor to enable allow peace, and preclude violence from crossing borders.
Claim

(So) "Only if we all people to enjoy democracy, [and] cause the downfall of all tyrants equally, can we prevent threats to world peace from growing in the Americas."

Argumentation by cause

\begin{tabular}{|c|c|c|c|}
\hline $\begin{array}{lr}4 & 36 \\
(X X X V D)\end{array}$ & $\begin{array}{l}\text { History shows that those } \\
\text { who are afraid of } \\
\text { freedom have allowed } \\
\text { signs of oppression to } \\
\text { exist. }\end{array}$ & $\begin{array}{l}\text { (Since) Political oppression } \\
\text { can only be created by } \\
\text { people who are afraid of } \\
\text { freedom and have no human } \\
\text { values. }\end{array}$ & $\begin{array}{l}\text { (So) "The only } \\
\text { defense against the } \\
\text { enemies of freedom } \\
\text { is to strengthen } \\
\text { freedom and } \\
\text { democratic } \\
\text { institutions." }\end{array}$ \\
\hline
\end{tabular}

Argument by generalization

\begin{tabular}{|c|c|c|c|}
\hline $\begin{array}{lc}5 & 12 \\
(\mathrm{XXXXIV})\end{array}$ & $\begin{array}{l}\text { Costa Rica has been } \\
\text { strong, free and } \\
\text { democratic without } \\
\text { having an army. } \\
\text { by generalization }\end{array}$ & $\begin{array}{l}\text { (Since) What free people } \\
\text { believe in their souls } \\
\text { and live daily can't be } \\
\text { taken away. }\end{array}$ & $\begin{array}{l}\text { (So) "[Democracy] } \\
\text { is invulnerable to } \\
\text { totalitarian attacks. }\end{array}$ \\
\hline
\end{tabular}




\section{CHART X}

\section{THREE EXAMPLES OF ARIAS' ARGUMENTS ON \\ THE SECOND COMMON THEME, FAIR TREATMENT \\ IN INTERNATIONAL TRADE AND FINANCE}

\begin{tabular}{|c|c|c|}
\hline Discours & Data & Warrant \\
\hline No & P. \# & \\
\hline $\begin{array}{lr}1 & 17 \\
(\mathrm{XXXIII})\end{array}$ & $\begin{array}{l}\text { Internal and external } \\
\text { factors are } \\
\text { detrimental to Central } \\
\text { American economies. }\end{array}$ & $\begin{array}{l}\text { (Since) Good economic } \\
\text { conditions precludes } \\
\text { poverty and social } \\
\text { unrest. }\end{array}$ \\
\hline
\end{tabular}

Argument by cause

Claim

\begin{tabular}{|c|c|c|}
\hline $\begin{array}{lc}4 & 6 \\
(\mathrm{XXXVII})\end{array}$ & $\begin{array}{l}\text { New democracies do not } \\
\text { receive the economic } \\
\text { and political support } \\
\text { expected from interna- } \\
\text { tional economic } \\
\text { institutions and the } \\
\text { industrialized world. } \\
\text { by sign }\end{array}$ & $\begin{array}{l}\text { (Since) Economic and } \\
\text { political support from th } \\
\text { the industrialized world } \\
\text { and international } \\
\text { economic institutions } \\
\text { are a pre-requisite for } \\
\text { democracy.. }\end{array}$ \\
\hline $\begin{array}{ll}12 \\
(\mathrm{XXIX})\end{array}$ & $\begin{array}{l}\text { Using the "pretext of } \\
\text { saving democracy," } \\
\text { severe economic } \\
\text { deprivations are } \\
\text { being forced on } \\
\text { Latin American countr }\end{array}$ & $\begin{array}{l}\text { (Since) Unfair economic } \\
\text { treatment precludes } \\
\text { democracy. }\end{array}$ \\
\hline
\end{tabular}

Argument by classification.

(So)"Central America needs [...] fair treatment in trade and finance to avoid war and oppression."
(So) "[It] is too early to talk about consolidation of a democratic era in Latin America." institutions and the are a pre-requisite for 


\section{CHART XI}

\section{FOUR EXAMPLES OF ARIAS' ARGUMENTS ON THE THIRD COMMON THEME, VIABILITY OF PEACEFUL SOLUTIONS IN CENTRAL AMERICA}

\begin{tabular}{|c|c|c|c|}
\hline Discourse & Data & Warrant & Claim \\
\hline No & P. \# & & \\
\hline$l_{(\mathrm{XXX})}^{13}$ & $\begin{array}{l}\text { Costa Rica is peaceful, } \\
\text { neutral and believes in } \\
\text { self-determination } \\
\text { for Nicaragua and all } \\
\text { countries. }\end{array}$ & $\begin{array}{l}\text { (Since) Physical intervention } \\
\text { in other country's affairs is } \\
\text { not appropriate for neutral, } \\
\text { peaceful democracies. }\end{array}$ & $\begin{array}{l}\text { (So) "Nicaraguans } \\
\text { are the ones who must } \\
\text { solve their internal } \\
\text { problems." }\end{array}$ \\
\hline
\end{tabular}

Argument by generalization

$\begin{array}{lll}7 & \text { The USSR and the US are } \\ \text { negotiating peace and } & \begin{array}{l}\text { (Since) Conflict between } \\ \text { superpowers is not different reason to support the } \\ \text { reducing nuclear }\end{array} & \begin{array}{l}\text { (Som conflict between } \\ \text { armaments through } \\ \text { peaceful dialogue. }\end{array}\end{array}$

Argument by parallel case

$514 \quad$ Nuclear and conventional (Since) Nuclear war and (XXXXVI) wars have their own horrors. conventional war are equally harmful and threatening to humankind.
(So) "[We must] equally fight together against the possibility of other Hiroshima, [or another] Vietnam."

Argument by parallel case

$\begin{array}{ll}5 & 7 \\ (\mathrm{XXXXI}) & \begin{array}{l}\text { Latin American } \\ \text { tyrannies are } \\ \text { oppressing their } \\ \text { people. }\end{array}\end{array}$

Argument by generalization
(Since) The oppression of people should never be supported.
(So)"We should be neither political or economic allies of governments which oppress their people." 
CHART XII

\section{THREE EXAMPLES OF ARIAS' ARGUMENTS ON THE FOURTH COMMON THEME, CORRELATION BETWEEN PEACE-MAKING AND OPPOSITION TO WARFARE}

\begin{tabular}{|c|c|c|}
\hline Discourse Data & Warrant & Claim \\
\hline No $\quad$ P. \# & & \\
\hline 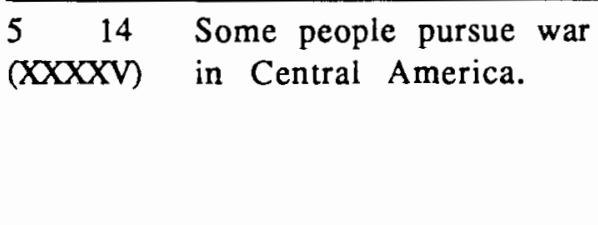 & $\begin{array}{l}\text { (Since) The pursuit of war } \\
\text { is antagonistic to the } \\
\text { pursuit of peace. }\end{array}$ & $\begin{array}{l}\text { (So) "No matter how } \\
\text { noble the crusade is } \\
\text { [peace efforts], some } \\
\text { wish for and } \\
\text { encourage its failure." }\end{array}$ \\
\hline Argument by classification & & \\
\hline $\begin{array}{l}7 \quad 15-6 \text { "The Central American } \\
\text { (XXXXVIII) Peace Plan is being } \\
\text { crucified [as Christ was } \\
\text { in his time]." } \\
\text { Argument by analogy }\end{array}$ & $\begin{array}{l}\text { (Since) The force of peace } \\
\text { should not be silent. }\end{array}$ & $\begin{array}{l}\text { (So) "History } \\
\text { repeats itself [with } \\
\text { the Peace plan]." }\end{array}$ \\
\hline 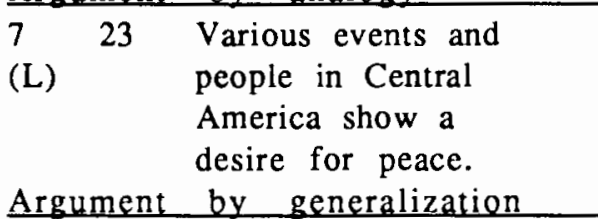 & $\begin{array}{l}\text { (Since) The desire for peace } \\
\text { is permeating Central } \\
\text { America. }\end{array}$ & $\begin{array}{l}\text { (So) "Central America } \\
\text { is committed to } \\
\text { peace." }\end{array}$ \\
\hline
\end{tabular}

\section{CHART XIII}

TWO EXAMPLES OF ARIAS' ARGUMENTS ON THE FIFTH COMMON THEME, ACKNOWLEDGMENT OF MAJORITY CONCERNS IN CENTRAL AMERICA BY LOCAL GOVERNMENTS

\begin{tabular}{|c|c|c|c|}
\hline Discourse & Data & Warrant & Claim \\
\hline No & P. \# & & \\
\hline $\begin{array}{l}4 \quad 6 \\
(X X X V I I)\end{array}$ & $\begin{array}{l}\text { In Central America, } \\
\text { people are affected by } \\
\text { things not under their } \\
\text { own control. } \\
\text { by generalization }\end{array}$ & $\begin{array}{l}\text { (Since) People denied a } \\
\text { a voice will respond with } \\
\text { violence. }\end{array}$ & $\begin{array}{l}\text { (So) "Migratory } \\
\text { problems and violence } \\
\text { will continue } \\
\text { spreading." }\end{array}$ \\
\hline $\begin{array}{l}5 \quad 11 \\
(\mathrm{XXXXIII})\end{array}$ & $\begin{array}{l}\text { Central American's } \\
\text { desire for freedom had } \\
\text { not been adequately } \\
\text { addressed by politicians } \\
\text { and public officials for } \\
\text { centuries. } \\
\text { by analogy }\end{array}$ & $\begin{array}{l}\text { (Since) The people's call } \\
\text { for freedom cannot long } \\
\text { be suppressed. }\end{array}$ & $\begin{array}{l}\text { (So) "Ignoring the } \\
\text { clamor for freedom } \\
\text { may condemn Latin } \\
\text { America to another } \\
\text { century of horror } \\
\text { and death." }\end{array}$ \\
\hline
\end{tabular}


CHART XIV

\section{THREE EXAMPLES OF ARIAS' ARGUMENTS ON THE SLXTH COMMON THEME, RECONCILIATION AS PRE-REQUISITE FOR LASTING PEACE}

\begin{tabular}{|c|c|c|c|}
\hline Discourse & Data & Warrant & Claim \\
\hline No & P. \# & & \\
\hline $\begin{array}{lc}5 & 5 \\
(X \times X X I)\end{array}$ & $\begin{array}{l}\text { There are many view- } \\
\text { points and interests in } \\
\text { the Central American } \\
\text { conflict. }\end{array}$ & $\begin{array}{l}\text { (Since) "[Peace] cannot be } \\
\text { forced in the smallest } \\
\text { nations nor can it be } \\
\text { imposed by the biggest } \\
\text { nation." }\end{array}$ & $\begin{array}{l}\text { (So) "The endless } \\
\text { process [of peace] } \\
\text { requires that we } \\
\text { work together." }\end{array}$ \\
\hline
\end{tabular}

Argument by generalization

6 Conflicting parties in (Since) Reconciliation is a (So) "IIn Central

(XXXXVII) Central America are prerequisite to peace. America] there is having a hard time reconciling their differences to reach a peace accord with one another. no peace because there is no reconciliation."

Argument by cause

3 11-2 Several discussion have (Since) Words are part of a (XXXIV) taken place to foster a a major role for Central Americans in the peaceful solution of their own conflicts. commitment, action is the next logical step. (so) "Peace and democracy demand datelines and deeds, not just words. The accords in good faith bring us closer to peace, if we are able to put them into practice."

Argument by classification 


\section{ANALYSIS}

Arias' arguments have not been analyzed using available approaches to analyze argument such as those of Lewis' narrative forms(1987), Wander's ideological criticism (1984), and McGee's ideograph (1980) which apply to the study of political argumentation. Because those approaches mainly focus on intracultural aspects of presidential rhetoric, and there are no similar or alternative studies on Costa Rican discourses or Arias' presidential rhetoric they did not seem appropriate for this chapter. Despite that fact, Arias' rhetoric carries a message which is consistent and has received the attention of many audiences around the world. The attention paid to Arias' words contributed to the success of his peace plan.

The respective common themes or lines of argument drawn from Arias' arguments, introduced above, serve as guidelines to analyze his discourse. The data Arias presents to justify his claims are often factually insufficient, but related to situations tacitly or contextually understood by his audience. In other words, where Reagan uses an inductive pattern of thinking - moving from details to general principles -, Arias does the opposite, trying to communicate broad principles while demanding an active effort from his audience. Because deductive reasoning dominates European and Latin American patterns of thinking, Arias claims that he "speak [s] of our problems with the simplicity of [his] people." Arias further explains that Costa Ricans decided that their "problems would be solved by reason and reason alone. [This may explain why] there is no violence in our behaviour, nor threats in our speech" (Discourse 1, p. 12).

\section{Arguments}

In Arias' 1986 addresses, "Roads to freedom" and 
"Opportunities for democracy in the Americas," both of which directly relate to his first line of argument, the threats to democracy come from the absence of a set of intertwined elements of democratic living, such as freedom of expression, pluralism, dialogue and transaction, and equality, within any nation. Arias assumes that democracy cannot be defended if those elements do not exist. "Freedom is out of reach for dictators only if it is based on freedom, justice, and the absence of poverty" (Discourse 4, p. 5), he says. Democracy, then, prevails as long as the system increases the political and economic participation of its citizens. Ideally, democracy must not foster what Arias considers traits of the enemies of freedom, envy, selfishness, fear, and immorality (p. 5).

Arias' 1986 speech "Democracy in the Americas" provides a strong support for the second line of argument. Arias has posited here two pre-conditions for democracies if they are to prevail in the Americas. They are the following: that all tyrannies, whether from the left or the right, must be overcome, and that democracies must be accorded better economic treatment from those nations which already have privileged economic positions in the world. His stance is derived from thinking in a North-South direction rather than a geopolitical East-West configuration. This approach is consistent with the ideological position of his political party, which is a member of the International Socialist party and has subscribed to the Brandt report on North-South relations. Basically, that document suggest policies which address the inequality, in terms of economic exchange, between third world countries and superpowers and industrialized countries. Through most of his discourses Arias suggests that violence in Central America is not, as Reagan assures, due to the expansionist intent of Soviet-Cuban backed regimes in the region, but chiefly a result of the underdevelopment of Central American economies as well as the dominance of dictatorial regimes whose concerns reflect those of a small powerful elite, rather than those of the majority.

Arias' 1986 address "Democracy in the Americas" (Discourse 1), which was already cited, and his 1988 speech "Architects of the 
century of peace" (Discourse 7) are fundamental to understanding his third line of argument. They provide a basis to define the role of democratic systems in political and military crises in other countries. On this topic, Arias draws heavily on his Costa Rican experience. He claims that "peace and social progress can only be achieved in open societies with democracies where the government is chosen through free and pluralistic elections" (Discourse 1, p. 13). Costa Rica is not neutral regarding the alternatives of democracy and dictatorship, but will take that position in face of a war. The role of a democracy is to encourage change peacefully, without physically intervening in another country' affairs. And because Arias stresses that equality, among other elements, sustains democracy, he expects that between democracies or states equality should be the source of peaceful change. This correlates with a strong desire which Arias made public during the 41 st session of the United Nations General Assembly in 1986. There he expressed Costa Rica's "desire to see all of the great powers remove themselves from Central American disputes." $\mathrm{He}$ said: "Costa Rica does not tolerate the fueling of war or the extension of death in the region by external forces" ( p. 15). Arias specifically demanded that the same civilized treatment that dominated the USSR-US armament talks be applied in Central America. "If the conflicts between superpowers are solved through dialogue, there is no reason to foster the use of military force in the solution of the Central American conflict" (Discourse 7, p. 19).

In Arias 1987 speech, "Peace doesn't recognize borders" (Discourse 5), which relates to the fourth line of argument, Arias explores the topic of commitment, to either peace or war. Those who attack and mock the Peace Plan are compared by Arias, in a rare use of reasoning by analogy, to those who tried to crucify an ideal of peace by crucifying a man, Christ. The analogy is extendable to many polarities such as moral-immoral, good-bad, peace-war, friendenemy, etc. The purpose of the comparison seems to be to establish a tacit difference between those who are committed to peace, and so to the Arias Peace Plan, and those who are not. This is particularly 
important to Arias because one of the premises of the peace process initiated in Guatemala in mid-1987 is that all the presidents who signed the peace accord known as Esquipulas I, were committed to peace. Thus, any disagreement about the procedures to reach that desirable peace are bound to the acceptance of the plan, even if critical. Those who rejected it, chose the easy way "to forecast defeat rather than triumph, war rather than peace," said Arias (p. 7). They value hate more than love, and military victory more than human reason, Arias continued (P.14). He disregarded those who opposed the peace plan in order to ensure the right, perhaps a moral right, of those who are working for peace to talk about it. However, as in most of his claims concerning this line of argument there are no substantial facts or details offered as data. Given certain data lacking specifics the audience is obliged to draw deductively a conclusion. For instance, given the data that some people pursue war in Central America, Arias claims that "no matter how noble the crusade is when started [peace efforts], some wish for and encourage its failure" (Argument XXXXV). Neither the specific people nor the reasons why they oppose the peace plan are mentioned. Only the warrant "the pursuit of war is antagonistic to the pursuit of peace" sustained the move from data to claim. A sort of tacit understanding seems to prevail between Arias and his audience. Perhaps Arias never mentions names, countries, and facts for giving grounds to his claims because the details are already known by the audience, or perhaps the audience may at least infer who or what they are.

Arias 1986 speech "Opportunities for democracy in the Americas" (Discourse 4) addresses the fifth line of argument more precisely than any other discourse made by Arias. After explaining the poor economic conditions which frame the return of democracy to most Central American countries, Arias stresses that its advent heightens the expectations of the majority, which are oppressed under dictatorships. As a result, there is a growing demand for political and economic participation in the less resourceful democratic regimes. Lack of response from the government encourages the underprivileged country people to move to the 
urban areas and increases social unrest. Arias deplores this situation. "Ignoring the clamor for freedom may condemn Latin America to another century of horror and death," he says (Argument XXXXIII). Arias holds the opinion that as long as concerns of the majority are not addressed by new democratic leadership, as is the practice under dictatorships, new migratory tides will begin and violence will spread rapidly. This is consistent with the thesis he has developed for the last fifteen years. That is, democracy only works and prevails as long as a "greater participation of the population in the process of adopting decisions" takes place, creating a "society capable of producing the basic necessities for its population under a basically democratic political and economic control system" (Arias, 1973, p. 9). Aside from suggesting the inclusion of popular concerns in the political agenda, Arias does not explain if such a situation is avoidable. His presentation of the problems is more a diagnosis than a cry for change. And, his claims here, like others previously cited, (such as the need for a fair economic treatment and threats to freedom) are tied together. The responsibility for making a difference is divided between the returning democracies, which fight against great odds, and the United States, whose government and economic agencies, public and private, financed dictatorships all over Latin America for years. It seems, as Arias points out, that "the international political support in favor of the re-establishment of democratic regimes is not consistent with the goodwill expended in the economic arena" (p.7). In fact, Arias remarks that the still existing Latin American dictatorships enjoy better economic treatment than do new democracies (p. 6).

The last theme claims reconciliation as the pre-requisite for peace in Central America, framed by the Arias peace plan. In his 1988 speech, "Peace- Supreme hope of the world" Arias presented arguments to justify reconciliation as a primary step to carry out the peace accords signed the previous year in Guatemala by the five Central American presidents. As he does in many arguments, Arias frames the claim that "[In Central America] there is no peace because there is no reconciliation," in contemporary history (Argument 
XXXXVII). However, rather than citing historical facts he begins a monologue in which he thoughtfully asks himself about the origin of "a bloody and martyred Central America" (p. 8). The story is abruptly interrupted by a claim, tied to a moral chain of concurrent elements, which allows peace to exist. Arias says "there is no peace because there is no reconciliation. There is no reconciliation because there is no justice. There is no justice because there is no compassion; there is no compassion because there is no love" (p. 8). After the claim is established he seems to have no need for elaboration. As indicated earlier, Arias draw general conclusions without explicitly addressing the reasoning process through which the conclusion has been obtained. Following the process of reason seems to be the work of his audience.

In general, thoughts proclaimed in a self-reflective fashion are Arias' basis for making claims. Nevertheless, as it is shown in the next section, Arias often uses reasoning by generalization to build his arguments.

\section{Warrants}

The six lines of argument found in our sample of seven discourses concerning Costa Rica's policy towards Central America have been illustrated by sample arguments using Toulmin's model. All the claims analyzed were chiefly supported by warrants. The warrants, as has been explained, are rarely made explicit by the speaker. In fact, their implicitness is what allows the speaker to establish a link with his audience. As Jeffrey R. Sweeney (1981) elaborates, the warrant provides justification for the act of inference require to move from data to claim.

This chapter as well as Chapter II is concerned with showing the warrants of the speaker's discourses. Chart XV below shows a sample of those warrants related to each specific line of argument, numbered from one to six, and according to the type of reasoning used by Arias to assert his arguments case by case. Although not 
exhaustive, the chart shows a noticeable dominance of argument by generalization in his discourses. From the twenty-three arguments studied, seventeen of which are shown in Chart XV, argumentation by generalization counts for $36 \%$ of all Arias' arguments studied for this particular research. Arguments by cause account for $22 \%$ of the total, and arguments by sign, parallel and classification make up $40 \%$. Clearly, reasoning by analogy is disregarded by Arias.

Argument by generalization uses a reasoning which can move from small examples to general principles or viceversa. This process works deductively in Arias' arguments. He offers a few outlines as the claim from which one may infer deductively the supporting data. Two arguments illustrate Arias' preference for the deductive generalization type of reasoning. First, when Arias claims that "Democracy is the only road to peace and justice [in Central America]" (Argument XXXV), which is a broad statement, the data he offers should be inferred deductively because is not explicit in his argument. In fact, the grounds for the claim he asserts are not specific or detailed [Undemocratic regimes deny individual rights]. In another case, Arias puts forth the claim that "The endless process [of peace] requires that we work together" (Argument XXXIX). The data from the latter could be inferred deductively [There are many viewpoints and interests in the Central American conflict] Despite the fact, that Arias sometimes gives specifics which we can infer as data, these specifics are broad statements rather than particular details or facts. The data of reasoning by generalization was used by Arias to argue the stability of democratic systems which fulfill their citizens lives even in the face of totalitarism (Arguments XXXVI, XXXXIV), and he defined a democracy as a system that does not, intervene militarily in other countries affairs (Argument XXX).

Reasoning by cause ranks second in importance. In this type of argument, the data function as a cause for the claim, and the warrant is a statement justifying the cause-effect relationship (Rieke \& Sillars). Arias' reasoning by cause differs from Reagan's reasoning in that he approaches life events such as war, peace, democracy and freedom more wholistically. That is, he points out causes of 
problems, but does not commit himself to one cause, or one effect. His arguments should be seen as part of a whole set of interacting causes and effects. This causal reasoning seems more interactive than that of Reagan's arguments as outlined in the following discussion. Arias uses reasoning by cause when clarity and simplicity are important. This is not the case of the "Soviet-Cuban threat" which, to be accepted by the listeners, attains from the speaker plenty of convincing details. This is a case of linear understanding to which the causal path of reasoning fits better. As Arias points out, "Central America needs fair treatment in trade and finance to avoid war and oppression." Why? Because good economic conditions preclude poverty and social unrest (Argument XXXIII). Therefore, there is a causal relationship between severe economic pressures on a democratic system and the presence of war, oppression, poverty or social unrest. In another speech, Arias said "[In Central America] there is no peace..." Why? He answered because "there is no reconciliation." Indeed, conflicting parties in Central America are having a difficult time reconciling their differences in their attempt to reach a peace agreement with each other (Argument XXXXVII). The causal relationship between peace and reconciliation is quite clear.

Considering reasoning by classification, Arias seldom uses specific cases or elements which behave as a member of a class with which they have been associated. The only situations in which Arias uses this type of reasoning is to differentiate himself and those who support the peace initiative he leads, from those who disapprove or attack the plan (Argument XXXXV), and when he wishes to distinguish between words and deeds concerning the peace initiative. Because Arias has shown a lesser interest in providing specific details or facts to prove his arguments than Reagan, reasoning by sign, which is preferred by Reagan, is quite unimportant to Arias. The only circumstance in which this type of reasoning acquires relevance here is in connection with the idea of the "instability" of Central American freedom systems due to economic, rather than military, pressures (Argument XXXVII). Other types of reasoning, 
such as parallel, analogy and authority, are downplayed in Arias' arguments. Their importance seems to be thwarted by the dominant role of reasoning by generalization. The lack of a clear-cut style, which has been described as characteristic of Arias' rhetoric, uses reasoning by generalization in order to achieve soundness and consistency. Nevertheless, the primary issues addressed by Arias -cultural context, political decision-making by consensus, among other factors -- often don't require probing via other types of reasoning, but should be examined by generalization.

Arias' arguments that were analyzed are supported by a selection of warrants and the types of reasoning which are represented in Chart XV.

\section{CORRELATION OF WARRANTS AND CLAIMS}

For the purposes of making clear the correlation between warrants and claims in Arias' arguments, the warrants summarized on chart $\mathrm{XV}$ are grouped according to the degree of connectedness between Arias' warrants and claims (See Figure 4.) This time all twenty-two of Arias' arguments are taken into account to draw the main warrants and their respective claims.

The first general warrant (W.1) is that fair treatment in international trade and finance guarantees democratic stability. The example selected is that [Unfair economic and political development is only possible in peace] (Argument XXIX), which underlies the following claims:

(1) "Sacrificing the political system of freedom to very severe economic pressures could have serious consequences for the political future of Latin America" (Argument XXIX, p. 12). 


\section{CHART XV}

\section{COMPREHENSIVE LIST OF WARRANTS AND TYPES OF REASONING SUPPORTING ARIAS' ARGUMENTS}

\begin{tabular}{|c|c|c|c|}
\hline Argument & Common & Warrant & Reasoning type \\
\hline XXXII & 1 & $\begin{array}{l}\text { Only democracy can guarantee } \\
\text { reconciliation, allow peace, and } \\
\text { preclude violence from crossing } \\
\text { borders. }\end{array}$ & Cause \\
\hline XXXVI & 1 & $\begin{array}{l}\text { Political oppression can only be } \\
\text { exerted by people who are afraid } \\
\text { of freedom and without human } \\
\text { values. }\end{array}$ & Generalization \\
\hline XXXXIV & 1 & $\begin{array}{l}\text { What free people believe in their } \\
\text { souls and live daily can't be taken } \\
\text { away. }\end{array}$ & Generalization \\
\hline $\mathrm{XXXXI}$ & 1 & $\begin{array}{l}\text { The oppression of people should } \\
\text { never be supported. }\end{array}$ & Generalization \\
\hline XXXIII & 2 & $\begin{array}{l}\text { Good economic conditions } \\
\text { preclude poverty and social } \\
\text { unrest. }\end{array}$ & Cause \\
\hline XXXVII & 2 & $\begin{array}{l}\text { Economic and political support } \\
\text { from the industrialized world and } \\
\text { international economic institutions } \\
\text { is a pre-requisite of democracy. }\end{array}$ & Sign \\
\hline $\mathrm{XXIX}$ & 2 & $\begin{array}{l}\text { Unfair economic treatment } \\
\text { precludes democracy. }\end{array}$ & Classification \\
\hline$x \times x$ & 3 & $\begin{array}{l}\text { Physical intervention in other } \\
\text { country's affairs is not } \\
\text { appropriate for neutral, peaceful } \\
\text { democracies. }\end{array}$ & Generalization \\
\hline IL & 3 & $\begin{array}{l}\text { Conflict between superpowers } \\
\text { is not different from conflict } \\
\text { between Central American nations. }\end{array}$ & Parallel case \\
\hline XXXXVI & 3 & $\begin{array}{l}\text { Nuclear war and conventional war } \\
\text { are equally harmful and threate- } \\
\text { ning for humankind. }\end{array}$ & Parallel case \\
\hline
\end{tabular}




\section{CHART XV}

\section{COMPREHENSIVE LIST OF WARRANTS AND TYPES OF REASONING SUPPORTING ARIAS' ARGUMENTS (continued)}

\begin{tabular}{|c|c|c|c|}
\hline Argument & mmon & Warrant & Reasoning type \\
\hline $\mathrm{XXXXV}$ & 4 & $\begin{array}{l}\text { The pursuit of war is antagonistic } \\
\text { to the pursuit of peace. }\end{array}$ & Classification \\
\hline XXXXVIII & 4 & $\begin{array}{l}\text { The force of peace cannot be } \\
\text { silenced. }\end{array}$ & Parallel case \\
\hline L & 4 & $\begin{array}{l}\text { The desire for peace is permeating } \\
\text { Central America. }\end{array}$ & Generalization \\
\hline XXXVIII & 5 & $\begin{array}{l}\text { People denied a voice will respond } \\
\text { with violence. }\end{array}$ & Generalization \\
\hline XXXXIII & 5 & $\begin{array}{l}\text { A people's call for freedom cannot } \\
\text { be suppressed for long. }\end{array}$ & Analogy \\
\hline $\mathrm{XXXXI}$ & 6 & $\begin{array}{l}\text { "[Peace] cannot be forced in the } \\
\text { smallest nations nor can it be } \\
\text { imposed by the biggest nation." }\end{array}$ & Generalization \\
\hline XXXXVII & 6 & $\begin{array}{l}\text { Reconciliation is a pre-requisite } \\
\text { for peace. }\end{array}$ & Cause \\
\hline XXXIV & 6 & $\begin{array}{l}\text { Words are part of a commitment. } \\
\text { Action is the next logical step. }\end{array}$ & Classification \\
\hline
\end{tabular}



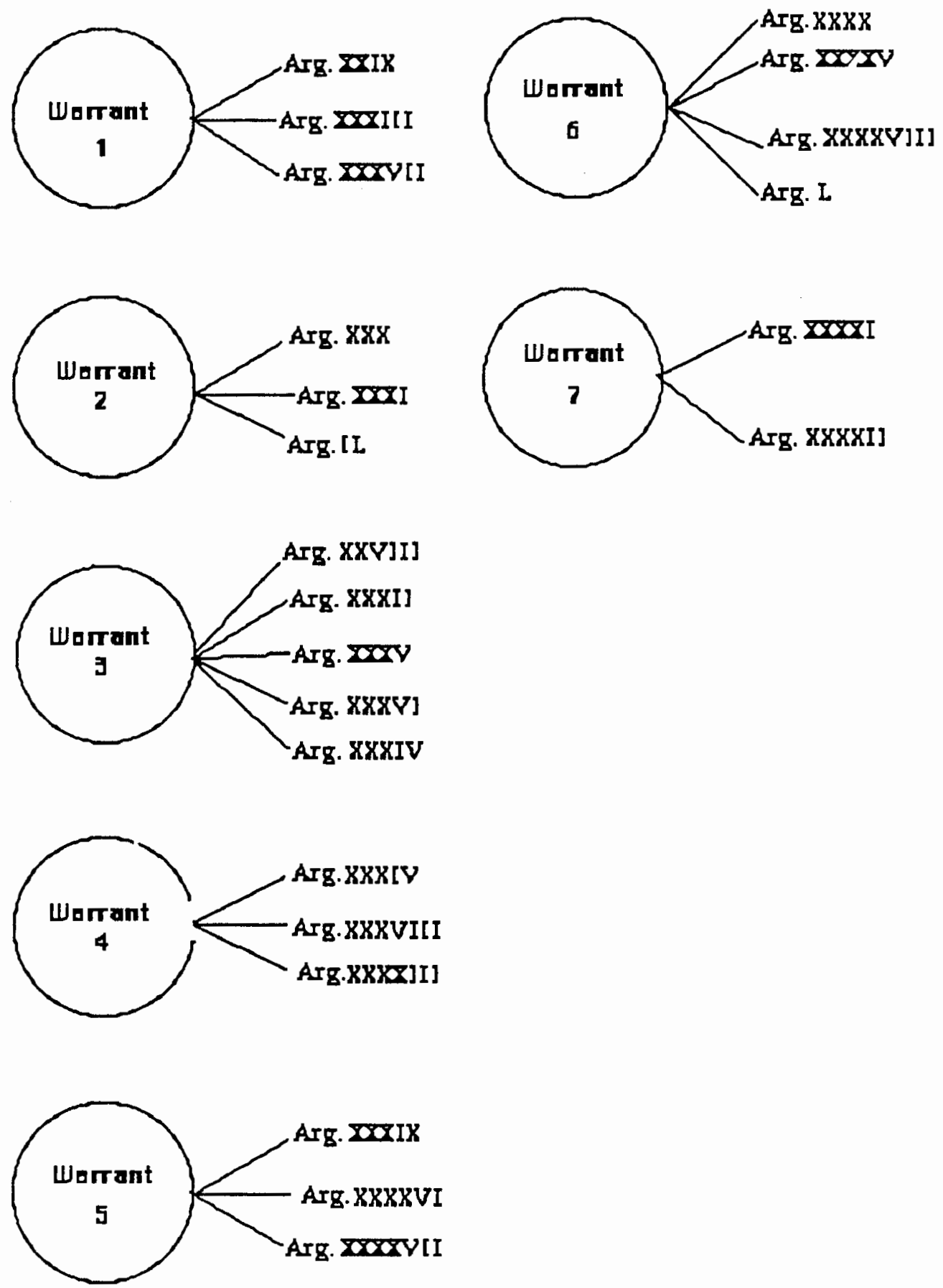

Figure 4. Graph correlation between general warrants and claims in Arias' arguments. 
(2) "Central America needs [...] fair treatment in trade and finance to avoid war and oppression" (Argument XXXIII, p. 17).

(3) "[It] is too early to talk about consolidation of a democratic era in Latin America" (Argument XXXVII, p. 6).

The second general warrant (W.2) concerns the role of democracies in avoiding military intervention in other countries affairs. This is shown by the warrant [Physical intervention in other country's affairs is not appropriate for neutral, peaceful democracies], (Argument XXX) which synthesizes the available warrants to the following claims:

(1) "Nicaraguans are the ones who must solve their own internal problems" (Argument XXX, p. 13).

(2) "Costa Rica is neutral with respect to war" (Argument XXXI, p. 13).

(3) "There is no reason to support the use of military force in the solution of Central American conflict" (Argument IL, p. 19).

The third general warrant (W.3) states how democracies can defend themselves from the threat imposed on them by totalitarism. This is illustrated by the warrant [Only democracy can guarantee reconciliation, allow peace, and preclude violence from crossing borders] (Argument XXXII), which lies at the core of the principles supporting the following claims:

(1) "Latin America is living an era of a return to democracy" (Argument XXVIII, p. 11).

(2) "Only if we endeavor to enable all peoples to enjoy democracy, [and] cause the downfall of all tyrants equally, can we prevent threats to world from growing in the Americas" (Argument XXXII, p. 32).

(3) "Democracy is the only road to peace and justice" (Argument XXXV, p. 5).

(4) "The only defense against the enemies of freedom is to strengthen freedom and democratic institutions" (Argument XXXVI, p. 5).

(5) "[Democracy] is invulnerable before the totalitarian attacks" (Argument XXXXIV, p. 12). 
The fourth general warrant (W.4) names Central American leaders as responsible for putting peace into practice. The warrant [Words are part of a commitment; action is the logical next step] (Argument XXXIV) is at the core of the warrants which support the following claims:

(1) "Peace and democracy demand datelines and deeds, not just words. The accords in good faith bring us [Central Americans] closer to peace, if we are able to put them into practice" (Argument XXXIV, pp. 11-2).

(2) "Migratory problems and violence will continue spreading" (Argument XXXVIII, p. 6).

(3) "Ignoring the clamor for freedom may condemn Latin America to another century of horror and death" (Argument XXXXIII, p. 11). The fifth general warrant (W.5) claims reconciliation and cooperation as necessary supports for peace. The warrant ["[Peace] cannot be forced on the smallest nation nor can it be imposed by the biggest nation" (Argument XXXIX) supports the following claims.

(1) "The endless process [of peace] requires that we [Central Americans] work together" (Argument XXXIX, p. 5).

(2) "[We all must] equally fight together against the possibility of another Hiroshima, another Vietnam" (Argument XXXXVI, p. 14).

(3) "[In Central America] there is no peace because there is no reconciliation" (Argument XXXXVII, p. 8).

The sixth general warrant (W.6) concerns peace as a desirable outcome, opposed only by those who favor war. An example of this is the warrant [Peace is to be sought as desirable] (Argument XXXX). This is the core principle of the warrants which support the following claims:

(1) "I can't accept defeatism" (Argument XXXX, p. 7).

(2) "No matter how noble the crusade is [peace efforts], some wish for and encourage its failure" (Argument XXXXV, p. 14).

(3) "History repeats itself [with the Arias Peace Plan] " (Argument XXXXVIII, pp. 15-6).

(4) "Central America is committed to peace" (Argument L, p. 23). 
The seventh general warrant (W.7) is concerned with individual rights and freedom, as opposed to totalitarianism, oppression and dogma. The warrant, [The oppression of the people should never be supported] (Argument XXXXI) maintains the following claims:

(1) "We [democrats] should be neither political or economic allies of governments which oppress their peoples." (Argument XXXXI, p. 41)

(2) "Dogmas are the enemies of human creativity [individual freedom] " (Argument XXXXII p. 11).

\section{SUMMARY}

Although Oscar Arias has not been considered as talented a speaker as Ronald Reagan, his public discourses on Central American policy have met with consistent success. Chapter III examined the role Arias' words played in convincing audiences of the validity of the claims presented in his discourse. Unlike Reagan's speeches Arias' seem to have no specific structure and no clear style. He tends to cite fewer facts than Reagan and to speak on a more philosophical or idealistic plane.

As was done in Chapter II to Reagan's discourse, in this chapter Toulmin's model of analyzing argument was applied to a selection of Arias' public speeches on Central American policy. The warrants underlying Arias' discourse - reflecting cultural values inherent in Arias' words- were determined. Types of reasoning employed were examined; Arias used argument by generalization more than any other type of reasoning. Finally, following the pattern of Chapter II, the warrants repetitive through Arias' speeches studied in this research were displayed according to the degree to which they connected corresponding data and claims. This data will provide a base for determining the cultural values Arias' relies upon to effectively communicate with his audiences. 


\section{CHAPTER IV}

\section{CULTURAL VALUES AFFECTING POLITICAL ARGUMENTS EXCHANGED BETWEEN PRESIDENTS REAGAN AND ARIAS}

This chapter provides a comparative analysis of the data collected: It looks at the warrants of each speaker's arguments, interprets their similarities and differences in terms of cultural values, and draws implications for an intercultural communication perspective. By doing so, this chapter finds that since Arias and Reagan belong to different cultures, their political arguments are underlaid with different cultural values which may affect their mutual understanding.

The interpretation of the data presented relied on three sources: the list of value orientations used by Condon and Yousef (1975) in linking argumentation and cultural values, the summary of cultural assumptions and values developed by Stewart, Danielian and Foster (1969) and, Edward C. Stewart's cross-cultural perspective of American cultural patterns (1971) in contrasting U.S. patterns with those of other cultures. These three sources have relied heavily on the original five sets of value orientations proposed by Florence Kluckhohn and Fred L. Strodtbeck in their study,Variations in value orientations (1961). Condon and Yousef have kept the three variations for each set, but they have added to the original five sets, for a total of twenty. Thus, a new chart of value orientations combining the three sources has been developed to suit the need for the identification of value orientations found in each speaker. (See Chart XVI )

In referring to the chart, this chapter takes into consideration the following aspects: (1) All the variations summarized may exist in any society beyond the United States and Costa Rica; (2) this 
summary is neither definitive nor exhaustive, and to apply it to the specific inquiry of this thesis concerning communication between political speakers from particular cultures, it has been necessary to make major adjustments.

Each of the sources consulted for this section provides a different, but complementary approach to the authors' common field: intercultural communication. Condon and Yousef provide a base for understanding relativism in public argument that is, the different cultural frames, which, existing across cultures, give different perspectives to help describe, interpret and evaluate political claims because of differences in cultural values reflected in warrants. Nevertheless, "culturally [influential] rhetorical forms themselves help shape one's world view, one's thoughts, and one's actions" (Condon \& Yousef, 1975, p. 233). Stewart, Danielian and Foster established a cross-cultural set of categories within which the cultural values and patterns of thinking underlying public argument explain differences between different cultural speakers. Finally, Stewart provides the four different components to classify the cultural values underlying Reagan and Arias' arguments by way of warrants. They are form of activity, form of relation to others, perception of the world and perception of the self (Stewart, 1971, p. 26). These components are fully explained through the three sections of this chapter: first, cultural values underlying warrants, which relate warrants to cultural values using the XVI, which is based on E. C. Stewart et al.'s (1969) and Condon and Yousef's value orientations lists; second, a brief description of distinctive patterns of thinking operating in Reagan and Arias' arguments, which enhance our understanding of how cultural values affect reasoning; third, conflict(s) between Reagan and Arias' arguments, obtained by eliciting and discussing conflicts between arguments when comparing them; and fourth, implications according to the intercultural communication perspective.

It is important to emphasize that cultural values cannot be found alone, because they are part of a vast fabric of culture. As has been observed, values classify within the perception of human 
nature which under a broad perception of the world (Stewart, 1971, p. 26) merge into one another subconsciously as human behavior does in an underlying value system. Stewart points out that "each component of a culture affects the others and, in turn, is limited by them." In American culture, for instance, the stress on the value of equality among all is sometimes incompatible with achievement and, also, freedom (Williams,1964, pp. 27-8). Therefore, this chapter stresses the prevailing cultural values over those which may be there implicitly, but may be dependent on the main value.

I have established in chapters II and III that warrants carry important information which increases understanding of how and why arguments are made. The arguments selected from either Reagan's or Arias' discourses about the Central American conflict have been explored and their main warrants summarized in Charts XVI and XVII.

\section{CULTURAL VALUES UNDERLYING ARGUMENTS}

In order to first relate Reagan and Arias' warrants to cultural values this section relies on the data from chart I to XVIIII and figure 3 of Chapter II for Reagan's cultural values, and from chart IX to chart XV and figure 4 of Chapter III for Arias' cultural values. Reagan's warrants are analyzed first, followed by Arias' warrants.

\section{Reagan's warrants}

In chapter II, Reagan's warrants were summarized into nine categories which are orderly consubstantiality (W1), political dualism (W2), U.S. international role as policeman (W3), U.S. fairness and maturity (W4), legitimacy (W5), signs of war and ill-will (W6), old solutions to new problems (W7), only democracy guarantees freedom and development (W8), and totalitarism threatens democratic systems and actions (W9). 


\section{CHART XVI}

\section{CULTURAL VALUE ORIENTATIONS AND PATTERNS OF THINKING}

\section{A. Cultural Value Orientations:}

\section{FORM OF ACTIVITY}

\section{Orientation to action}

1. doing

\section{Temporal orientation}

\section{1. past}

2. being-in-becoming

2. present
3. being

3. future

\section{FORM OF RELATION TO OTHERS}

\section{Social reciprocity}

1. Independence

2. symmetrical-obligatory 3 . complementaryobligatory

\section{Fair-play}

1. fairness

2. mixture of both

3. unfaimess

\section{PERCEPTION OF THE WORLD}

\section{Progress and the concept of time}

1. linear-causal chain of

2. interaction of events (one event affecting the event $s$

3. events are cyclical (no events, only a time and space working as a system )

\section{PERCEPTION OF SELF}

\section{Individualis m-interdependence}
1. Individualism
2. Individuality
3. Interdependence
Good and Evil
1. Good
2. Mixture of good and
3. Evil evil

Based on sets of value orientations proposed by Kluckhohn \& Strodtbeck (1961), Stewart, Danielian, Foster (1969), Stewart (1971), and Condon and Yousef (1975)

\section{B. Patterns of thinking:}

\begin{tabular}{llll}
\hline 1. Dichotomous (Dualistic) 2. Non-dichotomous & $\begin{array}{l}3 . \\
\text { third pelativistic (or }\end{array}$ \\
&
\end{tabular}

1. Inductive 2. Circular 3. Deductive

Based on Edward C. Stewart (1971) list of patterns of thinking connected with cultural values. 
The general warrant 1 concerns consubstantiality, which is common ground. Reagan, as speaker, seems to seek common ground with his audience showing that the United States and Central America or the Caribbean basin are really very much alike. This is true of most of his addresses whether to Latin American or U.S. audiences. As shown in 1982 "Aid to the Caribbean Basin": he claims "We are the new world [...] We [U.S. and Latin America] are all America" (Argument I, p. 322); 1983 "The Problems in Central America" where in stressing the strategic value of Central America he puts forth the claim "Central America is the U.S. lifeline to the outside world" (Argument VII, p. 450); or 1986 "Nicaragua" where in defending the "Contras" Reagan says "The resistance has contributed directly to the security of the United States" (Argument XVIII, p. 388).

Reagan's focus on common ground as warrant for the aforementioned claims supposes the existence of the theme of equality. The term has been estimated by Stewart $(1971$, p. 46) as one which pervades the American (U.S.) social relationship. Consubstantiality or common ground is rooted in the value of equality understood here as one of humanness, "We're all human after all," explains Stewart. Paraphrasing it, "We're all [U.S. and Central America] America [after all]" a claim that implies that the link Reagan wanted to establish with his audience was one of an interpersonal relationship. In other words, Reagan apparently was not talking down to the people listening, but horizontally as in typical interpersonal relationships, conducting a communication between presumed equals. The purpose, which is explored to a greater extent in the discussion section of this chapter, seems to reduce the risk of confrontation with seemingly different audiences from different social strata and culture by establishing an atmosphere of equality.

By using the list of value orientations from XVI, the general warrant 1 , common ground, fits into the category of the value equality under form of relations to others.

The general warrants $2,5,6,8$ and 9 can be summarized into one chief concern, dualism, that is the use of an "either/or" pattern. 
Reagan, as speaker, seems to warrant many of his claims by suggesting to his audience that there is always a choice between only two alternatives, and that one of them, usually implicit as a rejection of the explicit one, is better than the other in dealing with or describing the Central American or Caribbean basin problems. This is noticed in addresses such as the 1982 "Aid to the Caribbean Basin" where he claims that "There are only two possible futures for Central America: [Democracy or dictatorship] (Argument III, p. 324); or the implicit appeal to a positive choice instead of the negative alternative explicit in the warrant as in 1983 "The problems in Central America" where in depicting negatively the leftist guerrillas Reagan says "Salvadoran guerrillas are a small minority who want power for themselves and their backers" (Argument IX, p. 451); or 1987 "Central America at a critical juncture" where in dividing the political scenario into democrats or antidemocrats he says "The Sandinistas in Nicaragua are not democratic" (Argument XXIII, p. 2).

Reagan's use of dualism, which has been cited above as an "either/or" pattern, as warrant for the aforementioned claims has been widespread in most of his speeches. Dualism supposes the existence of the theme of good versus evil, and the existence of a choice between them. In the logic of Reagan speeches, he tends to judge every situation as being good or bad. The term dualism, as used in this chapter, is considered by Condon and Yousef (1975, p. 97) as one connected with how human nature is perceived in American culture. Dualism is underpined by the values of choice, good and evil and change. In Stewart's words "while religion in the

U.S. is committed to the doctrine that man is evil by nature, most Americans are unlikely to give the concept much thought. More likely they will see man as a mixture of good and evil or a creature of his environment and experience. Most important, they will stress his ability to change" (1971, p. 59).

Through the arguments linked to the above mentioned warrants, this value orientation takes many forms: suspicion towards the Sandinistas "Nicaragua is an outlaw regime" (Argument 
XVII, p. 387), pessimism about Soviet and Cuban political intentions in Central America "Foes of freedom will destabilize Caribbean basin countries" (Argument IV, pp. 324-25). Therefore, Reagan claims there is a choice between one alternative that is better than another, good versus evil, in a scenario where things can change for the good only if the U.S is allowed to intervene. This last element implies the value of "doing" which is located under the category of form of activity according to Condon and Yousef (1975), and Stewart, Danielian and Foster (1969) and Stewart (1971).

By using XVI, the general warrant 2, to which has been added warrants 5, 6, 8 and 9, dualism, fits into the category of the value choice between good or evil under perception of the world.

The general warrant 3 is concerned with the U.S. role as the international policeman, that is, assuming task-oriented activities such as a moral commitment to preserving freedom and stability in and out of the United States. Reagan, as speaker, seems to warrant some claims by suggesting to his audience that there is a moral obligation from the U.S. to its allies in Central America and elsewhere which is manifested by engaging in some activities which can change the future for the better no matter how serious the problems are. This is noticeable in addresses such as the 1982 "Aid to the Caribbean Basin" where he claims that "Freedom and peace requires help from the U.S. to those nations confronted with communist aggression" (Argument V, p. 325); or the explicit commitment acquired unilaterally by the U.S. with Central American nations, whether or not its governments agree. Additional support to U.S. international policing is found in Reagan's 1983 "The problems in Central America" where he says that the "U.S. will support the security of the region's threatened nations" (Argument XI, pp. 4523); and 1987 "Central America at a critical juncture" where Reagan makes personal his position towards the region, by saying that he "won't walk away from the fight for freedom in Central America" (Argument XXV, p. 4).

Reagan's use of a police role, which has been cited above as engaging in task-oriented activities because of a moral commitment, 
as the warrant for the aforementioned claims, has permeated his rhetoric. Policing supposes that there is a duty. In his 1988 "State of the Union" address Reagan has noted that "the love of freedom that God places in each of us...has [been] entrusted in a special way to this nation [by God]" (p. 258). He supported this vision in the work ethic-doing. In the logic of Reagan speeches, he tends to place a high value on action which yields the principle that one can improve upon the present. Following such logic, action and hard work will bring about what the individual, the nation and the government wants; hence, Reagan describes his policies as having what Clyde and Florence Kluckhohn call the attribute of effort-optimism (1947). That is, through one's effort or hard work one will achieve one's ambitions. No goal is too remote, no obstacle is too difficult, for the individual or nation which has the will and the determination and which expends the effort. Stewart summarizes the spirit of this when saying "hard work is rewarded by success" (1971, p. 34). As Reagan highly regards task-oriented action, "doing", he also stresses other values such as "individualism" and "progress". The form of activity developed as a category by Stewart (1971).includes the aforementioned values as an interrelated group. It is possible to delineate them from the Reagan's arguments already cited and put them under a form of activity. Therefore, the warrant of the U.S policing the world is underpined by Reagan's action values. Reagan, the speaker, uses them to enable his administration to carry out the policies he wishes, such as supporting the "Contras" and increasing economic and military pressures against Nicaragua or other opponents. In Reagan's arguments linked to the general warrant 3, the value orientation using action to change Central American conflicts, stresses the value "doing" to change the present time, thus tacitly implying a temporal orientation to the future. In Florence Kluckhohn's words the most distinctive feature of the value of doing "is a demand for the kind of activity which results in

accomplishments that are measurable by standards conceived to be external to the acting individual" ( 1963 , p. 17). Through the arguments linked to the mentioned warrants, this value orientation 
has taken two main forms: Reagan insists on "getting things done" when he says that he "won't walk away from the fight for freedom in Central America" (Argument XXV, p. 4). He also shows that the U.S. will take action, employing phrases like the "U.S. will support the security of the region's threatened nations" (Argument XI, pp. 452$3)$.

By using XVI, the general warrant 3 fits into the category of the value doing, which is closely related to the values of progress and individualism. Doing is under form of activity .

The general warrant 4 concerns the U.S. image as a fair power, that is one which engages in fair play. Reagan tries to persuade his audience of his administration's ability to maturely and responsibly handle international crises, particularly in Central America. This is true of three of his speeches delivered to the American people as, for example, his 1983 speech "The Problems in Central America" where in diminishing the impact of the economic embargo and the funding of the "Contras," he sets forth the claim that "Our actions [are] hardly the actions of a nation implacably hostile to Nicaragua" (Argument VIII, p. 451); in the 1984 speech "Central America policy" Reagan notes the good will of his country in world affairs by saying that "the U.S. will never be the aggressor" (Argument XIII, p. 482-3); and in a 1986 speech "Nicaragua" Reagan depicts U.S. policy towards Central America as one of peace-seeking rather than that of a belligerent supporter of the "Contras", by saying that "the U.S. has sought and still seeks - a negotiated peace and a democratic future in a free Nicaragua" (Argument XIX, p. 388).

Reagan focuses the above mentioned claims on fair-play warrant and supposes the existence of the warrant as a cultural value. The term fair-play has been defined by Stewart (1971, p. 53) as one which pervades American decision-making. Margaret Mead points out that fairness doesn't consists of rules which ought to be followed as

The inclusion of [the] other person's weakness inside the rule so that "fair play" [encompasses] a statement of relative 
strength of the opponents and it ceases to be fair [when it] beat a weak opponent (Mead, 1965, p. 143).

In Reagan's arguments the notion of "fair-play" stands for his administrations fair share in world and regional affairs as well as its concern in acting fairly towards other nations. Therefore, Reagan cannot initiate action if it involves aggression since he, according to the logic of his arguments, does not believe in beginning a war. It resembles his claim that the "U.S. will never be the aggressor" (Argument XIII, pp. 482-3). Nevertheless, it becomes very important to him to be able to say "they started [war]," and then of course, "we'll finish it." According to Stewart, "the significance of the value - accommodation to the weakness of another-- is brought out in the mutual misunderstanding of the concept of fair play between Americans and member of other cultures" (1971, p. 54).

Fair-play is rooted in the value of fairness understood here as one of "accommodation to the weakness of the other" explains Stewart. In Reagan's words that would equal the claim, "Our actions were hardly the actions of a nation implacably hostile to Nicaragua" (Argument VIII, p. 451). This claim implies that the link Reagan, the speaker, wanted to establish with his audience is again, as in the first general warrant, a connotation of an interpersonal relationship. In other words, Reagan appeals to his audience by exploiting the value of fairness which is shared by the American audience. The purpose, which is explored more in depth in the discussion section of this chapter, seems to enhance the seriousness and consideration with which the decision-makers view a hostile or friendly confrontation with Central American nations.

By using XVI, the general warrant 4, fair play, fits into the category of the value fairness under form of relation to others.

The general warrant 5 covers the adequacy of "cold-war" solutions to contemporary problems. Reagan tries to persuade his audience of the validity of old policies to new problems, implying that the usefulness of those policies is directly related to the sameness of political conditions along different stages in history. The 
applicability of such analogy in terms of Reagan's decision-making processes depended on the selective perception of causes as producers of the present crisis in Central America as existed in the region during the cold war years. This is evident in the claims that suit the following three discourses: in the 1983 speech "The Problems in Central America," Reagan posits Truman's success in preventing communism from expanding in 1947, by stating that "President Truman's words are as apt today as they were in 1947" (Argument XII, p. 452); in the 1984 speech, "Central America policy" Reagan engages again in an analogy by finding the U.S. citizens' opposition to his policies in Central America as a repetition of the isolationism during World War II, he then claims that "[Isolationism] ensures war instead of preventing it" (Argument XV, p. 486); and, in the 1987 "State of the Union," address Reagan causally finds that the Soviets are at war and consequently want to have a beachhead at the U.S. doorstep and he warns that "Freedom Fighters won't allow the Soviets to have a beachhead [in Central America]" (Argument XXII, p. 259).

At first glance, Reagan seems to have relied heavily on the past, but to consider that his arguments are not directed to the future seems attractive. However, his concept of time is eminently suited to a rational view of the world. One can distinguish various moments in time, note their relationship, and convey their connection by calling the preceding moment a cause and the next an effect. The description made by Stewart (1971, p. 65) identifies Reagan's predilection for seeing the world, Central America in particular, in rather simple terms and, ideally, evoking a simple cause and effect sequence to explain events.

Despite Reagan's apparent lament for the passing of the good old days, he is optimistic that the future will be bright if one acknowledges the lessons of the past in a linear fashion, suggesting that the same cause produces the same effect. This made his arguments future-oriented or concerned with progress. As has been pointed out by Condon and Yousef "the past, too, is not denied or forgotten; more likely it is interpreted as a more distant present" 
(1975, p. 110). Reagan's focus on progress from the past, old solutions to new problems, warrants the aforementioned claims and supposes the existence of progress as a cultural value. Reagan introduced an appealing past, whether the lessons of the cold war or isolationism during WW II, to his audience, but moves forward to show its applicability under new historical conditions. The differences are neglected and the similarities enhanced, thus allowing Reagan to master the past and to conquer the future. Reagan draws from history what he needs, and forgets the rest. Social inequality, external debt, corruption, civil war are not the causes of Central American problems, at least not the ones externalized in Reagan's rhetoric. In his arguments he sees Central America as being threatened, invaded, troubled by external factors-Soviets, Cubans and communism. By using XVI, the general warrant 7 , old solutions to new problems, fits into the category of the value progress under Perception of the world.

\section{Arias' warrants}

In Chapter III, Arias' warrants were summarized into seven categories which include: fair treatment in international affairs and finance in order to guarantee democratic stability (W1), nonintervention in other nations' affairs (W2), democracies' self-defense capability against totalitarian threats (W3), leaders' responsibility to change words into deeds (W4), cooperation (W5), peace as a desirable outcome over war (W6), individual rights and freedom as opposed to totalitarian oppression and dogma (W7).

The general warrants 1,4 , and 5 are permeated by the concepts of fair treatment in international affairs and finance, and social reciprocity within underdeveloped Central American societies as a means to achieving democratic stability. That is, first, fair play based on cooperation between democratic nations, particularly aid from the rich to the poor countries, and second, acknowledgment of people's needs and possibilities within social classes in democratic 
nations. Arias, as speaker, seems to seek an understanding with his audience about the fragility of democracies before poor external and internal economic conditions because of unfair international trade and finance and because of internal social injustice and lack of cooperation to carry out politic and economic reforms. He also implies that democracies, whether economically rich or poor, should respect each other- but that the wealthy might help those that are not as wealthy. This is true of most of all his addresses as demonstrated in a 1986 speech entitled "Democracy in the Americas," in which Arias claims that "Sacrificing the political system of freedom to very severe economic pressures could have serious consequences for the political future of Latin America" (Argument XXIX, p. 12); in a 1987 speech, "Peace doesn't recognize borders," Arias stresses the notion that peace in the region cannot be achieved without acknowledging popular needs, he warns that "Ignoring the clamor for freedom may condemn Latin America to another century of horror and death" (Argument XXXXIII, p. 11); or, in a 1988 speech, "Peace -supreme hope of the world," he explains that the first step to filling the gap between political enemies and classes divided because of social injustice is social reciprocity and cooperation. In his own words, "[In Central America] there is no peace because there is no reconciliation" (Argument XXXXVII, p. 8).

Arias focuses on fair-play based on international cooperation and national social reciprocity warranting that these claims seem to underpin two value categories: form of activity and form of social relations. The first category is understood as the link between the individual and the concrete event in the world. It reflects other assumptions, such as the second category - form of social relations, in the context of a specific moment and place and the demands of a given situation (Stewart,1971, p. 26). According to the reading of Arias' arguments, being, which is form of activity, is the dominant cultural value underlying warrants 1,4 and 5. Likewise, Arias' warrants underlie the values of fair-play and cooperation, which are under the form of social relations in Stewart list. These values require further explanation. Although Arias' exhortation to change 
words into deeds "Peace and democracy demand datelines and deeds, not just words. The accords in good faith bring us [ Central Americans ] closer to peace, if we are able to put them into practice" (Argument XXXIV, pp. 11-12) seems at first a typical American orientation to action, but it is not. The inclusion of the qualifier "if" makes any claim a proposal, an intent, not an assertion to which action or reaction automatically follows. In other words, Arias apparently was not talking literally. As explained by Kluckhohn and Strodtbeck

In the being form of activity, there is a preference... for the kind of activity which is a spontaneous expression of what is conceived to be "given" in the human personality. As compared with [other value orientations], it is a nondevelopmental conception of [form of] activity. It might even be phrased as a spontaneous expression in the activity of impulses and desires; yet care must be taken not to make this interpretation a too literal one (1961, p. 16).

Arias' being orientation toward activity, which is explored more deeply in the discussion section of this chapter, seems to enhance his persuasiveness before Central American audiences and political leadership, particularly the presidents who came together to sign the peace accords and who are responsible for carrying out political and economic reforms in their own countries.

In considering the values of fair play and cooperation, more precise definitions must be applied. Cooperation for Arias is not necessarily given for the sake of action, but because it often implies that the Costa Rican, in particular, and the Central American, in general, doesn't easily yield in matters of principles. For instance, in dealings with the different pro or anti-government in the Central American scenario, Arias has acknowledged that "[We all must] equally fight together the possibility of another Hiroshima, another Vietnam" (Argument XXXXVI, p. 14) but that first reconciliation must be achieved, "[In Central America] there is no peace because there is no reconciliation" (Argument XXXXVII, p. 8). In other words, Arias' 
audience has a difficult time adjusting its private and national goals to those of the region or making a practical adjustment "to getting the job done," because it would be interpreted by the audience as a compromise of principles. In other words, Arias' intent to increase understanding and inform the U.S. and European audiences about the Central American viewpoints and needs precedes any intent by making the principles a matter of agenda. That happens when he promotes among the above mentioned audiences a major understanding and support for a new international economic order, based on such principles as fair international trade and finance, cooperation of rich countries in favor of poor countries, and social justice, and acknowledgment of public needs and rights within nations. To him, as well as to most of his Latin American audience, principles should precede any orderly list of priorities in any agenda. Agreement around the contents of an agenda should be underpined by an acceptance of principles ruling the whole process whether economic or political.

The third value, fair-play, can be better understood by relying on Condon and Yousef's value orientation of complementaryobligatory social reciprocity, located in Chart $\mathrm{V}$ under Stewart's form of relation to others. Condon and Yousef have indicated that this value orientation supposes, in a sense, that a people or a nation, are forever indebted to other(s), "especially those of superior...status" $(1975$, p. 81). This pattern stresses the importance of the obligation of returning, in kind or worth, what has been given, be it an actual thing or a favor. In the pattern of complementary-obligatory values, the interaction valued is between unequals, what is often called, by Arias, the North-South relationship between the U.S. and Central America. The United States, as well as other industrialized nations, has certain obligations to its democratic allies, or zones of influence, and they in turn have obligations to the U.S. Failure to meet these obligations, of course, can alter the countries' relationship and thus such systems are difficult to stop because the mutual obligations have accrued over a long period of time. 
By using XVI, the general warrants 1,4 and 5, fair international treatment and local social justice, fit into the three-fold values of being, which is located under form of relations to others, and fairness and cooperation (that is complementary-obligatory social reciprocity) located under form of activity .

The general warrants 2,3 and 7 concern two ingrained themes: (1) non-intervention in other nations' affairs, which is a focus on influence from the outside; and (2) the individual as a pillar of freedom and democracy. The first concept is included by Condon and Yousef as one of the categories suggested to link arguments with cultural values by way of warrants (1975, p. 220). Arias regards outsiders' influence in the internal affairs of a nation as having serious consequences, particularly when linked to economic or to military pressures whether directly or through a proxy such as the "Contras." By relying on Condon and Yousef's ideas, it is noted that Arias' claims, warranted by non-intervention, implies that he perceives "social constraints and the power structure of society as the motivating agent in human events." That is, people and nations exert influence only through acts, not through thoughts. The second concept, individual rights and freedom, reveals Arias' confidence in the strength of his countrymen and Central American neighbors' characters, values, and idiosyncrasies. Following Stewart's (1971, p. 69) observations of Latin American individuality, the people on whom Arias relied to carry out the defense of democracy against its foes seem to live in cultures where authority (usually family) or tradition exercise considerable control over the individual. Therefore, Arias may seek to persuade an audience, which may be outside the region, of the pivotal principles underlying his claims: non-interference from outside in Central American affairs, and reliance on people's individuality to defend democracy. This is true of most of his addresses whether they be to Latin American or to U.S. audiences as shown in his 1986 speech "Democracy in the Americas": where Arias claimed that "Nicaraguans [were] the ones who must solve their internal problems" (Argument XXX, p. 13); in his 1988 speech, "Architects of the century of peace," in which he pointed out 
the breakthrough in U.S.-U.S.S.R relations and the reduction of nuclear armaments. Later he claimed "There is no reason to support the use of military force in the solution of Central American conflicts" (Argument IL, p. 19); in another 1986 speech, "Opportunities for democracy in Latin America," Arias praised democracy and assigned to individuals the responsibility of defending freedom and democracy, "The only defense against freedom's foes in strengthening freedom and democratic institutions" (Argument XXXVI, p. 5); or in a 1987 speech "Peace doesn't recognize borders" in which Arias made a case for others to imitate Costa Ricans who benefit from democracy, making it, Arias claims, "invulnerable before the totalitarian attacks" (Argument XXXXIV, p. 12).

Arias' focus on outsiders' influence and the individual as warrants for the aforementioned claims supposes the existence of two values, with one merging into another -- independence into individuality. Individuality has been estimated by Stewart (1971, p. 70) as pervading Latin American perceptions of self and of society. It carried political and social freedom as well as an implication of solitary action; but, in contrast with U.S. individualism, it lacked the idea of the self as the source and sole-limiting factor. There is in Arias' arguments, warranted by individuality, a strong attachment to family and the immediate group. Actually, individual's dependence on society is not deplored. It explains why Arias stresses the need Central America has for fair international treatment in trade and finance and its rejection of outsider influences. That is, from Arias' perspective the region wants help which doesn't constrain its individuals' freedom. Another claim made by Arias should clarify the point. This is taken from a 1986 speech, "The roads to freedom," a direct address before President Reagan, "Only if we endeavor to enable all peoples to enjoy democracy, [and] the downfall of all tyrants equally, can we prevent threats to peace throughout the world from growing in the Americas" (Argument XXXV, p. 32). To paraphrase this claim: only if the United States and other industrialized countries create conditions for Central American countries to have economically stable democracies where benefits 
can be divided justly between individuals, and the same powers do not again enthrone dictators, can Central Americans defend democracy without outsider influences.

By using XVI, the general warrants 2, 3 and 7, nonintervention and the individual as pillars for freedom and democracy, fit chiefly into the category of the value individuality under perception of the self, although the values being and present orientation lie behind the same set of warrants.

The general warrant 6 concerns peace as a desirable outcome over war, that is what is called in this section a relativistic "both/and another" pattern. Arias, as speaker, seems to warrant many of his claims by suggesting to his audience that there is always a choice, but not necessarily between only two alternatives, and neither of them being the absolute best.

Although Arias sometimes explicitly rejects one of the alternatives, he often does so by choosing what he considers to be the most appropriate choice within the context of the situation at hand, rather than openly judging an alternative as bad or evil. It makes his judgments less comparative and more contextual, less linear and more relativistic in over-looking the cause-effect relationship as a means to deal with Central American problems. This is apparent in addresses such as in 1987, "Peace doesn't recognize borders," where the appropriate response to defeatist statements about the Costa Rican peace plan, which according to him paralyze people and jeopardize peace efforts in Central America, is that he "can't accept defeatism" (Argument XXXX, p. 7); also in that address, even when he implicitly appeals to a positive choice instead of the negative alternative, such as the choice between war and peace, he is not absolute, "No matter how noble the crusade is [peace efforts], some wish for and encourage its failure" (Argument XXXXV, p. 14); or 1988 speech "Architects of the century of peace," he stressed the commitment to peace made by most Central Americans, labeling their choice not as the "right one", but merely by claiming that "Central America is committed to peace" (Argument L, p. 23). 
Arias' use of a relativistic "both/and another" pattern, differing from the Reagan's "either/or" pattern, warrants the aforementioned claims which are widespread through his discourses. This pattern supposes the existence of choice beyond good and evil, and black and white comparative judgment. In the logic of Arias speeches, he judges solutions as being best within the appropriate context. This observation may be misinterpreted if a comparison is made using an absolute standard or a literal reading of his discourses. Arias in fact, criticizes cruelty, violation of human rights, social injustice, oppression and war as undesirable outcomes to the Central American situation, but his judgments are oriented to creating consensus among his audiences rather than towards dividing the world between "good guys, and bad guys, "good and evil", or "black and white".

By contrasting Arias with Reagan's judgment some important differences emerge. They are, first, Arias doesn't base his comparison only on his country's experiences as Reagan generally does. The only exception is when he speaks of the Costa Rican democratic experience; second, his viewpoints rarely pose a threat in the other Central American democracies by comparing how well-off they are with respect to Costa Rica, as happens with Reagan. In Arias' speeches there is no mention of the leftist guerrillas or the rightist "Contras" as good or bad movements, more likely he points at the danger of war and poverty for democracy than to one cause, one effect. Whether this finding suggests that it is not the subject matter as much as it is the way of thinking about almost everything that leads to this relativistic distinction, is further developed in the discussion part of this chapter.

In Arias' arguments the link to the general warrants 6, the direction toward contextual appropriateness in Central American problem-solving methods, stresses essentially the value of seeing human nature as a mixture of good and evil, but above all capable of change. Through the arguments linked to the mentioned warrants, this value orientation takes many forms: optimism about the peace efforts "Central America is committed to peace" (Argument L, p. 23), 
and will to influence attitudes "We [democrats] should be neither political or economic allies of governments which oppress their peoples " (Argument XXXXI, p. 41).

By using XVI, the general warrant 6 , peace as desirable outcome over war, fits the value of choice by seeing the individual and the world as a mixture of good and evil under the category of perception of the world.

The chart XVII lists the findings of this first section, in accordance with the four components of value orientations and assumptions cited at the opening of this chapter. 
CHART XVII

FINDINGS ON VALUE ORIENTATIONS
FROM REAGAN AND ARIAS' ARGUMENTS

Components:
$\begin{aligned} & \text { Form of activity } \\ & \text { Form of relation to others }\end{aligned}$




\section{PATTERNS OF THINKING UNDERLYING ARGUMENTS}

Cultural differences in patterns of thinking are important issues for both Reagan and Arias' perception of the world and each other. They can not be separated from the main focus of this research: cultural values affecting political argumentation. In fact, the inclusion of patterns of thinking used by both speakers will make the differences between Reagan as an American thinker and Arias as a European-oriented Costa Rican more striking.

Two types of patterns of thinking have been explicit between Reagan and Arias in the previous chapters: inductive-deductive and dichotomous (dualistic)- non-dichotomous (relativistic) ways of thinking. Because dichotomous patterns and relativistic patterns were fully discussed in connection with the value choice of good and evil, this section explores in more detail the first type of thinking which pervades Reagan and Arias' argumentative reasoning.

It has been noted in Chapter II that Reagan used argument by sign in nearly half the discourses studied here, where in Chapter III, it has also been noted that Arias used argument by generalization more than any other type of reasoning. Each type of reasoning stresses a different type of thinking in public argumentation: the sign type stresses induction, and the generalization type, deduction.

Reagan is not one hundred percent inductive, and Arias is not totally deductive, therefore the use of the term "more" will precede any characterization of their opposing styles. Reagan is more inductive than Arias because he sees the world as composed of facts which he relies upon to make his claims. The inductive process of thinking (beginning with facts and then proceeding to ideas) has an operational quality that makes Reagan's thinking culturally grounded. He expresses an incessant need to systematize the perception of the world, Central America in our research, into a frame that enables the U.S. and him to act. 
Arias is more deductive than Reagan; he is more concerned with ideas, rather than facts. Because of his deductive thinking he tends to attach primacy and reality to ideas and theories. His deductive and abstract style of thinking give priority to the conceptual world. Although the empirical world is not necessarily disdained in his arguments, it is treated with a symbolic and demonstrational attitude.

As a deductive thinker, Arias relies heavily on his ideas and theories so that it suffices for him to show one or two connections between his concepts and the empirical world. It explains why most of his claims use few facts as data, where Reagan fully details the grounds for his claims. Arias does not feel compelled in the same way as Reagan is to amass facts and statistics. He prefers to generalize from one concept to another, or to present facts by means of logic. As noted by Stewart, the deductive thinker has a faith and trust in the powers of thought which the American places upon his methods of empirical observation and measurement.

An important implication of the use of these opposite ways of thinking is that Arias, as deductive thinker, considers ideas as part of the world of reality, that is he considers them as organic and alive, while Reagan, the inductive thinker, considers concepts more in the nature of a construct or an invention and only "facts" as real.

\section{INTERCULTURAL CONFLICT IN VALUES AND STYLES}

This section consists of three main divisions: first, it focuses on some of the potential and explicit conflict(s) derived from the exchange of arguments between Reagan and Arias, in describing and dealing with the Central American problems; second, the implications of each speaker's cultural values, found in the intercultural setting of political arguments exchanged between the speakers from different cultures; and, third, the implications of each speaker's patterns of thinking, drawn from the cultural values underlying their arguments, in affecting intercultural understanding. 


\section{Intercultural conflicts}

To depict some of the potential and explicit conflicts between Reagan and Arias, a small selection of the total arguments from each speaker studied during this research has been made. In order to elicit differences or similarities between such arguments from both speakers, their claims and its supporting warrants are matched up.

For each general warrant, whose underlying cultural value has been previously elicited, a corresponding claim was selected. For instance, to Reagan's general warrants $2,5,6,8$ and 9 which underlie the cultural value "choice," corresponds the following claim, "There are only two possible futures for Central America:" [Democracy or dictatorship]" (Argument III). In addition, because warrants are linked to each speaker's cultural values discussed in the first section of this chapter, the respective warrants have been reduced in number. Hence, Reagan's nine categories of warrants became five categories ruled by the following cultural values: Equality for general warrant 1 , choice for general warrants $2,5,6,8$ and 9 , doing for general warrant 3, fairness for general warrant 4, and progress for general warrant 7 . On the other hand, Arias' original seven categories of general warrants have became three ruled by the following cultural values: being-fairness-cooperation for general warrants 1, 4 and 5; individuality for general warrants 2, 3 and 7; and, choice and individual as mixture of good and evil for general warrant 6.

In applying the chart XVI several conclusions can be drawn. First, claims' content and warrants from each speaker are different when contrasted. Second, despite the fact that some cultural values found in each speaker's warrants may imply some commonality, for example fairness and choice, that is only superficial, as noticed in the third part of this section. Third, differences which may be conflictive rather than commonalties between Reagan and Arias' arguments can be elicited from the chart XVI. 
The conflicts respectively are between U.S. policing (Doing) and non-intervention (individuality), dualism (choice) and peace as desirable outcome over war (choice based on individuals as mixtures of good and evil), and between the U.S as a fair power (fairness) and fair international treatment and social reciprocity (being, fairness, and cooperation).

The nature of the conflict between claims, warrants and values from each speaker goes beyond grammar and semantics. Each speaker articulates claims which are opposites. In Argument $\mathrm{V}$ while Reagan claims that the U.S. must help those countries confronted with communist aggression because freedom and peace require it, Arias in Argument XXXVI responds that the only defense in a democratic system against freedom's foes is the individual, who believes and benefits from the system. Thus, it is possible to infer that if the individual doesn't benefit from democracy or that democracy doesn't respond to individual needs, any attempt from outside to help would be useless, or make matters worse. Rather than U.S. intervention, Arias in Argument XXIX claims that Central America in particular, and Latin America in general, needs an improvement in trade and finance relations from the North to the South. It, Arias says, should accompany increasing social justice within Latin American democracies. Then, Reagan in Argument XIII argues in favor of U.S. defense and that his country "will never be the aggressor" that is, the United States is a mature power based on fairness to relate to those who are weak such as Central American nations. Reagan doesn't address the need to change the international economic order greatly influenced by the U.S. He just disregard Arias' argument by stressing what seems an American value, fair play. Therefore, for Reagan it is inconceivable to consider that the U.S. could be unfair to its democratic allies at "the U.S. doorstep." Another conflict emerges from Reagan's dichotomous pattern of judgment and Arias' relativistic or contextual pattern of judgment, as shown in their respective Arguments III and XXXXV. Where Reagan only sees a choice between democracy and dictatorship in Central America, Arias also sees a choice but beyond the good-evil 
comparison, he praises peace over war avoiding judging the parties involved in the latter whether or not their political agendas are democratic.

\section{Cultural Values: implications}

In order to explore some of the potential implications of the conflicts already elicited between Reagan and Arias' arguments, this section further discussed two aspects which can bring more light to the understanding of each speaker' patterns of thinking and cultural values, even if they did not have a corresponding value in Chart XVII. The first aspect concerns the implications of each speaker's cultural values, found in the intercultural setting of political arguments exchanged between speakers from different cultures; and, the second aspect concerns the implications of each speakers' patterns of thinking, drawn from the cultural values underlying their arguments, in affecting intercultural understanding. As pointed out before cultural values cannot be found alone, "each component of a culture affects the others and, in turn, is limited by them" (Stewart, 1971 , p. 26). On the other hand, patterns of thinking underlying and embodying those cultural values make useless the study of the components of each argument if not acknowledged properly.

Equality and Progress. The fact that these two value orientations could not be matched up with any opposite value orientations for the purposes of this chapter demands some attention. Certainly, Arias did not elicit a value contrast, but it doesn't mean that equality and progress are values shared in his culture. However, it should be noted that these values underlie better Reagan's intent to gain acceptance from either American or Latin American audiences. That's not Arias' case. In his speeches there are cultural variations with respect to Reagan that will merit further discussion later. Each value's implications are seen separately. 
Based on equality Reagan looks for common ground, that is to establish an atmosphere of equality. He doesn't want to talk vertically to unequals, but horizontally to equals. Arias avoids this appeal to common ground in most of his speeches. Instead he goes after humanistic principles which are ARCHETYPICAL in their symbolism such as peace, love, and reconciliation, regardless of whether they have the same specific meanings for all his audiences. While Reagan is specific in similarities, Arias is vague and general. For instance, Reagan goes to the Organization of American States and emphasizes the similarities in history and destiny between the U.S. and all Latin American countries. Arias, instead goes to Europe and United States and never mentions common ground, but talks about what Costa Rica is in particular, and what the presidents and peoples of Central America, in general, agree upon and carry out.

Reagan's stand reflects the pursuit of an ideal of equality which makes it difficult for him to understand hierarchical patterns of organization overseas, with the consequence that he ends up ignoring political questions. Common ground, Condon and Yousef point out, would seem common enough across cultures. But the role expectations of the speaker, the philosophical and political realities of the society in which he speaks, and the values which lie beneath all these suggest some culturally related differences (1975, p. 245). In fact, a culture may value a leader as one who is above and beyond them, as with the typical Latin American dictator or as Condon and Yousef suggest "a culture may demand the leader to speak as one of the people, seeking all possibilities for cultivating that common ground" (p. 245). The latter fits Reagan's case better .

Based on progress, Reagan tries to prove the adequacy and actuality of the cold war approach to contemporary conflicts, that is to establish an atmosphere of optimism. He wants to point out that the future will be bright if the lessons of the past are learned and included as part of a future orientation. Arias avoids this appeal to progress in most of his speeches. Instead he goes after an understanding that peace, love, democracy and reconciliation, are a painstaking process which cannot be forced from outside, or 
accelerated imprudently. Despite the fact that Arias also draws lessons from the past, he seems more interested in applying them to the present, working out one problem at the time, allowing things to take a normal course. While Reagan is future oriented and motivated to action by doing things, Arias is present-oriented and being-active. Reagan, for example, updated Truman's words to engage in action to protect U.S. interest in Central America, seemingly threatened by communism. Suddenly everything looks so simple and linear, Truman's words becoming the cause or struggle for freedom, in its use by Reagan in Central America to get rid of of communism. Arias, instead, meets with Latin American presidents and his region's colleagues and talks about datelines and changing words into deeds, without specifics, not pressing for an immediate answer, or invoking action as a solution for everybody's problems. Rather he talks of dialogue and flexibility within different time frameworks. He seems to consider more factors and people being involved in the peace process, no one having the absolute truth or power to overcome the main problems.

Reagan's stand reflects a temporal orientation to the future associated with doing in a linear fashion, where Arias is more present and being oriented in an interacting fashion, which makes it difficult for Reagan to understand the complexities of Central American problems and problem-solving methods, with the consequence that he ends up evaluating his allies negatively, and trying to get things done by himself rather taking into account Central American viewpoints and concerns. Progress is integrated with other values such as time and doing, which suits a rational view of the world, as noticed by Stewart $(1971$, p. 65). Progress, according to him, implies the dominant American belief in one's ability to master his environment. That implies, between Reagan and Arias, a potential for misunderstanding. Reagan negatively judging Arias or the Central American --independent from U.S. decision-making-efforts for reaching peace, as insufficient, irrational, or too slow. By contrast Arias may judge Reagan as dominated by emotion, more interested in war than peace, or bellicose. 
In contrasting Reagan and Arias' arguments, at least two implications can be drawn for these values. The first, equality, suggests that as long as Reagan the speaker stresses similarity across cultures he will miss political, economic and social cues vital for reaching his potential audience in order to be understood. The second, progress, indicates that because not all societies share the rational view of the world as one of linearity and subject to control as Reagan does, his message becomes a simplistic one. Because of this, his audience may not only overlook his content, but deny him intellectual abilities. Arias' stress on solutions that acknowledge differences between countries and within nations at present, rather than projecting into the future, allows him to focus on those aspects in which the five nation leadership agree upon.

Doing and Individuality. Reagan's valued doing as form of activity, as well as Arias' valued individuality as perception of self, are not dissociated from other cultural values which may enrich the understanding of their conflict when dealing with the issue of intervention or non intervention in other nations affairs. In fact, when examining the preeminence of the value of doing in Reagan's orientation to action, the values of progress, understood as futureoriented, and individualism emerge. Likewise, with Arias' reliance on individuality which is associated closely with being as oriented to action and present as time orientation. Therefore, any contrast between Reagan and Arias needs to be based on three-fold values: Reagan's doing-individualism-progress (future), and Arias' beingindividuality-progress (present). Progress, was discussed in the previous segment, so it won't be covered here. However, let us keep in mind that doing and individuality are the predominant values in each speaker's argument concerned with intervention.

The differences between speakers begins with a discrepancy between Reagan's conviction that the U.S. must act to help those threatened by communism, while Arias seems convinced that intervention is useless, because the only defense of democracies is to be more democratic. Their noticeable difference is reflected also in 
terms of cultural values. Reagan stresses "doing" and "individualism" while Arias stresses "being" and "individuality," while both are perceiving activity and the self differently. Accordingly, where Reagan tries to bring change to a situation by showing confidence that "where there's a will there's a way" Arias responds with sheer simplicity "we have other ways." That is, Reagan's focus on a linear approach to problems limits his vision, while Arias conceives of problems more as a part of an organic whole, not subject to change by focusing on cause-effect. Revealing as to their differences is Reagan's more technical approach in contrast to Arias' intellectual or philosophical approach. Arias' being oriented as form of activity, for instance, seems to enhance his persuasiveness before Central American audiences and political leadership, particularly the presidents who came together to sign the peace accords and who are responsible for carrying out political and economic reforms in their own countries, as individuals attached to their own culture's norms, and values.

Some evaluations affecting the exchange of arguments between Arias and Reagan may be from the doer's perspective, who may feel pity (for Arias' unwillingness to alter Central American conditions and improve them), or a willingness "to get things done" whenever Central Americans seem to him " lazy, inefficient, or philosophical." From the perspective of Arias' being orientation, Reagan may seem "arrogant, simple-minded, or imperialistic." By shifting now to the perception of self held by each speaker, Reagan's individualism and Arias' individuality, it is possible to realize that the lack of social or traditional attachments in Reagan approach allows him to be apparently more independent than Arias. The latter conceives of the individual as tied to tradition and familiar aspects of Central American societies, but with political and social freedom to defend his system. An interesting implication may be that Reagan perceives Arias as constrained by atavism or tradition which may seem to him a sign of "primitivism or immaturity", while for Arias Reagan may be perceived as "selfish, irresponsible, pushy." These evaluations, 
mostly negative, may affect their mutual understanding when exchanging arguments across their original cultures.

Choice and good/evil. The analysis of intercultural implications concerning the value of choice and its distinctive applications by each speaker's culture is carried out as part of the discussion of patterns of thinking culturally pervading Reagan and Arias. The reason is that dichotomies and relativism are more a matter of ways of thinking than subject or specific cultural values. The discussion on patterns of thinking is presented in pages 106-7 of this chapter.

Fairness. Talking about the same thing doesn't mean sharing the same assumptions. In fact, when faced with the cultural value of fairness, found in either Reagan and Arias speeches, more differences than similarities can be drawn. First of all, the significance of the value fairness - accommodation to the weakness of another (Stewart, 1971 , p. 54) is relative to who is considered weak and to the speaker's convenience. Reagan approaches Central America by describing the U.S. and its neighbors as equals, as discussed in connection with common ground, but at the same time he uses national security reasons for intervening politically or militarily in Central American affairs. Arias approaches U.S. and European audiences by demanding "equality" in terms of external debt, when he really is asking for a special economic treatment, that is inequality. This is like a reverse approach, Reagan trying to acquire political support from Latin America, in order to impose his will there. Arias in trying to acquire economic support for Central America, is trying to allow the region's countries to be democratic. Reagan is trying to seem fair, in order to be legally unfair with those opposing his policies, while Arias is trying to seem unfair, to be fair with his regional neighbors. This is not as complicated as it seems.

There are political and economic inequalities between both speakers' countries, as between the United States and Central America. However, while Reagan thinks of political and economic gaps with respect to the region, Arias thinks of only economic 
disparities. Therefore, each of them is trying to gain some advantage from the status of affairs. But, because their political agendas underlie different cultural values, they misunderstand each other. Reagan, for example, tries to gain foreign acceptance for carrying out his anti-communist policies in Central America by sending more economic aid to the region's nations and taking some steps to eliminate some U.S. economic barriers to products coming from the Caribbean basin. In exchange, governments in countries like El Salvador and Honduras become beholden to U.S. decision-making, in areas such as foreign policy, economy, and national security. The difference with Arias' approach is that there is no political price paid by Central America for being helped from outside the region. Arias asks, first, for fair international treatment, which means that democracies are too fragile too carry the burden of an external debt acquired in most cases under dictatorships. Second, in exchange for that help Arias "promises" to keep democracy working, and asks for nothing else--no constraint of their political system through military or any other form of intervention. Obviously, fairness means to both leaders different things. But, nevertheless, the value is there. Reagan doesn't seem to think that he is taking advantage of the weak, rather he is helping them to be rid of communism. Arias doesn't seem to think that he is also taking advantage of the strong, because Central America is poor, or begging like a servant, rather he is asking for respect from the U.S. but acknowledging economic differences not political ones; Central America is as sovereign as the U.S. is Arias' bottom line.

Mutual misunderstanding results from some of the implications of their contrasting cultural value, fairness. Mutual misunderstanding because of Reagan's difficulty in understanding why Arias, who is the weaker element in this equation, pretends to be treated like an equal without paying for his share. One may speculate that, if Arias wants to be considered an equal and treated fairly then he should not ask for help which he cannot reciprocate. He is not asking for fairness, but unfair play. On the other hand, Arias may see Reagan's fair play concerns as foolish, or hypocritical. 
Why should he trust Reagan if he does not realize that Central American democracies are politically worthy and equals to the United States? Why should he consider fair Reagan's statement that the U.S. is not an aggressor, if the U.S. is applying economic pressures to achieve political goals on many Central American countries?

Paradoxically, the implication that Reagan may be perceived as hypocritical or unfair by Arias, is consistent with Margaret Mead's notion that Americans cannot understand the deliberate and ruthless exploitation of a weak adversary by power and position in other cultures (1965).

Patterns of thinking: implications

Dichotomies and relativism. Dichotomous and relativistic patterns have been discussed, as have some of their implications, drawn under the subheading of choice and of good and evil.

Dichotomous patterns which merged into the value of choice between good and evil, which dominates Reagan's rhetoric, and Arias' choice based on appropriateness to a particular context, which contemplates both, human nature and the world as mixtures of good and evil. Reagan's dichotomous pattern of thinking and Arias' relativistic pattern of thinking have been stressed before as resulting from culturally different values. These values are choices based on seeing human nature and the world as divided into good and evil, and choices based on seeing human nature and the world as a mixture of good and evil. Reagan's discourse fits into the former description, Arias' into the latter. In both cases, the speakers reflect their own cultural values concerning the kind of choices they are willing to make or have made in dealing with Central American problems.

It is noteworthy to point out that in this particular case patterns of thinking and values are neatly contrasted to each other, justifying an additional discussion on their specifics and then, on their implications. 
Dichotomous patterns in Reagan's speech have been discovered in this line of research. His tendency to describe as an either/or pattern fit what the General Semanticists define as a "two-valued orientation, which is [contrary] to the facts of a multi-valued reality [like that stressed by Arias]" (Condon and Yousef, p. 234). This either/or pattern was identified centuries earlier as a fallacy in logic, "the disjunctive fallacy." The pattern can be attributed to influences of language, as some writers have indicated, and to cultural assumptions irrespective of the language, as concluded from this thesis so far.

This dualism differs from a dialectical system in that it, at least in Reagan' case, demands a choice of the better of the two rather than accepting the two as in a necessary opposition which will yield a third (thesis, antithesis, synthesis pattern). So consistent is this that even attempts by Reagan to seem neutral, make objective descriptions, usually involving choice, imply that one is better than the other. Thus modern and old-fashioned, slow and fast, peace and war, democratic and communist, protectionist or free market, are often not real choices; built into the usage of the terms is the expectation of one being better than the other.

As noticed by Stewart et al., (1969) in the U.S., the process of decision-making unfolds primarily through the anticipation of the consequences of alternative courses of action, the either/or pattern. That is consistent with Reagan's claims that any political decision concerning the future of Central America must be based on either democracy or totalitarism (Argument III). In Costa Rican society, however, the function of the decision maker or makers is to evaluate a situation by classifying it according to pre-established categories. In the view of Kalman H. Silvert (1961), whose expertise concerns Latin American cultural differences, whatever action ensues, or whatever decisions are made, will follow automatically from this tradition of classifying activity (p. 11).

A primary intercultural implication of these differences in decision-making is that Reagan may conclude that in underdeveloped Central America few decisions are required, where Arias thinks the 
opposite. The exploration of some of the cultural values underpinning Reagan and Arias' opposite patterns of thinking bring a major understanding of the preceding implications and of others, cited later.

Choice is a commonality between both speakers, but on which perspective becomes a major contrast. Reagan's dichotomous pattern, "either/or," has been fed by that value orientation, and has been strongly influenced by conservative religious views, of human nature and the world divided between good and evil, subject to change though, by active individualistic thrust. Instead, Arias' relativistic pattern, described before: a "both/and another" has been fed by that value orientation of man and the world as mixtures of good and evil. Because Reagan views the world and human nature as divided into polarities, it is possible that this affects his understanding of what Central Americans, through Arias' speeches, perceive as viable political systems, or even democracy. When Reagan, for instance, says that there are only two possibilities for the region, democracy or dictatorship, he is not talking about what Central America may think of democracy, that's taken for granted, he talks about U.S. conception of democracy. In his 1987 speech "Central America at a critical juncture", Reagan specifically details that democracy for him is "permanent, across-the-board human rights, guaranteed by a constitution and protected by the checks and balances of democratic government...democracy means returning power to the hands of the people" (p. 2). As a contrast, in his 1986 address "Opportunities for democracy in Latin America" Arias stresses that it is possible to have "political democracy if we are able to enlarge our economic democracy. Freedom is out of reach of the dictator's paw only if it is based on justice and lack of poverty" (p. 5). Interestingly enough is the fact that Reagan stresses a democratic ideal concerned with political aspects, whereas Arias focuses on social and economic justice as chief concerns of democracy.

It is possible to point to other differences in their perceptions about dictatorship, but the point has been made that Reagan's views on democracy differ from those of Arias. Therefore, a second 
intercultural implication may be that for Reagan it is hard, if not impossible, to see that the choice he proposes could be perceived as less good than he thinks it is, because its meaning is culturally different. Moreover, Arias' relativistic choice, implies that he may see more than two alternatives for Central America, but from the intercultural point of view may have a hard time adjusting to the idea that Reagan does not see the realm of social and economic democracy as more important. In fact, Arias may evaluate Reagan negatively by assuming a shortsightedness on Central American problems, as well as a closedmindedness because he only stresses those political aspects of democracy, which for him are worthless if people cannot afford to live with dignity.

Inductive and deductive patterns. Other implications drawn from the findings of this chapter concern the conflict between the two different patterns of thinking dominating Reagan and Arias' arguments: the inductive and the deductive, respectively. Reagan and Arias have often had corresponding positions in their topics and sometimes worked together under circumstances where political, social and economic factors were more salient Central American issues. Both speakers have met several times, and whether or not they have developed positive perceptions about each other, their discourses have shown sharp contrasts in terms of patterns of thinking.

A potential intercultural implication pervading their exchange of arguments is that because political, social and economic factors seemed more salient, differences in patterns of thinking have been ignored. Instead, Reagan and Arias, each one considered the foreigner by the other, may be perceived as irrational, uncultured, arrogant or antagonistic. These descriptions do not exhaust the range of depreciatory reactions elicited by differences in patterns of thinking. Since international politics is not insulated from competitions for power and influence, it does not facilitate the recognition and understanding of cultural differences in thinking. This is illustrated by Arias' depiction of the opponents to his peace 
initiative as people "anxious to bury the last hope, to close the door to the reason, reconciliation and dialogue in our America" (Discourse 7, p. 14) and Reagan's claim that "anyone who demands anything less [than true democracy] is not serving the cause of peace" (Discourse 6, p. 2).

The examples suggest that Arias' negative evaluation of those who, like Reagan, opposed his plan, are based on a lesser concern with facts, political agendas, accountability of democratic progress in the region. Arias deductively operates on the assumption that peace ideas fostered in Central America are more important while Reagan inductively stresses those democratic facts whose consequences will be subject to measurement.

Further connections can be established with specific cultural values, but this section's main focus is the two prevailing patterns of thinking found in Reagan and Arias' argumentation processes.

\section{THE GOLDEN RULE}

\section{A Far-reaching Intercultural Implication}

From the preceding discussion several implications have been drawn using the intercultural perspective. Summing up, there are noticeable differences between Reagan and Arias concerning their contrasting values.

While Reagan's warrants are underpined by the cultural values of equality, progress-future, doing-individualism, fairness and choice between good or evil, Arias supports his claims with cultural variations of them. Arias' dominant values are equality, presentorientation, being-individuality, fairness and choice of good and evil. Despite the use of similar nouns for two of the values mentioned, their meanings differ as explained in the respective discussions of equality and fairness.

At the core of the intercultural implications of these contrasting values is the pervasive influence of the assumption of similarity, 
which may be used unconsciously by both speakers. The assumption of similarity implies that others are like ourselves and therefore want to be treated similarly. Milton Bennett in his Overcoming the golden rule: Sympathy and empathy (1979, p. 407) has pointed out that underlying that assumption lies another: "that all people are basically the same, and thus they really do want the same treatment (whether they admit it or not)." This is what seems to happen in both speakers' discourses studied.

The extent to which each man implies that underlying values in his argument are universal indicates an assumption of similarity. Since both speakers are from different cultures, they are pretending to persuade their own constituents of the rightness or appropriateness of each others arguments on specific issues. To do so they primarily start with their native culture's view of the world which permeates their search for common ground. Reagan looks at specific commonalties between the U.S. and Latin America on historical and political aspects, Arias focuses on humanistic concerns expressed poetically, and philosophically, that seem to him common enough across cultures. However, because they are trying to find commonalties in order to persuade and get their viewpoints across, most similarities found imply a single, absolute reality, which means that if there were not a single, discoverable reality, we could never be sure whether the similarity we observed was "really" the case, or whether it was merely a function of our point of view. Therefore, intercultural misunderstandings may result because such thinking is the foundation of ethnocentrism.

Ethnocentrism is one of the main social consequences implied by the cultural values underlying Reagan and Arias' arguments. This is understood here as the tendency by each speaker to see their "own culture as the center of the universe - that is, as the true realitywhich affects all intercultural communication" (Bennett, 1979, p. 410). This concept is further refined by Porter and Samovar in their handbook Intercultural communication: A reader (1976). 
Porter and Samovar say that,

A major source of cultural variance in attitude is ethnocentrism, which is a tendency to view people unconsciously by using our own group and our own customs as the standard for all judgments... The greater their similarity to us, the nearer to us we place them: the greater the dissimilarity, farther away they are...We tend to see our own groups, our own country, our own culture as the best, as the most moral. This view also demands our first loyalty and produces a frame of reference that denies the existence of any other frame of reference. It is an absolute position that prohibits any other position from being appropriate for another culture (p. 10).

The preceding definition operates perfectly on Reagan's claims that Americans have a right entrusted by God to protect freedom anywhere, and Arias' stand on Costa Rica as a standard of democracy and role-model for other nations. Despite Reagan's intent to claim U.S. superiority and Arias more humble intent to brag about Costa Rican prowess in social, economic and political life, there is a consistent ethnocentric view in their arguments and underlying cultural values. Reagan and Arias use their own values as the basis for behaving toward others, and each other. There is a morality in behavior, whether or not they are aware of each others cultural values and patterns of thinkings. The conflict between their arguments, however, emerges when they find that no matter how much they try to persuade each other, and their audiences, many people don't respond to them. Then they face a choice, either they alter their behavior (and underlying cultural assumptions and values), or they must alter the unresponsive people. Supported by the ethnocentric conviction that those other people, Reagan, Arias, the Sandinistas, the guerillas, the Contras or, in general, the Central Americans are somehow wrong or ignorant, each speaker may choose the latter course. 
In fact, neither Reagan, nor Arias needed to fight each other bare-handed, or any of their opponents. They just simply relied on public arguments exchanged directly or mediated through the media in Central America, the United States and Europe. Their arguments may escalate in tone and content, and their disagreements increase, but they continue trying to convince each other of their own rightness. Interestingly enough, ethnocentrism always remains at the core of the cultural values sustaining their public arguments. This is the most noticeable intercultural implication found in this research. 


\section{CHAPTER V}

\section{CONCLUSIONS AND RECOMMENDATIONS}

The concerns of this thesis have been with the pattern of thinking and cultural values underlying political arguments exchanged in an intercultural setting and with how those patterns and values affect understanding across cultures. Used, if sometimes briefly, have been argumentation theories (Rieke \& Sillars, 1984; Condon \& Yousef, 1975; Toulmin, 1958), the narrative forms approach (Lewis, 1987), and intercultural communication perspectives (Bennett, 1986, 1979; Samovar and Porter, 1975; Condon \& Yousef, 1975; Stewart, 1971; Stewart, Danielian \& Foster, 1969).

\section{SUMMARY OF MAJOR FINDINGS}

Major findings are presented here in three parts, ea $h$ representative of a main line of inquiry, and answer to one of the research questions toward which this study has been oriented. Three questions about the role of cultural values and patterns of thinking in affecting international political understanding by way of arguments have dominated this research: (1) what salient arguments concerning Central American foreign policies exist in either Reagan and Arias' public discourse; how do Reagan and Arias' particular arguments reveal their respective underlying cultural values; and (3) how might the difference in underlying cultural values affect mutual understanding.

The following results are based on an analysis first of Presidents Reagan and Arias' arguments using the Toulmin model, 
second Lewis' narrative forms approach for Reagan's discourses, and third an Intercultural Communication Perspective as articulated chiefly by Condon and Yousef (1975), Edward C. Stewart (1969, et al., 1971) and Milton Bennett (1976, 1986).

The results are as follow:

First, fifty salient political arguments concerning Reagan and Arias' respective policies toward Central American political, economic and military problems have been found.

Second, each speaker's arguments have revealed contrasting underlying cultural values which operate by way of warrants pertaining to conclusions (claims).

And third, these differences in underlying cultural values may affect the mutual understanding between the two political leaders, since their discourses did not acknowledge each other's cultural differences in values and patterns of thinking when engaging in public exchanges about contemporary Central American problems.

Because of the novelty of this type of interdisciplinary interpretative research, the results found could not be compared adequately with previous research. However, some pertinent intercultural implications, as well as directions for action can be drawn. The differences found between the speakers were reduced to five value orientations: On the one hand, Reagan valued equality, progress with a future temporal orientation, doing and individualism. fairness. His thinking operates in a linear- inductive way, and relies on dichotomous patterns to make comparisons and judgments. On the other hand, Arias valued equality but respected traditional hierarchies and status, progress with a present temporal orientation, and he valued being and individuality. His thinking operates in an interactive-deductive, non-linear way, and relies on relativist patterns which are non-dichotomous, leading him to suggest rather than judge or compare. In addition, most of the warrants underlying cultural values appear to be built on the assumption of similarity which is not a recommended strategy for intercultural interaction "[I]ncreasing sensitivity to difference, [by] moving from 'ethnocentrism' through stages of greater recognition and acceptance 
of difference" (Bennett, 1986, p. 27) seems to be the key in order to acquire intercultural sensitivity and increase communication effectiveness across cultures. That is what Bennett has called ethnorelativism.

Because of the preceding noted differences between Reagan and Arias, the following misunderstanding, among others, could occur: mutual negative evaluation, reluctance to cooperate, distrust, different (if not opposite,) readings of each other's arguments, undermining of each others' efforts in Central America, and creating conditions for escalation of political conflict with unpredictable consequences. These likely misunderstandings may explain some of the change in attitude of the United States towards Costa Rica cited in the first chapter, which resulted in a substantial reduction of economical aid, less support to alleviate the Costa Rican external debt with the International Monetary Fund, and delays in sending highranked U.S. embassy officials to Costa Rica, etc.

However, further critical and descriptive research should be done to confirm such connections between U.S. governments policies towards Costa Rica and differences in cuitural values and patterns of thinking underpinning open disagreement through public political arguments.

\section{LIMITATIONS OF THE PRESENT STUDY}

Some limitations to this study should be noticed. First of all, when the disagreements between Reagan and Arias' discourses were noted, the point of departure was that they argue about similar issues from different standpoints and to similar audiences. However, it may be possible that some if not many of the addresses and speeches selected for this thesis were not directed toward each other or to the other's policies, but to their own constituencies. If that is the case, this thesis may not be useful to draw broad conclusions about the relation between the U.S. and Costa Rica, but as a potential line for further research. Secondly, the number of discourses 
selected, fourteen in all, and arguments chosen, fifty altogether, may not be enough to draw generalizations about how cultural differences affect political understanding internationally. Those discourse were selected because they focus on Central American issues, and articulate two distinctive policies toward the solution of the state of affairs in the region where U.S. and Costa Rica have concern for political and economical stability at the core of their foreign policies.

It is important for future researchers to explore content in areas of Ronald Reagan and Oscar Arias' discourses which were overlooked in this research because of the selective use of speeches made. Additionally, the application of more formal methods of content analysis may bring major understanding about how differences in cultural values by way of warrants pertaining to claims affect understanding across cultures.

\section{RECOMMENDATIONS}

In order to change or improve Reagan and Arias' intercultural perspective, they must acknowledge that "fundamental to ethnorelativism is the assumption that cultures can only be understood relative to one another. There is no absolute standard of 'rightness' or 'goodness' that can be applied to cultural behavior. Cultural difference is neither good nor bad, it is just different. One's own culture is not anymore central to reality than any other culture" (Bennett, 1986, p. 46).

At this point, taking into account the findings of this research and Bennett's affirmation in the sense that intercultural sensitivity is not natural, I am going to suggest some concrete actions that can be easily taken that can help Reagan and Arias, as political speakers, can improve and their mutual relationship as representatives of different cultures. Each speaker must be more sensitive in intercultural terms, but not simply sensitive in understanding their counterpart's culture specifics, what Stewart (1971) calls cultural norms or customs from which each member of a culture is usually aware. In order to be 
better at intercultural communication, both leaders must overcome their ethnocentric point of view and assume a difference-based approach to intercultural interaction. That is, to assume differences implies that to interact within a culture, a person can keep his or her own identity. It means, for instance, that Reagan and Arias, will interact based upon their own frame of reference, trying to create meaning together and attempting to originate a third culture. The concept created by John Useem, Ruth Useem, and John Donoghue (1963) supposes a culture different from either Reagan's or Arias' culture, that is from either the first or the second culture. In the third culture (Useem, et al., 1963, p. 171) it is assumed that the relationship between the members of the two societies, Costa Rica and United States for example, as well as the two societies themselves, should be coordinate. Instead of assuming that everybody is the same, a difference-based approach implies that there are differences among people from different cultures and one must respect them. Therefore, they need to shift completely from the similarity-based approach to the difference-based approach; otherwise they may continue being attached to a philosophical perspective which share the following kind of thinking: "the Central Americans or the U.S. Americans have to learn from us because we are better; our institutions must be imitated by those countries from where the political opponents or allies come; if they do what we do they will have what we have: i.e. freedom, higher standard of living, fair rules, better health, peace, democracy, etc." It is my concern also that through education and training in intercultural communication, as Bennett stated, politicians as well as public officials will be able to modify their "natural" conduct. So, a positive way to start a change in the presidents' intercultural approach is to improve the kind of training that they and their staff and cabinet receive and provide. Actually almost none of the Reagan and Arias staffers undertook any training or advising concerned with the intercultural communication perspective. In addition, for both statesmen some basic reading would be advisable that will give them a better understanding of the assumptions that support the intercultural communication. 
In conclusion, the direction that I suggest for both political speakers is to encourage adjustment to each other's views rather than try to assimilate each other, taking into account only their own states' interests. This must be accomplished by creating or increasing cultural self-awareness and sensitivity. I think that Reagan and Arias should be more aware of their own culture, values, patterns of thinking and norms when engaging in mutual political debates. Each speaker must learn to respect the other's culture in general as something normal, maybe different from their own culture but not wrong. The orientation of their rhetoric could be to try to create a third culture or perspective from which arguing, facilitated by the fact that they need each other to achieve their democratic goals. This will allow each to increase his repertoire, and not impose his own U.S. culture or Costa Rican culture as a substitute of the other's culture, even if one or both of them realizes a kind of weakness in the other's position, because of a cultural bias, when coming to political debates before their own constituency or before foreign audiences. 


\section{REFERENCES}

Arias, O. (1973). Barriers to development. International Development Review 15, 2.

Arias, O. (May 8, 1986). An alliance for freedom and democracy, May, 1986. Oficina de apoyo, Casa Presidencial, San José: Imprenta Nacional.

Arias, O. (September 24, 1986). Liberty and democracy for five nations, November, 1986. Oficina de Apoyo, Casa Presidencial, San José: Imprenta Nacional.

Arias, O. (December 5, 1986). Democracy in the Americas, December, 1986. Oficina de apoyo, Casa Presidencial, San José: Imprenta Nacional

Arias, O. (December 4, 1986). The roads to freedom, December, 1986, Oficina de apoyo, Casa Presidencial, San José: Imprenta Nacional.

Arias, O. (February 26, 1987). The peace is first, March, 1987. Oficina de apoyo, Casa Presidencial, San José: Imprenta Nacional.

Arias, O. (October 25, 1986). Opportunities for democracy in Latin America, November, 1986. Oficina de Apoyo, Casa Presidencial, San José: Imprenta Nacional.

Arias, O. (December 10, 1987). Peace doesn't recognize borders, January,1988. Banco Internacional de Costa Rica.

Arias, O. (October 6, 1988). Peace - supreme hope of the world, October,1988. Oficina de apoyo, Casa Presidencial, San José: Imprenta Nacional. 
Arias, O. (May 28, 1988). Architects of the century of peace, June, 1988. Oficina de apoyo, Casa Presidencial, San José: Imprenta Nacional.

Bennett, M. (1986). Towards ethnorelativism: A developmental model of intercultural sensitivity. In M. Paige (Ed.), Cross cultural orientation. University Press of America.

Bennett, M. (1979). Overcoming the golden rule: Sympathy and empathy. In D. Nimmo (ed.), Communication yearbook 3. New Brunswick, NJ: Transaction Books.

Blachman, M. J., Leogrande, W. M., and Sharpe, K. (1986). Confronting revolution: Security through diplomacy in Central America. New York: Pantheon Books.

Brembeck, W. L. (1952). Persuasion: A means of social influence (2nd ed.). New Jersey: Prentice-Hall.

CBS, 60 minutes. (News program). (1988, November 6). Costa Rica is different [Documentary]. New York: CBS transcriptions service.

Condon, J. C., \& Yousef, F. (1975). An introduction to intercultural communication (12th ed.). New York: Macmillan.

Dillon, S. (1984, June 17). Debt, rebels undercut U.S. relations with Costa Rica. Miami Herald.

Farrell, T. (1980). Critical models in the analysis of discourse. The Western Journal of Speech Communication, 44 (1), 300-314.

Férnandez, G. (1986). El primer domingo de Febrero (The first Sunday of February). San José, Costa Rica: Editorial Costa Rica.

Flores, J. (October 18, 1984). [Interview with Luis A. Monge, former president of Costa Rica: Relaciones con los Estados Unidos ]. Radio Monumental, San José, Costa Rica. 
Guatemala's summit of Central American presidents. (1987).

Procedure for the establishment of the firm and lasting peace in Central America. (Publicación de la Casa Presidencial). San José, Costa Rica: Imprenta Nacional.

Greenwald, J. (1988, January 25). Giving peace another chance.Time, p. 39.

Gurtov, M. (1988). Global politics in the human interest. Boulder, CO: Rienner.

Janda, K., \& Schrodt, P. (1987). Crosstabs: Student workbook for American government. Boston, MA: Houghton Mifflin Company.

Kluckhohn, C., \& Kluckhohn, F. (1951). Values and value-orientations in the theory of action: An exploration in definition and classification. In T. Parson \& E. Shils (Eds.),Toward a general theory of action. Cambridge: Harvard University Press.

Kluckhohn, F., \& Strodbeck, F. (1961). Variations in value orientations. New York: Row, Peterson.

McGee, M. (1980). The "Ideograph": A link between rhetoric and ideology. Quaterly Journal of Speech, 66, 1-16.

Mead, M. (1965). And keep your powder dry. New York: William Morrow.

Monge, C. (1982). Historia de Costa Rica. [History of Costa Rica]. San José, Costa Rica: Trejos.

Oscar Arias: el líder de la nueva generación. (1985). San José, Costa Rica: Publicaciones Partido Liberación Nacional.

Paulson, S. (1962). Social values and experimental research in speech. Western Speech, 26, 137.

Reagan, R. (August 22, 1987). Central America peace plan, November, 1987. Department of State Bulletin, 8 , 54-60. 
Reagan, R. (March 15, 1982). Aid to the Caribbean Basin: Freedom is our common destiny, February 24, 1982. Vital Speeches of the Day, 48, pp. 322-25.

Reagan, R. (May 15, 1983). The problems in Central America: The national security of all the Americas, April 27, 1983. Vital Speeches of the Day, 49, pp. 450-56.

Reagan, R. (June 1, 1984). Central American policy: No communist colonies in America, May 9, 1984. Vital Speeches of the Day, 50, pp. 482-86.

Reagan, R. (April 15, 1986) Nicaragua: Aiding the contras. Vital Speeches of the Day, 52, pp. 386-89.

Reagan, R. (December, 1987). Central America at a critical juncture, October 7, 1987. U.S. Department of State Bulletin, pp. 1-4.

Reagan, R. (February 15, 1987). State of the Union, January 27, 1987. Vital Speeches of the Day, 53, pp. 258-61.

Reagan, R. (February 15, 1988). State of the Union, January 25, 1987. Vital Speeches of the Day, 54, pp. 258-62.

Renuncia de embajador en EE.UU revela contradicciones [Resignation of ambassador before U.S. reveals contradictions]. (1988, March15). Centroamérica Hoy, pp. 1-2.

Rieke, R. D., \& Sillars, M. O. (1984). Argumentation and the decision making process (2nd ed.). Glenview, IL: Scott, Foresman and Company.

Samovar, L. A., \& Porter, R. E. (1975). Intercultural communication: A reader (5th ed.). Belmont, CA: Wadsworth.

Scheele, H. (1984). Ronald Reagan's 1980 acceptance address: A focus on American values.The Western Journal of Speech Communication, 48 (2), 51-61.

Silvert, K.. H. (1961) The conflict society: Reaction and revolution in Latin America. New Orleans, LA: Hauser Press (Rev. ed., American Universities Field Staff [1966]) 
Skidmore, T. E., \& Smith, P. H. (1984). Modern Latin America (2nd ed.). New York: Oxford University Press.

Smolowe, J. (1987, September 28). Whose peace plan is it anyway?.Time, p. 34.

Stanford, B. (1987). Costa Rica: a model of peacemaking and democracy. Little Rock, AR: Arkansas International Center Press.

Stewart, E. C., Danielian, J., \& Foster. (1969) Simulating intercultural communication through role playing. Alexandria, Va.: Human Resources Office, George Washington University.

Stewart, E. (1971) American cultural patterns: A cross-cultural perspective. Pittsburgh: Regional Council for International Education.

Sweeney, J. R. (1980). The status in 1980 of the Toulmin model of argument in the area of Speech Communication. Unpublished master's thesis, Portland State University, Portland, OR.

Szalay, L. (1974). Adapting communication research to the needs of international and intercultural communication. In F. Casmir (Ed.),International and intercultural communication annual (pp. 1-15). Cambridge: Harvard University Press.

Toulmin, S. E. (1958). The uses of argument. London: Cambridge University Press.

Useem, J., Useem, R., \& Donoghue, J. (1963). Men in the middle of the third culture: The roles of American and non-Western people in cross cultural administration. Human Organization, 22,4 , pp. 305-317.

Viglionese, P. (1982). Text and metatext in Hersey's a Single Pebble from the perspective of intercultural communication. International Journal of Intercultural Relations, 6, 41-53.

Wander, P. (1984). The rhetoric of American foreign policy.Quarterly Journal of Speech, 70, 339-361. 
Williams, R. (1964). American society in transition: Trends and emerging developments in social and cultural systems. In $\mathrm{J}$. H. Copp (ed.), Our changing rural society: Perspectives and trends. Ames, IA: Iowa State University Press.

World Bank. (1986). World development report. Washington DC: Oxford University Press. 


\section{APPENDIX}

\section{REAGAN'S AND ARIAS' ARGUMENTS}

This appendix includes the selection of public addresses, speeches and discourses exchanged by the Presidents Ronald Reagan and Oscar Arias concerning the Central American situation. Reagan's rhetorical pieces were made public between 1982 and 1988, where Arias' speeches were presented between 1986 and 1988. Fourteen discourses has been included in this section, seven for each speaker. A second selection took place for this thesis research, leaving for study purposes twenty-seven arguments from Reagan's discourses and twenty-three from Arias' discourses. The following arguments have been numbered from 1 to 27 for Reagan, and from 28 to 50 for Arias. Each of the arguments presented has been broken down into its parts in accordance to Stephen Toulmin's model of argumentation (1958). 
Discourse 1

"Aid to the Caribbean Basin"

Date: February 24, 1982

Argument I

P. 322

Data:

[There are several reasons why the U.S. and Latin America share a common destiny.]

Backing:

1- The migrants in US and Latin America faced,

a) the dangers and dreams of build a new world

b) moved from colonialism to nationhood

c) came from Europe for better life and searching of God

d) fought for independence and freedom

2- Ideals and principles are also similar

a) Rooted in self-government and nonintervention

b) Belief in the rule of the law

c) Belief that a nation cannot be liberated by depriving its people of liberty

d) Knowledge that a state cannot be free when its independence is subordinated to a foreign power

e) Knowledge that a government cannot be democratic if it refuses to take a test of a free election.

Warrant:

(Since), Nations who seek and share common destiny are consubstantial

Claim:

(So), "We are the new world...We [ Latin America and the US) are all America."

Reasoning by Generalization 

Arg. II
P. 322
D.

John F. Kennedy has said that "all people in America have the mission to demonstrate that man's unsatisfied aspiration for economic progress and social justice can best be achieved by free men working within the framework of democratic institutions." W:

(Since), people who share same aspirations are the same.

B:

John F. Kennedy is a credible source

C.

(So), in the "commitment to freedom and independence, the people of the hemisphere are one".

Reasoning by Classification 
Arg. III

P. 324

D.

There is a new colonialism in the Caribbean Basin which endanger democratic development.

B:

1 - Cuba, Grenada and Nicaragua served as a vehicle for the expansion of Soviet-backed Cuban-managed support for violent revolution in Central America

2 - Communism has exploited and aggravated temporary economic suffering to seize power, and then to institutionalize economic deprivation and suppress human rights

3 - Six million people worldwide are refugees from communist systems.

4 - Guerillas systematically burn, bomb and destroy bridges, farms and power and transportation systems to worsening economic and social problems in Central America.

W:

Communism and democracy are the two world ideologies at struggle. C

(So), "There are only two possible futures for Central America :

[democracy or dictatorship]"

Reasoning by Classification 


\section{Arg. IV $(*)$}

P. $324-5$

D.

Communists fear the success of democracy.

B:

a) Cuban and Soviets train guerillas to destabilize successful democracies.

b) Communists exploit Central American economical problems through an international campaign.

c) Cuba is receiving now more military supplies than in any year since 1962 missile crisis.

d) Nicaragua serves as a platform for covert military actions W:

(Since), "Democratic success will make the radical message a hollow one."

C.

(So), "Foes of freedom will destabilize Caribbean basin countries." Reasoning by Sign

Arg. V

P. 325

D.

"Freedom's foes would stamp out human rights, pluralism and free institutions."

B:

a) Guerrillas armed and supported by and through Cuba attempting to impose Marxist-Leninist dictatorship in El Salvador.

b) 1947 's Rio Treaty has established reciprocal defense responsibilities linked to "our common democratic ideals" (consubstantial).

W:

(Since), The US supports freedom, (Policeman role).

C.

(So), "Freedom and peace requires U.S. help for those nations confronted with communist aggression."

Reasoning by Sign 
Arg. VI (*)

P. 325

D.

"The people of the Caribbean and Central America are in a fundamental sense fellow Americans."

B:

1 - Freedom, pluralism and free enterprise are common values to US and Central America and the Caribbean people.

2 - US as well as Central America and the Caribbean belong to the same Western civilization.

W:

(Since), Freedom is the common destiny for the hemisphere.

B:

Freedom cannot survive if US neighbors live in misery and oppression.

C

(So), "[US] must help Central America and the Caribbean people to protect those values and principles that shape the proud heritage of this hemisphere."

Reasoning by Generalization 
Discourse 2

"The problems in Central America"

Date: April 27, 1983. Joint session of Congress

Argument VII

Page 450

Data:

"[CA] problems directly affect the security and well-being of [US] people"

Backing:

a) Many US cities are closer to Central American countries than to Washington D.C.

b) In an European crisis half of our (US) supplies for NATO would go through the Caribbean basin by sea.

c) Two thirds of all US foreign trade and petroleum pass through the Panama canal and the Caribbean.

d) In early 1942 a handful of Hitler's submarines sank more tonnage there than in all the Atlantic Ocean. They did so without an single naval base.

e) Today Cuba is host to a Soviet combat brigade, a submarine base capable of serving soviet submarines and military air bases visited regularly by Soviet military aircraft.

Warrant:

(Since), Regions which affects the security and well being of the U.S. are as important as the U.S.-proper.

Backing:

It is in the public interest to care about Central America and the

Caribbean troubled area.

Claims:

(So), "Central America is the US lifeline to the outside world." Reasoning by Parallel 
Arg. VIII

P. 451

D.

US works in good faith towards Nicaragua and other regional countries.

B:

a) send massive economic aid to the new regime in Nicaragua, more than any other after the Sandinist revolution of 1979: By January 1981, our emergency relief and recovery aid to Nicaragua totaled $\$ 118$ million. US sent five times more aid to Nicaragua in the first two years of Sandinist rule, then in the last two of Somoza's regime.

b) Nicaragua reject US peace efforts.

c) Nicaragua treated us as enemies.

d) Sandinists broke their promises for democratization before the OAS.

W:

(Since), US acts in good faith to those who also act in good faith.

B:

Justice

C.

(So), "Our actions were hardly the actions of a nation implacably hostile to Nicaragua."

Reasoning by Sign 
Arg. IX $(*)$

P. 451

D.

Salvadoran leftist guerrillas have turn against their own people. B:

a) Guerrillas destroyed hundreds of buses and trucks to keep the people from getting to the polling places.

b) Their slogan was brutal;" Vote today, die tonight."

c) A woman threatened by the guerrillas when voting told them :"you cant' kill us all." Guerrillas don't want elections they may know they would be defeated."

d) The government has invited the guerillas to participate in the election and is preparing an amnesty law. But they sabotaged the economy.

$\mathrm{W}$ :

(Since), Those who turn against their own are only out for themselves.

C.

(So), "Salvadoran guerrillas are a small minority who want power for themselves and their backers."

Reasoning by Generalization 
Arg. X

P. 452

D.

The "US has attempted to have a dialogue with Nicaragua. But [Nicaragua] persists in spreading violence."

B:

a) Costa Rica is a peaceful and unarmed democracy which has been object of bullying and threats from the Nicaragua's dictators

b) 36 new military basis have been built in Nicaragua (only 13 were during the Somoza regime).

c) The headquarters of the Salvadoran guerillas is in the capital, Managua, Nicaragua. From there attacks are directed against El Salvador.

W:

(Since), What is true of these cases is true of all. These are signs of war.

C.

(So), "Nicaragua refuses to make peace.[...] They are against peace." Reasoning by Sign 
Arg. XI

P. 452-3

D.

The goal of the Soviet-Cuban-Nicaraguan backed "professional guerrilla movements in Central America is as simple as it is sinister to destabilize the entire region from the Panama Canal to Mexico." B:

a) Cayetano Carpio, Salvadoran guerrilla leader, has said that after El Salvador falls, El Salvador and Nicaragua would be "arm-in-arm and struggling for the total liberation of Central America."

b) Nicaragua like to pretend that they are today being attacked by forces based in Honduras.

c) Nicaragua radio announced on April 18th the creation of a new, unified revolutionary coordinating board to push forward the Marxist struggle in Honduras.

d) Nicaragua, supported by weapons and military resources provided by the communist bloc, represses its own people, refuses to make peace and sponsors a guerrilla war against El Salvador.

e) More than a million of Central Americans had fled from Central America violence.

f) President Ortega has said that Nicaragua are willing to receive nuclear missiles from the Soviet Union if it is offered

W:

(Since), The US has a stake in preserving stability.

C

(So), The "US will support the security of the region's threatened nations."

Reasoning by Cause 
Arg. XII

P. 452

D.

President Truman said in 1947 that the "US must support free peoples who are resisting attempted subjugation by armed minorities or by outside pressures."

B:

a) Truman's policies secure decades of peace, prosperity and freedom.

b) Political and strategic stakes of postwar Europe are the same in Central America today.

W:

(Since), Today the situation is the same as then. "The political and strategic stakes are the same [in Central America]."

B:

Truman is a credible source

C.

(So), "President Truman's words are as apt today as they were in 1947."

Reasoning by Generalization 
Discourse 3

"Central America Policy"

Date: May 9, 1984 National Television from the White House Argument XIII

Page $482-83$

Data:

The "US doesn't start wars."

Backing:

a) U.S. won't send troops to Central America, like it did in Vietnam

b) Soviet Union provides Cuban with $\$ 4$ billion in assistance and it sends tons of weapons to foment revolution in our hemisphere

c) U.S. instead help its friends defend themselves.

d) U.S. maintain military strength in order to deter and defend against aggression - to preserve freedom and peace.

Warrant:

(Since), The U.S. defense policy stresses military strength to preserve peace and freedom.

Backing:

U.S. defense policy is based on fair play and freedom as values.

Claim:

(So), "U.S. will be never the aggressor."

Reasoning by Sign 
Arg. XIV

P.485

D.

"People in CA want hope and better lifes."

B:

a) Costa Rica is a well-established and healthy democracy.

b) Honduras made a peaceful transition to democracy in 1982 .

c) In Guatemala political parties and trade unions are functioning; this country can return to full constitutional government in 1985 .

d) 26 of 33 Latin American countries are democracies or striving to become democracies.

e) El Salvador is a democracy but many of its people cannot farm their land, they will be killed by the guerrillas if they do.

W:

(Since), Only democracy and freedom guarantees people's hope for a better future.

B:

Majority and Freedom

C

(So), "Central American people want freedom and democracy."

Reasoning by Generalization 
Arg. XV

P. 486

D.

Those who dissented in the past from the US position against the Nazis and U.S involvement in World War II did not stop the war.

B:

a) People who called for not involvement equals the isolationist of the late1930's who knew what was happening in Europe but chose not to face the terrible challenge history had given them.

b) The appetite of international aggressors is never satisfied.

c) Isolationist used a policy of wishful thinking.

W:

(Since), Isolation didn't stop the Nazis in the past, there is no reason why it can stop now the Sandinistas or the communists.

B:

Wishful thinking policy is dangerous

There is no control of the events.

C.

(So), "[Isolationism] assures war instead of preventing it." Reasoning by Analogy 
Discourse 4

"Nicaragua"

Date: March 16, 1986 Delivered to the American people Argument XVI

Page 386

Data:

Nicaragua is a Soviet-Cuban backed communist regime.

Warrant:

(Since), The Soviet Union and Cuba back regimes because of a desire to dominate.

Claim:

(So), The "Soviets and [the] Cubans can become the dominant powers in the regional corridor."

Reasoning by Sign 
Arg. XVII

P. 387

D.

The "Sandinistas are transforming their nation into a safe house, a command post for international terrorism."

B:

a) Sandinists sponsor terror in El Salvador, Costa Rica, Guatemala, Honduras that led last summer to the murder of four US marines in a cafe in El Salvador.

b) Italy has charged Nicaragua with harboring their worst terrorist, the Red Brigades.

c) Sandinist are involved in the international drug trade; a picture, secretly taken at a military airfield outside Managua, shows Federico Vaughn, a top aide to one of the nine commandants who rule Nicaragua, loading an aircraft with illegal narcotics, bound for the United States.

W:

(Since), Nations that harbor and support terrorists are outlaws.

B:

Sandinists threat the public interest and freedom.

C.

(So), "Nicaragua is an outlaw regime."

Reasoning by Sign 
Arg. XVIII

P. 388

D.

Freedom fighters are fighting communism in hopes of democracy. B:

a) Freedom fighters who had fought the old Somoza dictatorship took the hills when the Sandinist betrayed the revolution.

b) They like the French resistance that fought the Nazis, begin fighting the Soviet bloc communist and the Nicaraguan collaborators.

c) Today its numbers more than 20.000 volunteers but are running out of supplies and cannot fight against the Soviet helicopter gunships.

W:

(Since), Those who support and fight for democracy help the U.S.

C.

(So), "The resistance has contributed directly to the security of the U.S."

Reasoning by Cause 
Arg. XIX (*)

P. 388

D.

The U.S. has been acting responsible in Central America.

B:

a) Ten times US officers have met and tried to reason with the Sandinists.

b) Ten times those officers were rebuffed.

c) In 1985 US endorsed church-mediated negotiations between the regime and the resistance. The Soviets and the Sandinists responded with a rapid arms buildup of mortars, tanks, artillery and helicopter gunships.

d) The Soviet Union, Warsaw pact, Fidel Castro, Arafat, Qaddafi and the Ayatollah decided to support the communists in Nicaragua, US didn't take a last decision on this respect.

W:

(Since), Responsible nations pursue all arenas of peace.

C

(So), "US have sought and still seeks - a negotiated peace and a democratic future in a free Nicaragua."

Reasoning by Sign 
Arg. XX

P. 388

D.

There are signs that Nicaragua isn't preparing for peace.

B:

a) Soviets, East Germans, Bulgarians, North Koreans, Cubans and terrorists from the PLO and the Red Brigades are in Nicaragua.

b) Soviets have invested $\$ 600$ million to build Nicaragua into an armed force almost the size of Mexico's, a country 15 times as large, and 25 times as populous.

c) Daniel Ortega go to Cuba to endorse Castro's cause for the worldwide triumph of communism.

W:

(Since), To stand for peace, a nation cannot harbor aggresive intentions.

C.

(So), "Nicaragua doesn't stand for peace."

Reasoning by Sign 
Discourse 5

"State of the Union"

Date: January 27,1987, Congress

Argument XXI

Page 20

Data:

Backed by U.S. diplomatic effort in the region, democracy in C.A. is moving forward despite aggression from Nicaragua.

Backing:

a) More than two thirds of Latin American countries is democratic contrasted with one third ten years ago.

b) US has fostered economical and military aid to countries willing to become democracies.

c) Nicaragua is the only country in Central America which has resisted diplomatic efforts to become democratic. In fact, they sponsor guerrillas against other democracies such as El Salvador.

d) The headquarters of the Salvadoran guerrillas are in Managua.

e) Freedom and basic human rights are not granted for all in Nicaragua.

\section{Warrant:}

(Since), The only thing that can stop democratization is violent communist expansion.

Claim:

(So), "[US] diplomatic efforts for democratization in Central America will fail if communism prevails and expands from Nicaragua." Reasoning by Classification 
Arg. XXII
P. 259
D.

The Freedom fighters are struggling against the Soviets and communism.

B:

a) Soviet backed and Cuban managed military build-up in Nicaragua

b) International terrorists camped there.

c) Political repression and a belligerent attitude against its neighbors

d) Freedom fighters have dwarf Sandinists forces gaining time to US democratic efforts in the region.

W:

(Since), Noble struggles prevail.

B:

Communism can only be deter by military strength.

C

(So), "[The] Freedom Fighters won't allow the Soviets to have a beachhead [on the U.S. doorstep]."

Reasoning by Cause 
Discourse 6

"Central America at a Critical Juncture"

Date: October 7, 1987 Organization of American States Argument XXIII

Page 2

Data:

"Nicaragua does not grant freedom to all its citizens."

Backing:

a) A Christian Democrat legal demonstration of 4.000 person-rally was harassed by "divine mobs" paramilitary Sandinist forces.

b) Former president of Venezuela, Luis Herrera Campins, who was there condemn the repression.

c) A dozen of radio stations remain closed or censored in Nicaragua.

d) Only two media were reopen "La Prensa" and "Radio Catolica."

e) Only a few political prisoners were release. 10.000 remain imprisoned.

Warrant:

(Since), Democracy guarantees freedom for all.

Backing:

Freedom and Majoritarism

Claim:

(So), "The Sandinistas in Nicaragua are not democratic."

Reasoning by Sign 


\section{Arg. XXIV \\ P. 3 \\ D.}

"Nicaraguans are against tyranny and they fight for this ideal." B:

a) The US independence freedom fighters of 1776 like the Nicaraguans today stood against outside tyranny, and freedom.

b) The US freedom fighter like those in Nicaragua were mainly farmers fighting against odds.

W:

(Since), Those who fight communism in Nicaragua today and those who fought for independence in 1776 are alike.

C

(So) "They [Freedom Fighters] are fighting for independence [in Nicaragua]."

Reasoning by Parallel 
Arg. XXV

P. 4

D.

The U.S. is committed to preserve freedom and democracy anywhere, particularly, on its doorstep.

B:

Central America and Caribbean.

W:

(Since), The commander-in-chief (President) is the protector of that moral commitment.

C.

(So) Reagan "won't walk away from the fight for freedom in Central America."

Reasoning by Cause 


\section{Discourse 7}

"State of the Union"

Date: January 25, 1988 Delivered to the American People Argument XXVI

Page 6

Data:

The Sandinistas broke their promises for democratic reforms, by failing to comply with international accords.

Backing:

a) Consensus among the four Central American democratic Presidents that the Sandinists have not comply with the Arias peace plan.

b) They did not comply with the 1979's OAS agreement to democratize Nicaragua after the revolution.

c) Roger Miranda, former high-level Sandinist Major, revealed that as Sandinists talk of peace its government has established plans for a large 600,000-man army.

Warrant:

(Since), Past violations of trust can only be overcome by large acts of good faith.

Backing:

Communism uses democratic facades to hide their real intentions Claims:

(So), "[Sandinist'] challenge is to take irreversible steps towards democracy."

Reasoning by Sign 
Arg. XXVII

P. 261

D.

There are signs of democratization in Central America.

B:

a) $90 \%$ of CA countries are democratic now, as contrasted with $33 \%$ ten years ago.

b) Resurgence of democracy is owed to those who have struggle to take control of their own destiny.

c) Democratic rights negotiate with church authorities and release of few political prisoners even in non-democratic Nicaragua result from resistance by freedom fighters.

W:

(Since), Moves toward democracy reflect a general trend.

$\mathrm{C}$

(So), "Political freedom is winning a battle against totalitarism. [...]

Freedom is finding its way in CA."

Reasoning by Sign. 


\section{ARIAS' ARGUMENTS}

\section{Discourse 1}

"Democracy in the Americas"

Date: December 5, 1986 International Press Club, Washington DC Argument XXVIII (*)

Page 11

Data:

Never have so many people been able to freely elect their leaders as has been in the last 5 years.

Warrant:

(Since), Elect freely political leaders is the cornerstone of democracy Backing:

Majority principle

Claim:

(So), "Latin America is living an era of return to democracy."

Reasoning by Sign 


\section{Arg XXIX}

P. 12

D.

Using the "pretext of saving democracy," severe economic deprivations are being forced in Latin American countries. W:

(Since), Unfair economic treatment precludes democracy.

B:

In account that economical and political development is only possible in peace.

C.

(So), "Sacrificing the political system of freedom to very severe economic pressures could have serious consequences for the political future of Latin America."

Reasoning by Classification. 
Arg. XXX

P. 13

D.

Costa Rica is peaceful, neutral and believe in self-determination for Nicaragua and all countries.

B:

a) Costa Rica first proclaimed its neutrality 163 years ago.

b) Costa Rica has reiterated its neutrality during its history on more than ten occasions because of continuous internal armed conflict in Nicaragua.

c) Again Costa Rica reiterated its neutrality before a new internal conflict in Nicaragua after the Sandinist revolution.

d) Costa Rica has encouraged peaceful negotiations and dialogue between nicaraguans.

W:

(Since), Physical intervention in other country's affairs is not appropriate for neutral, peaceful democracies.

B:

(In account of the fact that) Non-intervention is the base of peace among nations.

C.

(So), "Nicaraguans are the ones who must solve their own internal problems."

Reasoning by Generalization 
Arg. XXXI $(*)$

P. 13

D.

"Costa Ricans believe in democracy not in totalitarism."

B:

a) For the last five years Costa Rica has been active proponent of democracy and freedom.

b) Costa Rica support a lasting peace for the Americas through the so called Alliance for Democracy.

W:

(Since), Democracy cannot be neutral in the battle of ideas but it can with respect to war.

B:

Democracy attains freedom of expression not violence.

C.

(So), "Costa Rica is neutral with respect to war."

Reasoning by Sign. 


\section{Discourse 2}

"The roads to freedom"

Date: December 4, 1986, Rose Garden White House

Argument XXXII

Page 17

Data:

Democracy causes peace.

Backing:

a) Costa Rica is a democracy whose people live in peace.

b) Costa Rica has been bordered on the North (Nicaragua) by oppression and violence.

c) Oppression and violence are part of most tyrannies, and troubled countries in Central America.

Warrant:

(Since), Only democracy can guarantee reconciliation, allow peace, and preclude violence from crossing borders.

Backing:

Tyrannies should fall to have democracy.

Claim:

(So), "Only if we endeavor to enable all people to enjoy democracy, [and] cause the downfall of all tyrants equally, can we prevent threats to world peace from growing in the Americas."

Reasoning by Cause

\section{Arg. XXXIII}

P. 17

D.

Internal and external factors are detrimental to Central American economies.

$\mathrm{W}$ :

(Since), Good economical conditions precludes poverty and social unrest.

C.

(So), "Central America needs...fair treatment in trade and finance to avoid war and oppression."

Reasoning by Cause. 


\section{Discourse 3}

"La Paz esta primero" (Peace is first)

Date: February 26, 1987 State's dinner offered by the president of Mexico, Miguel de la Madrid

Argument XXXIV

Page 11-12

Data:

Several discussions have taken place to foster a major role of Central Americans in the peaceful solution of their own conflicts.

Backing:

a) Contadora Group and its Latin American support group.

b) Central American Presidents summit in Guatemala; it is now also as Esquipulas I

Warrant:

(Since), Words are part of a commitment, action is the next logical step.

Backing:

Words without deeds isn't useful (Pragmatism)

Claim:

(So), "Peace and democracy demand datelines and deeds, no just words. The accords in good faith bring us closer to the peace, if we are able to put them into practice."

Reasoning by Classification. 
Discourse 4

"Oportunidades para la democracia in America" (Opportunities for democracy in Latin America)

Date: October 25, 1986, Cariari Hotel, Exchange Conference on "La democratización del hemisferio" (The Democratization of the hemisphere)

Argument XXXV (*)

Page 5

Data:

Undemocratic regimes deny individual human rights.

Backing;

a) Under dictatorship most citizens experience injustice and poverty.

b) A free man shouldn't expect equality, freedom of expression, dialogue and transaction, and peace in a dictatorship, but democracy. Warrant:

(Since), Individual rights are the basis of peace and justice.

Backing:

Individual is above government.

Claims:

(So), "Democracy is the only road to peace and justice [in Central America]."

Reasoning by Generalization. 
Arg. XXXVI

P. 5

D.

History shows that those who are afraid of freedom allowed oppression of any sign to exist.

B:

a) Many individuals lived and still live under oppression from either leftist or rightist regimes.

b) People who are value-less or afraid of freedom oppressed its own people.

W:

(Since), Political oppression can only be exerted by people who are afraid of freedom and without human values.

B:

Majority has a voice only within democracy.

C

(So), "The only defense against the enemies of freedom is to strengthen freedom and democratic institutions."

Reasoning by Generalization. 
Arg. XXXVII

P. 6

D.

New democracies do not receive the economical and political support expected from international economic institutions and the industrialized world.

B:

a) Dictatorships have received better economic treatment than most new democracies.

b) New international crisis and enormous external debts may new democracies' economies very fragile.

c) International creditors put the hardest conditions on new democracies to pay their obligations.

W:

(Since), Economical and political support from the industrialized world and international economic institutions are prerequisite of democracy.

C

(So), "[It] is too early to talk about consolidation of democratic era in Latin America."

Reasoning by Sign. 


\section{Arg. XXXVIII}

P.6

D.

In Central America, people are affected by things not under their own control.

B:

a) Urban lower class and countryside's population don't have an active participation in political programs which affect their destiny. b) Social and economical obstacles limit their involvement in public affairs.

c) More migration from the countryside to the cities contributes to increase political tensions and subsequent urban violence. W:

(Since), People denied a voice will respond with violence.

B:

Democracy is based on the participation of majorities. C.

(So), "Migratory problems and violence will continue spreading." Reasoning by Generalization. 


\section{Discourse 5}

"La Paz no tiene fronteras" (Peace doesn't recognize borders) Date: December 10, 1987 Oslo, Norway Argument XXXIX $(*)$

Page 5

Data:

There are many viewpoints and interest in the Central American conflict.

Backing:

a) This process involves numerous decisions based on consultation with many people from different countries.

b) Peace is an attitude, way of life, and a way of conflict-solving which is based on consensus.

c) Most successful peace negotiations are based on understanding and mutual respect.

Warrant:

(Since), "[Peace] cannot be forced on the smallest nation nor can it be imposed by the biggest nation."

Backing:

Consensus attains taking into account the voice of the majority Claim:

(So), "The endless process [of peace] requires that we work together."

Reasoning by Generalization. 
Arg. $\mathrm{XXXX}\left({ }^{*}\right)$

P. 7

D.

Defeatist statements about Costa Rican peace plan paralyze people and jeopardize peace efforts in Central America

B:

It is more easy to forecast defeat than triumph, war than peace. W:

(Since), Peace is to be sought as desirable

B:

Defeatism denies human will.

C.

(So), "I can't accept defeatism."

Reasoning by Cause. 


\section{Arg. XXXXI}

P. 7
D.

Latin American tyrannies are opressing their people

B:

Torture, exile, gigantic external debt, corruption and injustice are the heritage of dictatorships in Latin America.

W:

(Since), The oppresion of the people should never be supported B:

It is in the public interest to don't support tyrannies, but democracies

C.

(So), "We [democrats] should be neither political nor economic allies of governments which oppress their peoples."

Reasoning by Generalization.

\section{Arg. XXXXII $(*)$}

P.11

D.

There are those in Central America who preach dogma and stifle creativity

B:

Pascal said that "we know too much to be skeptics. We know too little to be dogmatic."

W:

(Since), That which stifles human creativity is bad/evil

B:

Pascal is credible source

C.

(So), "Dogmas are the enemies of human creativity [individual freedom]."

Reasoning by Classification 
P. 11

D.

C.A. population's freedom clamor for centuries had not been adequately addressed by politician and public officials.

B:

Most tyrannies oppressed, exiled, and tortured Central Americans to quiet claims for freedom, peace and justice.

W:

(Since), People's call for freedom cannot long be supressed.

B:

The voice of the Majority should be respected

C.

(So), "Ignoring the clamor for freedom may condemn Latin America to another century of horror and death."

Reasoning by Analogy.
P. 12
D.

Arg. XXXXIV

Costa Rica has been strongly free and democratic without having an army.

B:

a) Lowest index of unemployment in the Western Hemisphere

b) Strong policies to guarantee housing to all its citizens

c) Free and mandatory education for all.

d) Socialized health care for everybody. W:

(Since), What free people believe in their souls and live can't be taken away

C.

(So), "[Democracy] is invulnerable before the totalitarian attacks." Reasoning by Generalization. 
Arg. XXXXV

P. 14

Some people pursue war in Central America

B:

a) They accept the war as the normal course of events in the Central America scenario.

b) They react with wrath and fury when peace efforts take place in Central America.

c) For them history consists of military victories.

W:

(Since), The pursuit of war is antagonistic to the pursuit of peace.

B:

Civilized behavior is rooted in rationality

C

(So), "No matter how noble the crusade is [peace efforts], some wish for and encourage its failure."

Reasoning by Classification. 
Arg. XXXXVI

P. 14

D.

Nuclear and conventional war have their own horrors.

B:

78 million people have died during the conventional wars of this century.

W:

(Since), Nuclear war and conventional war are equally harmful and threatening to humankind.

B:

Life is sacred

C.

(So), "[We must] equally fight together against the possibility of another Hiroshima, or another Vietnam."

Reasoning by Parallel. 
Discourse 6

"La paz- suprema esperanza del mundo" (Peace - supreme hope of the world)

Date: University of Peace, October 6, 1988

Argument XXXXVII (*)

Page 8

Data:

Conflicting parties in Central America are having a hard time reconciling their differences to reach a peace accord with each other. Backing:

a) Same parties who fight each other claim for peace.

b) More intransigent parties in peace talks are those who claims for keeping the dialogue open.

Warrant:

(Since), Reconciliation is a prerequisite to peace

Claim:

(So), "[In Central America] there is no peace because there is no reconciliation."

Reasoning by Cause. 
Discourse 7

"Architects of the century of peace"

Date: Georgetown University, May 28, 1988

Argument XXXXVIII

Page 15-16

Data:

"The Central American Peace Plan is being crucified [as Christ was in his time]."

W:

(Since), The force of peace could not be silence.

Claim:

(So), "History repeats itself [with the Arias Peace Plan]."

Reasoning by Parallel.

Arg. IL
P. 19
D.

The U.S.S.R. and the U.S. are negotiating peace and reducing nuclear armaments through peaceful dialogue.

W:

(Since), Conflict between superpowers is not different than conflict between Central American nations.

C.

(So), "There is no reason to support the use of military force in the solution of Central American conflict."

Reasoning by Parallel. 
Arg L

P. 23

D.

Various events and people in Central America show desire for peace B:

An indigenous woman in Guatemala thanks Oscar Arias for his efforts for peace after the signature by Central American presidents of the peace accord of Esquipulas I.

W:

(Since), The desire for peace is permeating Central America. C. (So), "Central America is committed to peace." Reasoning by Generalization 